\title{
Research Commons
}

\section{http://researchcommons.waikato.ac.nz/}

\section{Research Commons at the University of Waikato}

\section{Copyright Statement:}

The digital copy of this thesis is protected by the Copyright Act 1994 (New Zealand).

The thesis may be consulted by you, provided you comply with the provisions of the Act and the following conditions of use:

- Any use you make of these documents or images must be for research or private study purposes only, and you may not make them available to any other person.

- Authors control the copyright of their thesis. You will recognise the author's right to be identified as the author of the thesis, and due acknowledgement will be made to the author where appropriate.

- You will obtain the author's permission before publishing any material from the thesis. 


\title{
Lake Taupo: A Multi-Sector Collaborative Partnership towards Sustainable Development
}

\author{
A thesis \\ submitted in partial fulfilment \\ of the requirements for the degree \\ of \\ Master of Management Studies \\ at \\ The University of Waikato \\ By \\ Josef de Jong \\ The University of Waikato \\ 2011
}




\begin{abstract}
This thesis has created a case study that centres on stakeholder engagement within Lake Taupo, documenting the largest environmental protection project in New Zealand. The purpose of the case study is to determine how multiple stakeholder perspectives affect the business case for sustainable development.

In the late 1990s regional council, along with the community, realised that intensive land use was threatening the pristine quality of water. Forestry and sheep and beef farming are the two dominant productive sectors within the area. Science indicated that due to the porous nature of soil within the catchment, farming deer, dairy and sheep and beef, resulted in an increase of nitrogen entering the lake and consequently reduced water quality.

A range of stakeholders, including local, regional, central government, along with many other private businesses, cooperated and engaged in an effort to ensure sustainable development could continue within the Taupo catchment. The process spanning more than ten years from 2000-2011 resulted in legislation that initiated a behaviour change to low intensive land uses. The partnership also included the establishment of a trust to administer the use of public funds to reduce the amount of nitrogen entering the catchment by 20 per cent.

The multi-sector, stakeholder partnership, produced innovative methods to secure a future for sustainable development in Taupo. Policy documents and newspaper articles were analysed while interviews were conducted with a range of crucial stakeholders, including forestry trusts, government representatives, farmers and a range of businesses operating within the catchment.

The results of the research suggests the involvement of such an array of stakeholders, enabled a coherent and all-encompassing strategy, due to the input from diverse public and private stakeholders, even if some stakeholders took a self-interested approach. The findings illustrate a business case that was created for many landowner stakeholders which aided in the creation of new business models. Engagement enabled the majority of stakeholders to see the perspectives of others because policy development was brought down to a community level. However there was an apparent lack of industry involvement from the farming sector as many stakeholders felt that the farming industry needed to play a crucial role, when in fact, they avoided the issues of their farmer members within the catchment and did not engage until it was too late.

A large number of stakeholders felt that an uncertain environment was created due to legislation. Nonetheless the involvement of community groups and businesses such as the Lake Taupo Protection Trust (LTPT) and Mighty River Power (MRP) in trading nitrogen and carbon has enabled the creation of a sound business model for landowners. A sustainable business model by promoting the economic benefits to landowners ensured the farming community had support to generate new revenue streams. Therefore the uncertainty, as local legislation has not come into effect and the uncertainty surrounding a national and international Emissions Trading Scheme (ETS), has been diminished as these businesses engage with farmers. The realisation for landowners to rationalise their land for sustainable uses has increased their bottom line and decreased their nitrogen leaching, thus protecting the lake. The Lake Taupo case illustrated important learning's that can be applied to any environmental protection project. The inclusion of private and public entities can enable a sustainable future where businesses can be the 'engines of change.'
\end{abstract}




\section{Preface and Acknowledgements}

Be the change that you want to see in the world,

Mahatma Ghandi.

Sustainable development was not a concept I had come across until I was exposed to it in my bachelor's degree. Realising that I was not going to be able to change the world on my own, I have made it my mission to 'be the change I want to see in the world'. Seeing the positive impact that businesses and business leaders can have through integrating strategic sustainable policies is inspiring and something I wish to be able to achieve in my future career. The Lake Taupo Project was therefore an ideal topic to research as it combined a multi-sector approach for the protection of a natural asset. To observe leaders from many sectors collaborating to create an innovative, world first environmental intervention was a great learning experience.

There are a range of individuals and organisations that I need to thank for their help and contribution. Firstly I must thank my flatmates and friends who continually offered support and motivation or kindly presented numerous opportunities for many relaxing coffee breaks throughout the year. A special thank you goes to a colleague and friend, Neihana Jacob, who was there to translate any Maori terms that I had trouble with. Thank you to my parents who I conned into reading my thesis and managed to give me some helpful feedback. My deepest appreciation goes to the Waikato Management School and the University of Waikato who provided me with a Masters Research Scholarship which helped support me financially over the year. The support of Staff in the Strategy and Human Resource Management department of the Waikato Management School is also gratefully acknowledged. My deepest thanks go out to Associate Professor Eva Collins and Professor Juliet Roper who, through their Marsden Research, offered me a research position as a Masters student on their research team. This also included a research stipend and fees payment which again significantly helped financially. The guidance that Eva and Juliet offered throughout the year was amazing and I thoroughly enjoyed being part of an enthusiastic research team. Finally thanks must go out to all of my interview participants who so openly welcomed me into their homes or offices. Without their input, this research would not have been possible. 


\section{Table of Contents}

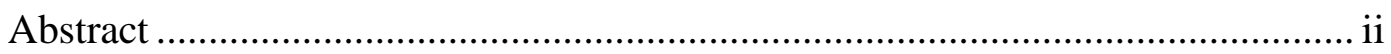

Preface and Acknowledgements ............................................................... iii

List of Figures ..................................................................................... vii

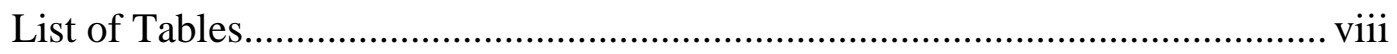

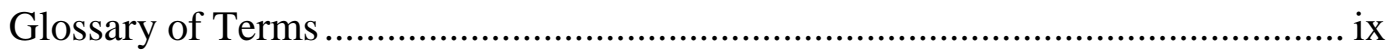

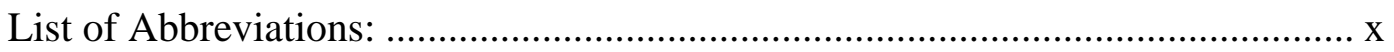

Chapter I: Introduction ....................................................................... 1

Lake Taupo- the Gem of the North Island: ..................................................... 2

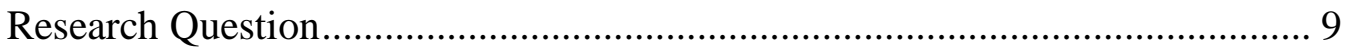

Chapter II: Review of the Literature.................................................. 11

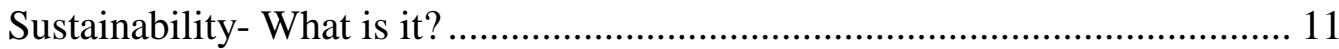

The Realm of Sustainability ................................................................ 11

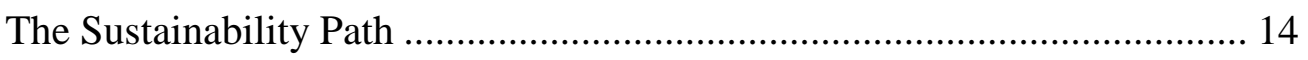

Environmental Politics..................................................................... 17

Regulatory Measures: Environmental Governance ................................... 20

Stakeholders: who and what are they? .......................................................... 22

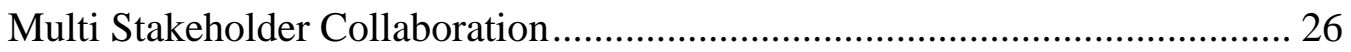

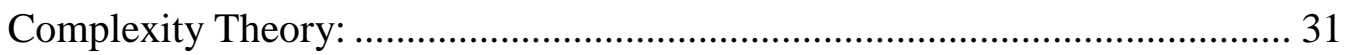

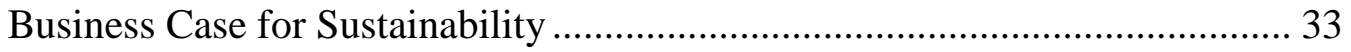

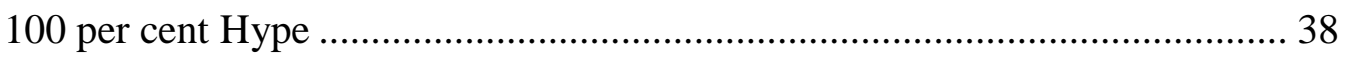

Lake Management- Cases from all over the World ....................................... 41

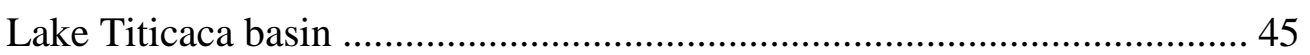

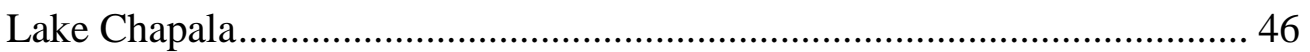

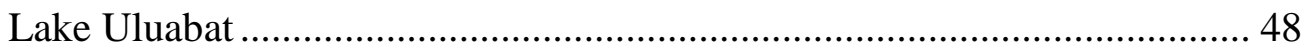

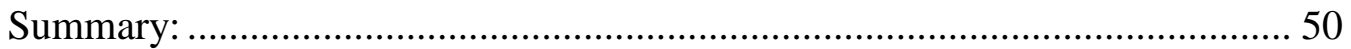

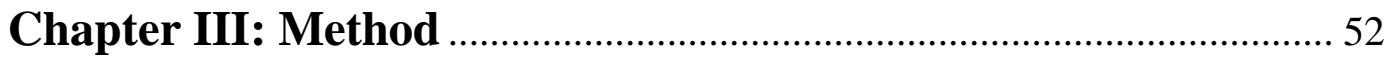

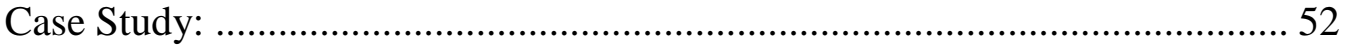

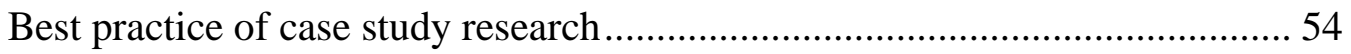

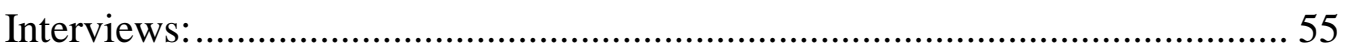

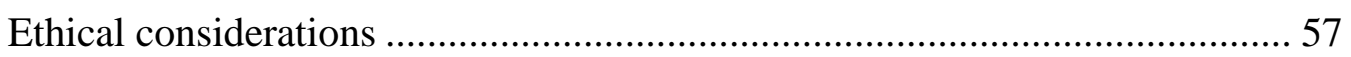

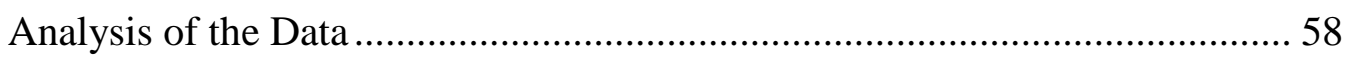

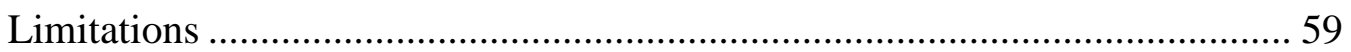

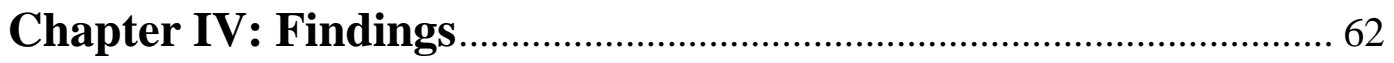

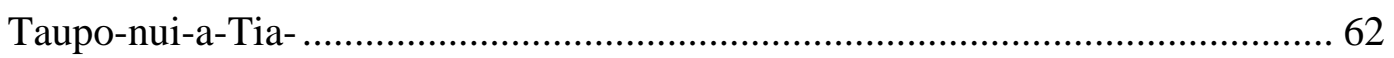

Multi-Sector Collaboration for Sustainable Development.................................. 62

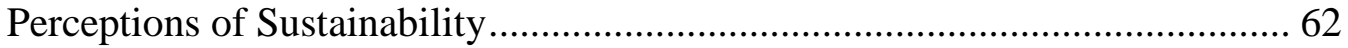

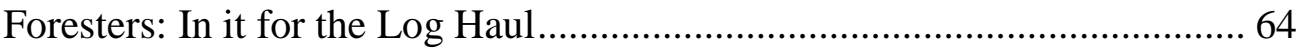




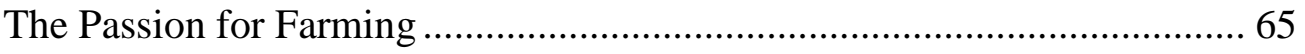

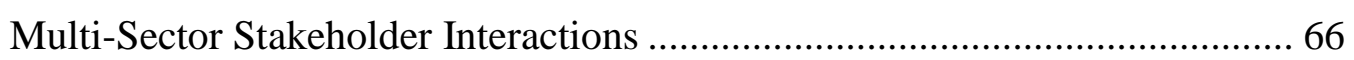

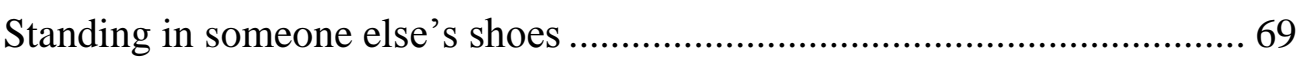

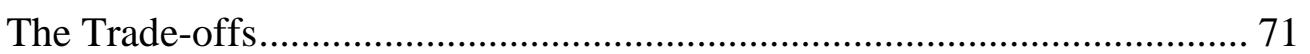

Stakeholders Relationship with the Lake Taupo Protection Trust (LTPT)....... 74

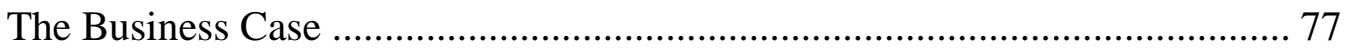

Creating Environmental Stability and Uncertainty .................................... 81

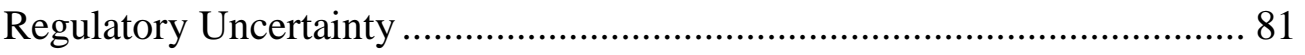

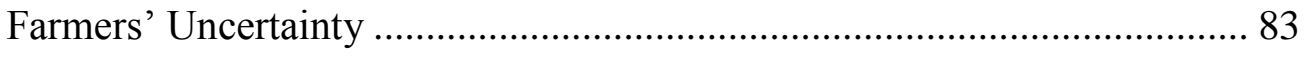

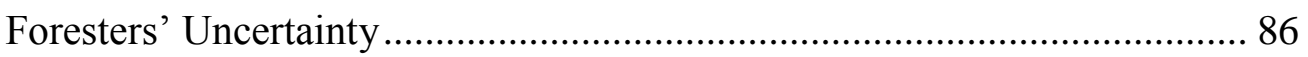

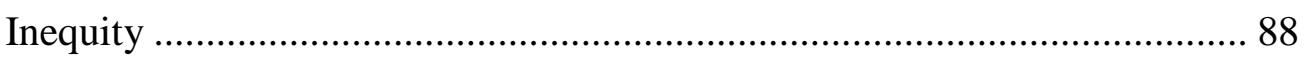

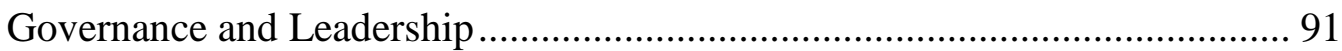

Where Was Leadership From the Farming Industry? ................................. 92

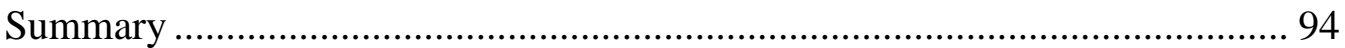

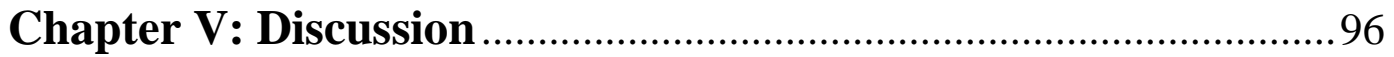

Understanding the Lake Taupo Project .......................................................96

Stakeholder Interactions and Their Perception of Sustainability ..................... 96

Multiple stakeholder interactions ............................................................. 101

The Business Case - Reducing Uncertainty for a Sustainable Future ............ 106

Uncertainty and inequalities.............................................................. 110

Governance and Leadership ................................................................ 112

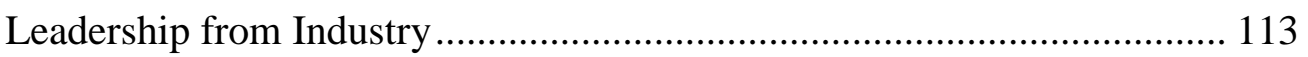

Dynamic nature of societies changing opinions.......................................... 115

Lake Taupo and its comparison to international water management cases .... 115

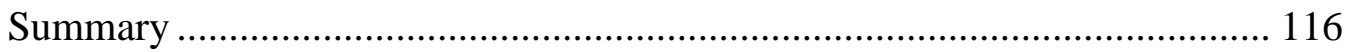

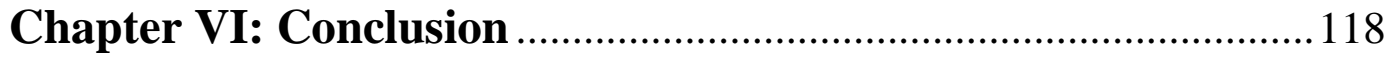

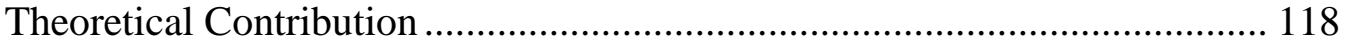

What are the Implications for Policy-Makers, Business Managers and

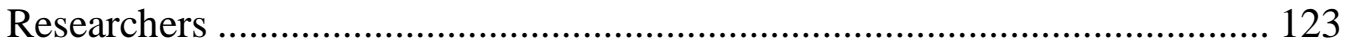

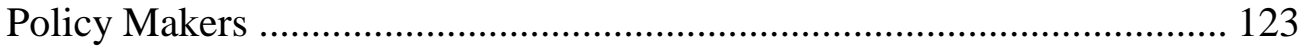

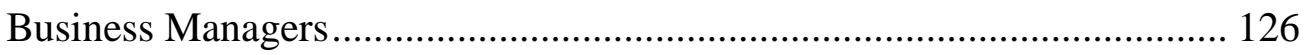

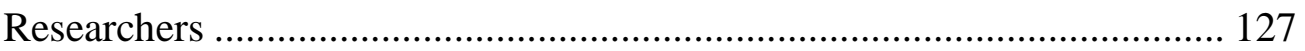

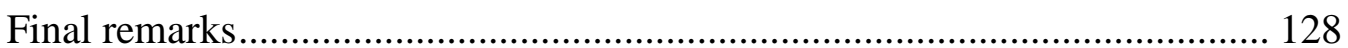

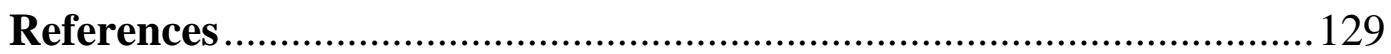

Appendix 1: Stakeholder Collaboration for the Protection of Lake Taupo:

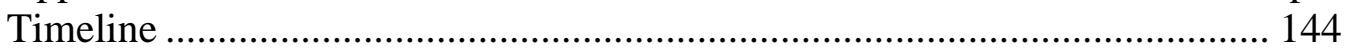

Appendix 2: Ranking Quality of Life Threats ............................................ 148

Appendix 3: Taupo-nui-a-tia Survey Respondents' level of concern about issues affecting Lake Taupo 
Appendix 4:Interview Checklist

Appendix 5: List of Interviewees

Appendix 6: Waikato Management School Ethics Application 152 Appendix 7: Letter of invitation................................................................... 153

Appendix 8: Participant information Sheet 154

Appendix 9: Consent forms 155

Appendix 10: Sample of themes emerging from transcript analysis 156 


\section{List of Figures}

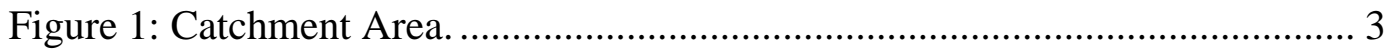

Figure 2: The three relationships used by the Brundtland Commission .............. 16

Figure 3: Shift to systems view in stakeholder engagement .............................. 27

Figure 4: Networks and their ability to generate social capital.......................... 30

Figure 5: The greatest benefits to an organisation in regard to sustainability ...... 36

Figure 6: Water Management Structure ........................................................ 43

Figure 7: River Basin Councils in Mexico......................................................... 47

Figure 8: Problem formulation of Environmental Risk. ..................................... 49

Figure 9: Stakeholders Commitment to Sustainability ........................................ 99

Figure 10: Lake Taupo Stakeholder Engagement Matrix ................................. 102

Figure 11: Bell Curve of Landowner Mind-sets within the Taupo Catchment.. 107

Figure 12: Sustainable Business Models for Landowners................................ 109

Figure 13: Matrix of Multi-Sector Stakeholders Engaging.............................. 124 


\section{List of Tables}

Table 1: Typologies of participation and collaboration ...................................... 24

Table 2: Main Stakeholder Groups Perception of sustainability ......................... 97 


\section{Glossary of Terms}

Averaging

Benchmarking

Grand-parenting

Ha

NDA

NMP

Overseer

RPV5

Sec 30 of the RMA Section 30 of the Resource Management Act is the "control of discharges into or onto land ... or water" and also "the control of the use of land for the purpose of ... the maintenance and enhancement of the quality of water in water bodies (Sec 30(1)(c)(ii).

Was a proposed method of allocating nitrogen to land owners within the catchment. Averaging involves taking the average amount of nitrogen leaching from a landowner within the catchment over the benchmarking years of 20012004 and creating an average of the four years to be the NDA. This option was argued in the Environment Court by forestry but disregarded as a viable option because it was found to be inequitable towards farmers.

Is the process of collecting all on-farm data (such as cattle numbers, grazing sites, cattle types etc) to establish a Nitrogen Discharge Allowance (NDA) for a particular farm.

Is the process of taking the best year of production that a landowner had between the years of 2001-2004 and utilising that as the set cap or NDA. This limit is then used as the cap within the NMP for a landowner.

Is an area used for measurement of land generally $1000 \mathrm{~m}=$ $10000 \mathrm{~m} 2$.

Nitrogen Discharge Allowance has been calculated by looking at the best year a farm has had between the benchmarking years of July 2001- June 2005and determines the nitrogen leaching which is the cap (maximum a farm can leach).

Refers to the Nitrogen (N) that is an organic compound entering the lake. For the purposes of this thesis and the context of the lake Taupo Catchment, $92 \%$ of the manageable nitrogen entering the lake comes from the agricultural sector. A large amount of that is from animal urine and manure.

Nitrogen Management Plan is a plan that is developed for farming practices and how they will align with particular farms NDA.

A computer program created by Ag-Research and MAF which processes a farms information to establish an NDA for a property.

Regional Plan Variation 5 is the legislation created by Environment Waikato (the Waikato Regional Council). 


\section{List of Abbreviations:}

$\begin{array}{ll}\text { AR } & \text { Ag-Research } \\ \text { CG } & \text { Central Government } \\ \text { CGEBFE } & \text { CGE Burgess Family Estate } \\ \text { CHH } & \text { Carter Holt Harvey } \\ \text { DCD } & \text { Dicyandiamide (nitrification inhibitor) } \\ \text { E-Court } & \text { Environment Court } \\ \text { EDS } & \text { Environmental Defence Society } \\ \text { EW } & \text { Environment Waikato } \\ \text { Fed-Farmers } & \text { Federated Farmers } \\ \text { Ha } & \text { Hectare } \\ \text { LRFT } & \text { Lake Rotoria Forest Trust } \\ \text { LTFM } & \text { Lake Taupo Forest Management } \\ \text { LTFT } & \text { Lake Taupo Forest Trust } \\ \text { LTPT } & \text { Lake Taupo Protection Trust } \\ \text { LWAG } & \text { Lake and Waterways Action Group } \\ \text { MAF } & \text { Ministry of Agriculture and Fisheries } \\ \text { MfE } & \text { Ministry for the Environment } \\ \text { MOU } & \text { Memorandum of Understanding } \\ \text { MRP } & \text { Mighty River Power } \\ \text { N } & \text { Nitrogen } \\ \text { NDA } & \text { Nitrogen Discharge Allowance } \\ \text { NMP } & \text { Nitrogen Management Plan } \\ \text { NTAG } & \text { Ngati Tuwharetoa Agricultural Group } \\ \text { RFT } & \text { Rotoria Forest Trust } \\ \text { RMA } & \text { Resource Management Act } \\ \text { RPV5 } & \text { Regional Plan Variation 5 } \\ \text { TDC } & \text { Taupo District Council } \\ \text { TLC } & \text { Taupo Lake Care } \\ \text { TMTB } & \text { Tuwharetoa Maori Trust Board } \\ \text { TPK } & \text { Te Puni Kokiri } \\ \text { TPL } & \text { Taumata Plantations Limited } \\ & \end{array}$




\section{Chapter I: Introduction}

A sustainable environment is crucial for the continual wellbeing of a nation's economic, social and cultural wellbeing (Gago and Antolin, 2004). Therefore a sustainable economy is vital, especially for New Zealand a nation that is young with a vibrant culture and a rich bounty of natural resources. Preserving this setting for future generations is considered an imperative goal (Valente, 2008). However pressures are increasingly threatening the pristine quality of the environment that New Zealanders and visitors both enjoy. Such pressures that cause environmental degradation include carbon emissions, waste water run-off, residential development (Williams and Lawson, 2001), and nitrogen leaching into waterways (Scion, 2010).

Society, business and government are required to make informed and timely decisions about environmental risk. Determining the acceptability of that risk means decisions must be based on individual and community perceptions (Stewart, Johnston, Rosen, and Boyce, 2000).

With population growth expected to drastically increase and water intensive programs to follow, this has meant that water infrastructure has had to satisfy demand over the past century (Gleick, 1997). Global concern for fresh water resources can be traced back to the United Nations Conference on the Human Environment in 1972 (Levy and Newell, 2005). During this time water concerns along with ecological issues were viewed as opposing economic development. There was a perception that the two did not go hand in hand (Levy and Newell, 2005). Over the past year 58 organisations in New Zealand have recently collaborated to investigate the management of water and determine a more collaborative and less confrontational approach. The creation of a Land and Water Forum report titled 'A Fresh Start for Fresh Water' includes recommendations to the government and illustrates a new era and new way of thinking when it comes to collaboration surrounding water resource management in New Zealand (Bisley, 2010). 
This thesis directly examines the outcomes of stakeholders engaging for sustainability. A diverse range of stakeholders making up an array of public and private entities are collectively working towards a solution for the Lake Taupo Catchment area that incorporates economic, social and environmental sustainability. A unique case study of collaboration illustrating a range of multi sector actors working towards a business case for sustainability is created surrounding the catchment area. The strategies that have been initiated by stakeholders are driven upon the business case for sustainability to improve the overall situation of each of the participating groups, and the overall health of the lake and region. Before the business case is explored in the literature, among other relevant themes, it is important to gain an understanding of the context of the Lake Taupo District and the catchment area.

\section{Lake Taupo- the Gem of the North Island:}

The Taupo district has land area 635,400 hectares and when broken down equates to 1,720 ha of residential property, 187,861 hectares for farming use and 189,000 hectares made up of planted forests (TDCAR, 2009). The population of the Taupo District Council area is 32,418 from the 2006 census (Taupo, 2010).

At the centre of the north Island, 'Te Ika-a-Māui', lies one of the remarkable treasures of this region, Lake Taupo, New Zealand's largest lake, a caldera volcano which was formed during an eruption that occurred over 26,500 years ago. As it is a volcanic region, the land is highly porous and groundwater is a pathway for nutrients to travel into the lake (Environment Waikato, 2001, B). The 3487 square kilometre catchment (Taupo-nui-a-tia, 2010) encompasses the area in which water drains into the lake and the land area is five times the size of Lake Taupo which is illustrated visually in Figure 1 as the shaded area. One major nutrient that flows in the groundwater system into the lake is nitrogen, mainly coming from animal urine and manure which can run through the pumice type soil and filter deep into waterways. This is particularly true with high rainfall in autumn and winter where it can take up to 50 years to flow through and influence the biodiversity and clarity of the water (Environment Waikato, 2003 A). The fresh water lake has a surface area of 60,000 hectares with the deepest point being 186 metres as seen in Figure 1 (Lowe and de Lange, 2000). The main tributaries 
for Lake Taupo are the Waitahanui River and the Tongariro River with the Waikato River being the sole river to which the lake is drained.

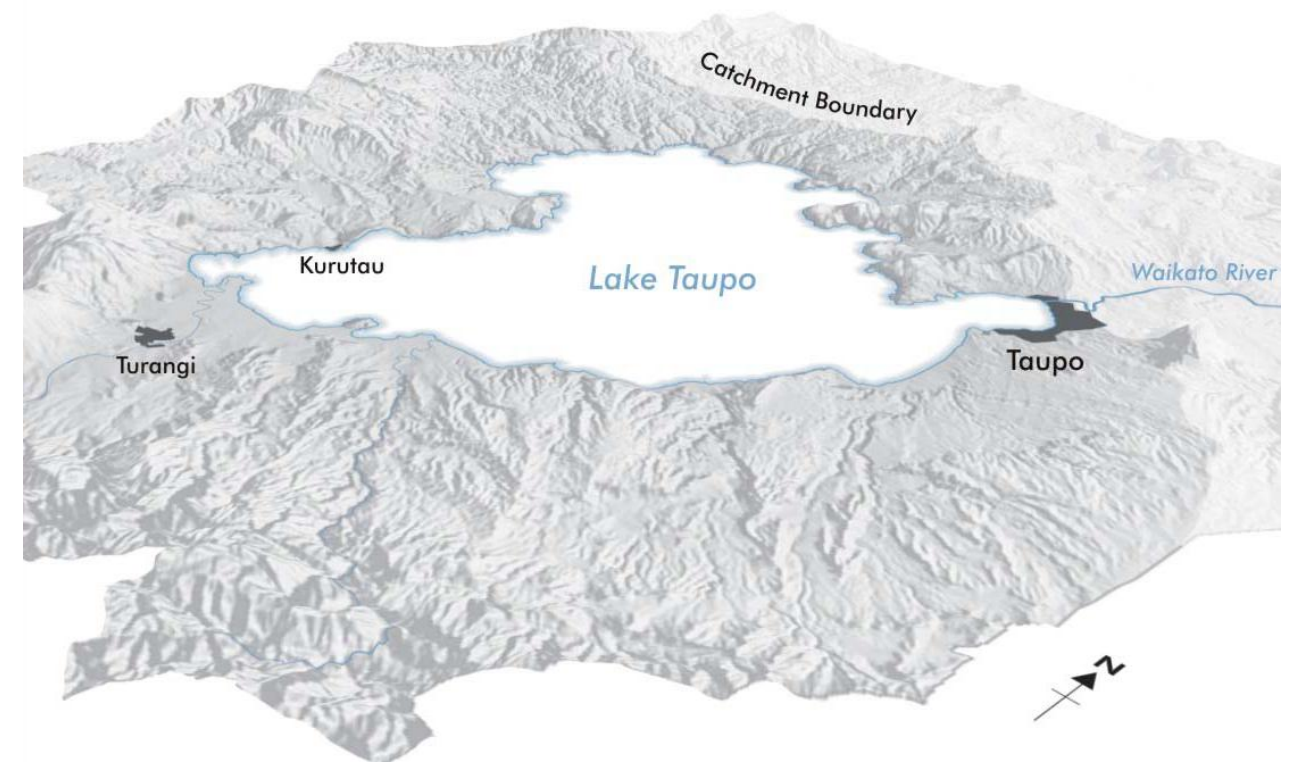

Figure 1 Catchment Area (Environment Waikato, 2001, B).

The water clarity of the lake has decreased by one meter since the 1980's according to an Environment Waikato report on hydrology (Environment Waikato, 2001, B). This is not acceptable for future generations to incur the cost of society's mistakes today. With population growth and the intensification of land use for agricultural purposes "the health of the lake is declining due to the amount of nitrogen reaching the lake from rural land, sewerage and septic tank seepage" (TDCAR, 2005, p 57). Nitrogen is a growth stimulant and can drastically increase the growth of algal blooms and weed growth, particularly in lakes affecting the ecosystem and significantly changing the biodiversity (Scion, 2010). There have been observations of dissolved nitrogen in the lake resulting in the creation of nutrient dependant weeds and slimes (Environment Waikato, 2003). Toxic algae has bloomed in the lake for the first time in 2001, and then late in 2003 where health issues had to be issued for areas such as Whakaipo Bay and Omori within the catchment (Environment Waikato, 2003). Similar international contexts with low nutrient, deep lakes, illustrates "an increasing load of nutrients almost always resulting in increased algal growth and reduce water clarity" (Environment Waikato, 2003, p 8).With water demand predicted to increase 50 per cent by 2041 (Watson, 2008), the wellbeing of the lake is gradually being compromised and 
..the choice we face is a stark one: either the lake's inestimable value to New Zealand and the world will gradually diminish, or we must find new ways of living in the catchment that will sustain both the health of the lake, and the viability of the surrounding community.

(Environment Waikato, 2003, A, p 5).

A lake can act as an environmental indicator (Shrestha, 2005) and this is evident in the case of surrounding regions such as the Rotorua Lakes which are slowly deteriorating. The community do not want to see this situation occur within the Lake Taupo area as it personifies an unspoilt, fresh and unique region (Cloke and Perkins, 2002) as the lake is seen as "the jewel of the North Island" (Environment Waikato, 2003, A, p 5). The area has a booming retirement population, is heavily dependent on tourist activity with ventures such as trout fishing, bringing in approximately $\$ 70$ million dollars annually (Environment Waikato, 2003, A), jet boating, sky diving, hydro electricity generation, skiing and snowboarding at the local ski fields on Mt Ruapehu, and the world's first bungy jump off a cliff by the Waikato river (Cloke and Perkins, 2002). The area is based around tourism and forestry with gross domestic product for the Taupo district region reaching $\$ 750$ million in 1998 (Environment Waikato, 2003, A).

The Indigenous people of New Zealand are the Maori people and the local tribe or Iwi of the Lake Taupo Catchment area are Ngati Tuwharetoa who have 'Mana Whenua'. This is the

mana [energy] that the gods planted within Papa-tua-nuku (mother earth) to give her the power to produce the bounties of nature. A person or tribe who 'possesses' land is said to hold or be the mana whenua of the area and hence has the power and authority to produce a livelihood for the family and the tribe from this land and its natural resources, (Williams, 1975, p 1).

Generations of Tuwharetoa have lived in Taupo and developed Tikanga Maori which are "customary values and practices" (MFE, 2010) that reflect "special and unique relationships with the environment; Tuwharetoa are Treaty partners with the Crown and hold legal title to the bed of the Lake and its tributaries" 
(Environment Waikato, 2003, A, p 7). Tuwharetoa are the Kaitiaki or guardians and stewards of the land, this is in specific relation to all physical and natural resources (MFE, 2010). Therefore it is in their interests to protect the Lake for the future generations of Tuwharetoa as they own over $40 \%$ of the land (approximately 109, $000 \mathrm{ha}$ ) in the catchment meaning the Iwi are the largest private landowners (Environment Court Decision, 2008).

It was identified that the most important and urgently pressing issue for the township of Taupo and the wider community is that of Lake Taupo's water quality. In a survey by the Institute of Geological and Nuclear Sciences, 90 per cent of the urban population and 91 per cent of the rural community found that water quality was central to the regions prosperity and 78 per cent said that protection of the lake should be ahead of any development in the region (Stewart, Johnston, Rosen and Boyce, 2000).

Land and Lake are so intricately linked, we must look to the land, and human activities on the land, for the necessary changes to protect the lake. There are significant nitrogen sources from activities that can be managed and reduced (Environment Waikato, 2003, A, p 10).

The protection of Lake Taupo has been a complex process involving an enormous amount of engagement from multi-sector stakeholders spanning over many years. The aim of this thesis is not to investigate in detail the 10 year process as this can be found by observing the Yurex (2010) and Arunachalam (2010) studies. However, to aid in an understanding of what has occurred over the last ten years it is important to briefly discuss the development of Lake Taupo protection strategies and how they have evolved. The challenges are around the perceptions of business, government and society incurring a financial cost, but the long term benefits for the region and the country will far outweigh this short term expense if nothing is done (Environment Waikato, 2003, A). A partnership of innovation is incorporated into a collaborative activity, resulting in new ways of protecting Lake Taupo. This resulted in the formation of multiple protection strategies where a range of actors could collaborate to ensure protection for current generations in the area as well as the future generations of New Zealand. 
A timeline which is a refined version of the Yurex (2010) case study along with up to date additions can be seen in Appendix 1. This timeline details the process from 1999 to 2010 and specifies the major milestones throughout the course of engagement.

The community and their concern for the quality of water within the lake was a strong motivator for Environment Waikato (EW) to protect the lake. The council had two options, to do nothing and let water quality deteriorate or take urgent action to stop nitrogen entering the lake. In $2000 \mathrm{EW}$ issued a survey in the newspaper regarding four options for lake water quality. These options included;

1. Better water quality than now, with much less intensive land use in the catchment

2. Maintain current water quality by reducing nitrogen output from existing land uses and preventing further land use intensification

3. Slightly lower water quality than now, with existing land use remaining the same but no further intensification.

4. Lower water quality. Do nothing to change land use in the catchment.

(Proposed Waikato Regional Plan Variation 5- Lake Taupo Catchment, 2007, p 3).

The community responded stating that option 2 and 3 were the best alternatives forward and in $2001 \mathrm{EW}$ decided to pursue option 2 to maintain the current water quality but prevent further intensification within the catchment.

EW conducted a cost benefit analysis which "assumed continued tourism growth in the catchment was a measurable benefit of continued excellent water quality in the lake" (Young, 2010, 6). A regulatory approach was needed to stop nitrogen leaching ${ }^{1}$, with the majority of the manageable nitrogen coming from agricultural farming ${ }^{2}$ needing to be removed (Environment Waikato, 2003, B). Tony Petch from EW stated that "If we can't do this in Taupo with the RMA (Sec 30), then we couldn't do it anywhere else, and the agricultural sector would be untouchable" (Yurex, 2010, p 12), illustrating that it was a project which could be precedent

\footnotetext{
1 "Leaching" refers to nitrogen not being captured by plant roots and draining through soil and entering ground water or streams and lakes.

${ }^{2}$ It was identified that nitrogen leaching from pastoral farming represents 93 percent of the total manageable load entering into the Taupo Catchment area (Young, 2010).
} 
setting for the rest of the country. Support in 2003 was gained from Taupo District Council (TDC), Central Government (CG) and the Ministry for the Environment (MfE) and EW councillors to determine a workable solution.

While the main government partners were meeting to address the problem from a regulatory perspective, a three year project and action plan titled '2020 Tauponui-a-Tia' sought to ensure sustainable development of Lake Taupo. This was a MfE funded, Tuwharetoa led non-statutory project which sought to determine specific issues and surveyed 14 key values and strategies to protect the Lake. The top concerns raised by the community can be seen in Appendix 2 and 3. Engaging with Tuwharetoa were representatives from the Department of Conservation (DOC), Internal Affairs, EW, TDC, and Lakes and Waterways Action Group (LWAG, a local community group). This initial collaboration was said to be the foundational undertaking for the protection of the lake and shows at a very early stage a multi sector group of actors working towards the protection of the catchment.

In 2003 a partnership involving EW (the regional council), TDC (the local council), CG (the crown) along with Ngati Tuwharetoa and other interested community groups consulted over a three year period with Taupo and Waikato communities leading to public funds being invested in the 'Protecting Lake Taupo Strategy' (Brookfields Lawyers, 2007). Scientists from EW and Ag Research identified a total amount of Nitrogen $(\mathrm{N})$ entering the lake and decided to take out $20 \%$ of the total nitrogen. That 20 percent referred to 153 Tonnes of Nitrogen that needed to be removed. This management regime involved regulatory and nonregulatory measures for the protection of the lake where "a key non-regulatory method is the establishment of a public fund of $\$ 81.5$ million to reduce nitrogen levels in the lake by 20 per cent by 2020" (Strategic plan, 2008, p 3). The fund will be drip fed to a trust over 15 years with the costs shared between central government (45 per cent), Waikato ratepayers (33 per cent) and Taupo residents (22 per cent). The Trust set up was the Lake Taupo Protection to responsibly reduce nitrogen levels in Lake Taupo by 20 percent (Strategic Plan, 2008). Such responsible initiatives included purchasing nitrogen intensive land, covenanting it and changing it to low intensity uses such as forestry to purchasing nitrogen from farmers. 
To be successful in safeguarding the lake we will be dependent on the actions and goodwill of a larger number of people including businesses, landowners, government agencies, and the wider community. The concept of 'Te wai, te iwi', 'The water, the people' therefore becomes a key driver of both what we do and how we will operate

(Strategic plan, 2008).

The regulation that was created was an aspect of the regional plan, titled RPV5 or Variation $5^{3}$, to influence land use to change to lower levels of nitrogen leaching. The process started in 2000 when EW initiated community meetings to alert land owners that land intensification could not continue. As Appendix 1 illustrates, the process of working with farmers and foresters along with many other entities to determine a workable cap and trade policy for nitrogen has been a lengthy one. Farming and forestry make up 20 and 25 per cent of the rural productive land respectively with the rest of the land undeveloped or in small areas of urban use (Young, 2010). Engaging with parties like MFE, TDC, EW, the Tuwharetoa Maori Trust Board (TMTB), Taupo Lake Care (TLC) Federated Farmers (Fed Farmers), Lake Taupo Forest Trust (LTFT), Landcorp Ltd, Environmental Defence Society (EDS, LWAG, Lake Rotoria Forest Trust (LRFT), Fonterra, Te Puni Koriki (TPK) and Carter Holt Harvey ( $\mathrm{CHH}$ ) showcases the varied selection of public and private interest groups. Lake Taupo really is both a public and private asset to the wider community.

All parties had to go to the Environment Court in 2008 to argue the finer details with utilisation of a best year rather than averaging eventuating as the final outcome. The best year is taken from the years of 2001-2004 and acts as a farmers' benchmark which results in a total Nitrogen Discharge Allowance (NDA) for a land owner. This means land owners are capped at an amount of nitrogen that leached in their best year and if they decide to farm to a lower NDA they can trade and sell their nitrogen to a buyer.

\footnotetext{
${ }^{3}$ View the RPV5 document for further detail, but to aid in understanding the purpose of the policy the first objective in the variation is the "Maintenance of the current water quality of Lake Taupo. The effects of nutrients discharges in the catchment are mitigated such that by 2080 the water quality of Lake Taupo is restored to its 2001 levels" (Young, 2010, p 5).
} 
Another milestone in the engagement process was in 2010 when EW revised its science and found that the original estimates of 153 Tonnes (T) of $\mathrm{N}$ to be taken out of the lake as a 20 per cent reduction of manageable nitrogen was not large enough. With 90 per cent of the farmed area within the catchment having been benchmarked and receiving an NDA, the 20 per cent reduction agreed to by the funding partners was looking more like achieving a 17-19 per cent reduction which potentially is 1 to 3 per cent lower than what is needed (McLay, 2010). This means that the total amount of nitrogen entering the lake is a more realistic figure of $180 \mathrm{~T}$ compared to the original $153 \mathrm{~T}$ that was estimated. These changes have come about from policy change, as it was agreed to take the best year compared to averaging over a four year period in the Environment Court in 2008. Entities have continued to meet over 2010 to finalise the wording of the policy before it is enacted as legislation. A range of businesses have been involved in the collaboration over a 10 year period, the Variation 5 is soon to be legislation, and it is now time for businesses to work within its boundaries.

\section{Research Question}

The overarching research question for this thesis is set in a way that broadly seeks to explore meaning behind stakeholder engagement and sustainability from a range of perspectives. This research aims to investigate the question:

1. How does a multiple stakeholder perspective affect the business case for sustainable development?

Stemming from this question are three aims. This first aim is to determine the motivation behind stakeholders engaging and their view of sustainability within the catchment area. The second aim stems from the first as it seeks to determine the effect that involvement has had through engagement and how this has affected their business or view on various businesses. This will aid in gaining the perspectives of stakeholders in the process to establish precedents for similar integrative engagement schemes in the future. The third aim is to explore the relationship between collaborative stakeholder engagement and sustainability. Other outcomes that will eventuate will be the creation of a complex case study of stakeholder collaboration for further understanding and the recognition of additional areas for research. 
The following chapter of this thesis will cover a literature review which will explore theories and concepts related to the research question. The qualitative methods in creating a case study will be reviewed with the findings and discussion section examined before conclusions are finally developed regarding collaboration among stakeholders in the Lake Taupo Catchment area. 


\section{Chapter II: Review of the Literature}

The focus of this thesis is on understanding the relationships that exists among stakeholders engaging in a business case for sustainability. Therefore it is important to identify sustainability in its many forms within the literature for its application in the Lake Taupo context. This literature section is broken down into six areas, firstly discussing the realm of sustainability which covers sustainability discourse, environmental politics and regulatory measures. Stakeholder theory and multi-stakeholder collaborations along with complexity theory are identified in a theoretical construct and then the business case for sustainability is discussed illustrating the conjoint environmental, social and economic benefits. New Zealand's environmental marketing is reviewed with international case studies surrounding lake management illustrated in the final section.

\section{Sustainability- What is it?}

The basic premise of this thesis surrounds the topic of sustainability, therefore it is helpful to set the context by firstly looking at its origins and evolution.

We abuse land because we regard it as a commodity belonging to us. When we see land as a community to which we belong, we may begin to use it with love and respect. -Aldo Leopold (Fennell, 1999, p66).

This statement surrounding natural resource utilisation and ecological preservation recognises the dilemma that our species has struggled to balance. On a world stage, human kind has been slow to realise the impacts of economic activities and the impacts this has on natural resources (Fennell, 1999).

\section{The Realm of Sustainability}

Therein is the tragedy. Each man is locked into a system that compels him to increase his herd without limit- in a world that is limited. Ruin is the destination toward which all men rush, each pursuing his own best interest in a society that believes in the freedom of the commons. Freedom in a commons brings ruin to all.

(Hardin, 1968, p 1244). 
With an array of definitions and related concepts (Costanza and Patten, 1995; WECD, 1987; Pearce and Atkinson, 1993) it is important to understand how sustainability as a definitional concept has evolved. The underlying belief of sustainability has been around for many years (Pezzey, 1992), however catch phrases such as sustainable development (Byrch, Kearins, Milne, \& Morgan, 2007) ecological sustainability (Callicott and Mumford, 1996) triple bottom line, corporate social responsibility(CSR), corporate sustainability (van Marrewijk, 2003), Eco-efficiency (Patterson and McDonald, 2004), and sustainable growth (Klaassen and Opschoor, 1991; Pezzey, 1992) demonstrate the continual evolution of the term and show variation and subsets that emerge from the concept. The values surrounding each of the aforementioned concepts, allows individuals to recognise how science can be used to advance political agendas. Individuals are,

empowered or disadvantaged depending upon whether they have a scientific language with which to express their agendas. For example, environmental science prior to the 1960's developed concepts and understandings that served the management agenda of minimising waste and maximising efficiency. During and after the 1960's, however, the language and logic of ecology empowered a management agenda that emphasised nutrient cycles, carrying capacity and biodiversity (Hull, Richert, Seekamp, Robertson, and Buhyoff, 2003, p1).

These terms illustrate language that is used to "envision, negotiate, and manage environmental conditions" (Hull, et al, 2003, p1). The New Zealand Sustainable Business Network defines sustainability as "the integration of economic growth, social equity and environmental management, both for now and for the future" (Zorn and Collins, 2007, p 402). This definition broadly sets a context compared to the more refined definition specifically focusing on an ecological context where Robinson (1993) states, sustainability refers to an organism's ability to avoid extinction and ensure that the population lives to survive and reproduce. In an economic sense "it means avoiding major disruptions and collapses, hedging against instabilities and discontinuities" (Costanza and Patten 1995, p 194).

Sustainability is identified by Costanza and Patten (1995) as "a sustainable system which survives or persists" (p193). This definition put forward by Costanza is an 
amalgamated version of his economic and ecological dimensions. It leaves speculation as to what a system entails and still leaves the reader with a vague understanding of sustainability.

Ambiguity in the numerous terms that are used to define sustainability and environmental quality is problematic. This is particularly so if public participate in the planning process and they perceive terms to mean similar or different things (Bendell, 2000). Sustainable development has been viewed as an ambiguous contradiction of terms (Hull, et al, 2003). It is evident that individuals seem to conceptualise a definition that is specific to their own context and their specific goals and objectives (Vionoz, 2008). The inter-changeability of sustainable development and sustainability seem to be inherently ambiguous for the wide range of actors who "present their own versions of the terms and to rest normative claims and policy demands on those versions" (Rydin, 1999, p 468). Zorn and Collins (2007) argue that sustainability as a concept has been used to initiate support for a range of political and social activities through the business, government and society matrix. Richardson (1997) finds that the concept needs to be radically redefined in a position that is relative to ecological terms, and if that is not possible then the concept should be abandoned.

Sustainable development is a political fudge, a convenient form of words, which is sufficiently vague to allow conflicting parties, factions and interests to adhere to it without losing credibility. It is an expression of political correctness which seeks to bridge the unbridgeable divide between the anthropocentric and bio centric approach to politics. (Richardson, 1997, 43).

Rydin (1999) interestingly finds that these concepts need to be ambiguous and contestable as it allows different actors to reach a mutual position even if their points are conflicting. Actors can pick and choose the specific dimensions of the concept that benefit their argument, for example choosing to focus on the economic arguments over the social dimensions leads to the danger of actors disregarding aspects that do not interest them (Rydin, 1999). 
Following on from the bounty of definitions, it is intriguing to consider sustainability as a science and compare its development to that of Carson's illustration. Carson (1962) alludes to the art of a science as if it is a river,

it has an obscure and unpretentious beginning; its quiet stretches as well as its rapids; its periods of drought as well as of fullness. It gathers momentum with the work of many investigators and as it is fed by other streams of thought; it is deepened and broadened by the concepts and generalizations that are gradually evolved ( $\mathrm{p} 157)$.

Over time the concept of sustainability, corporate social responsibility and the many other terms have stemmed into a paradigm with many thoughts intertwined (Carter, 2001). Individuals and society have started to garner an in-depth understanding as practitioners have further investigated and studied the paradigm being sustainability and its many subsidiary definitions (Sneddon, Howarth, and Norgaard, 2006).

The application of the concept needs rigour,

The real threat is that the concept becomes widely misunderstood, it is confined to the flow rates of depletion and replenishment, it remains regarded essentially as a scientific and managerial device, and it has no role either in institutional reform, mobilisation of new power relationships, or in the extension of a more pragmatic eco-morality (O'Riordan, 1988, $\mathrm{p}$ 49).

This illustrates the ambiguity and misunderstandings that surround the numerous definitions. The most cited definition is from the Brundtland report (WCED, 1987) being "development that meets the needs of the present without compromising the ability of future generations to meet their own needs" ( $p$ 43), and it will serve the purpose as the definition for this thesis.

\section{The Sustainability Path}

If we glimpse back over the years it is important to look at the history of some prominent articles and reports that have influenced societies thinking surrounding 
environmental issues. It was in 1962 before the concept of sustainability was formally conceptualised that Rachel Carson published her book Silent Spring. Rachel had spent the majority of her life as a marine biologist and it was in her time working for the government that she became aware of agricultural control programs and the impact that was having on the natural environment (Carson, 1962).

The book by Carson illustrates that intricate relationship between species and the environment by concentrating on the toxic effects of harmful insecticides which had been increasingly used to fuel the green revolution (Krebs, Wilson, Bradbury, and Siriwardena, 1999). Environmental problems have occurred long before this example, however it is the correlation documented by Carson (1962) between human activity and the environment which has been regarded as the beginning of an environmental movement (Briggs, 1997).

With the increasing trend of society becoming concerned regarding environmental issues, the United Nations decided to create an independent body to generate a global agenda for change. It was in April 1987 that this independent body, the World Commission on Environment and Development (WCED), released their report titled Our Common Future. The report is now referred to as the Burndtland report after the Chairperson Gro Harlem Brundtland was a driving force behind the publication. The report involved three years of rigorous research, numerous public hearings and many debates that directed the world to specifically focus its attention on reversing environmental degradation and the trend of decreasing poverty (McChesney, 1991).

The WCED had three specific long term environmental strategies that were created to achieve sustainable development. These are,

-Translate environmental concern in achieving common, and mutually supportive objectives;

-Consider how the international community can deal more effectively with environmental concerns; and

-Define the perceptions, goals and agenda for action needed to successfully protect and enhance the environment 
(World Commission on Environment and Development, 1985, 27)

These strategies stressed the urgency for action with Ekins (1989) stating the report was not creating a hyperbolic rhetoric, but rather a definitive and simple fact of global environmental decline. The Brundtland report demonstrates the issues that are central to environmental protection (Paehlke, 1989) even though some would argue that it is more of a political report rather than a scientific document (Timberlake, 1989). In the end the most important outcome is that it generated discussion surrounding environmental, economic and social sustainability "it should not be regarded as a bible, as an unchallengeable article of truth. Its value lies in its ability to initiate change, and to act as a catalyst for

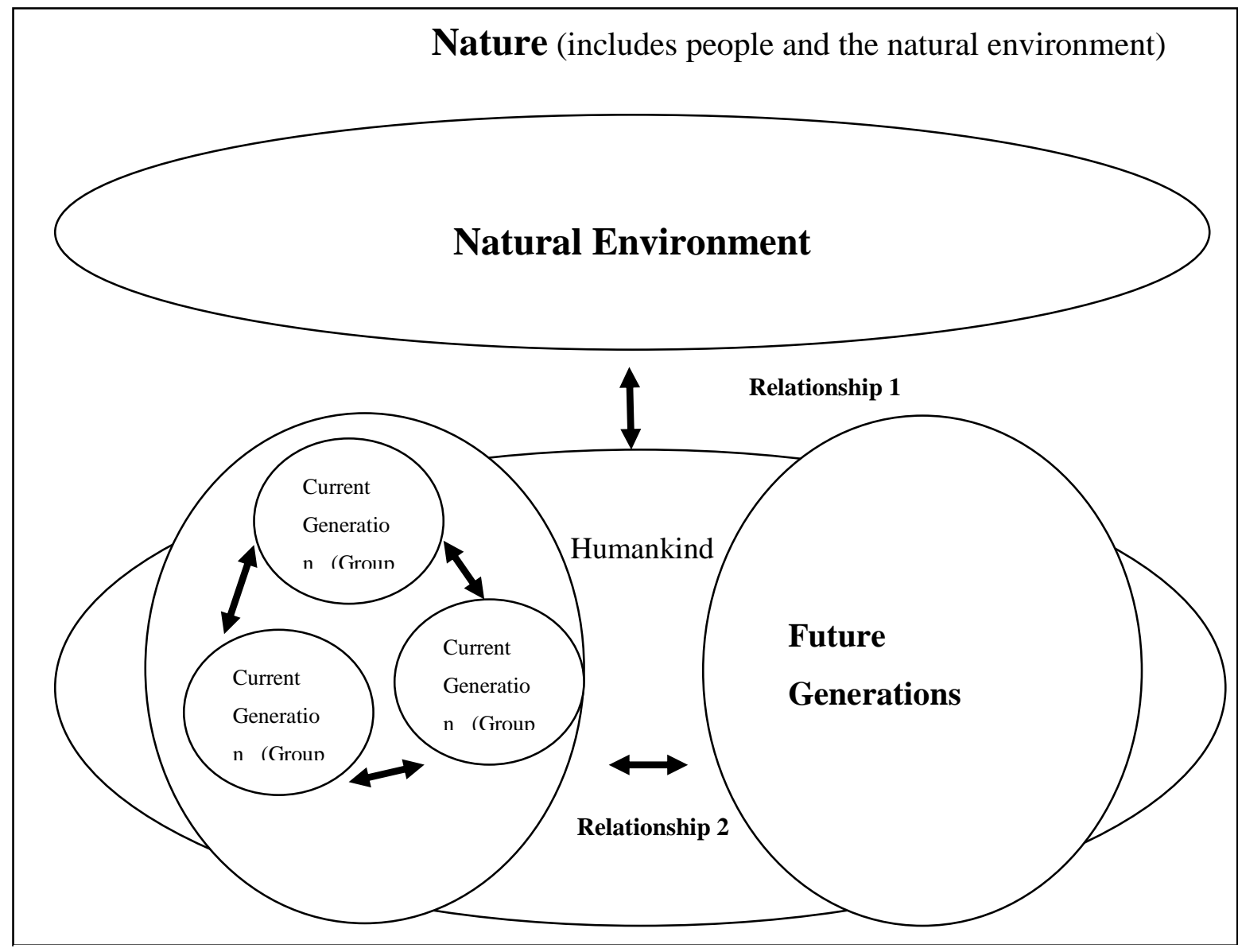

Figure 2: The three relationships used by the Brundtland Commission to define sustainability

Adapted from (Boutilier, 2009, p 20)

reflection, analysis and action" (McCheesney, 1991, p 53).

As part of the Brundtland recommendations Boutilier (2009) identifies three forms of relationships that are used by the Brundtland commission to define 
sustainability. The square in Figure 1 encapsulates people and the natural environment and has been labelled as nature. Numerous entities are linked through double headed arrows and illustrate the need for relationships to be balanced for sustainable development to occur, these are "humankind with nature, the current generation with future generations, and different groups within the current generation" (Boutilier, 2009, p 20).

Putting the Brundtland report into a New Zealand context, the government compiled an interim report that outlined steps to address the commission's concerns and emphasised the situation that New Zealand was in fact already following the reports concerns in a variety of areas (McCheesney, 1991). The Ministry for the Environment has taken on board the role of following up on the Brundtland report and implementing its recommendations (Ministry for the Environment, 1989). Progress has been made with incorporating indigenous values into environmental and social policy. The Maori perspectives brought about new values and a new dimension to the paradigm on sustainability in New Zealand (McCheesney, 1991; Snively Kupenga, Nepe, O’Dea, Rashbrooker, Robins, Stephens, and Stott, 1990; Wright, 1988).

There was a muted response to the report from an official capacity, however this is contrasted by New Zealand's response on global contemporary environmental issues which is far from muted.

What is positive is the fact that events such as the release of the Brundtland report have brought about the emergence of environmental issues into mainstream discussion. Consequently as society has been exposed to concepts surrounding sustainability, governments increasingly have had to incorporate the environment as an issue onto their agendas. The area of environmental politics will now be reviewed in the following section.

\section{Environmental Politics.}

Whether it is identified as subsidiarity, decentralisation, empowerment or participation, some component of democratisation is widely viewed as being integral to the achievement of an environmentally sustainable future.

(Agyeman and Evans, 1994, p 14). 
There have been many images that have screened through media channels portraying the intricate relationship between man and nature. The one that has dominated environmental politics the most is the image of planet Earth from outer space taken on the Apollo space trip. This photo is said to have caused a fundamental shift in individuals perception of the earth and the relationship it has with mankind (Hajer, 1997). The Earth image was used in a campaign to save "Our Common Planet" and is said to have been the cornerstone of environmental politics in the late 1980's.

If we were living 500 years hence, do you think we would wish that in respect of a particular problem we had been living now instead of then? If we do, then our present way of acting is a selfish one (Connelly and Smith, 1999, p 28).

Environmental policy needs to be encompassing and integrative in a manner that seeks to avoid and prevent rather than straight remediation (Bührs and Bartlett, 1997; Hajer, 1997). Governments are elected to represent a range of groups within society, so they need to think about the impacts that policies will have on future generations. "Sustainable development is as much about democracy as it is about limits to growth and our ethical relationship with the non-human world" (Connelly and Smith, 1999, p 61).

Policy is defined as viewing a set of approaches in an interpretive manner, looking from contradictory positions and comparing and combining approaches (Hajer, 1997). Bührs and Bartlett (1997) find that environmental degradation is caused primarily by disjointed thinking, narrow assessments and out of touch policy making.

Inherent in the concept of [the] environment itself is the notion that truly successful environmental policy must be anticipatory, comprehensive, and integrative. In a nontrivial way, all policy is environmental policy, hence the obvious need for environmental policy to address connections among the ecological, social, and economic dimensions of the environmental problematique

(Bührs and Bartlett, 1997, p 74). 
Long term planning surrounding environmental policy does not fit with political rationality as politics are based on short term election cycles due to "political survival (re-election) depending primarily on the rule of 'delivering the (mostly economic) goods' today rather than tomorrow”(Bührs and Bartlett, 1997, p 82). Governments are expected to deliver short term rewards and therefore recognize no benefit in placing an emphasis on uncertain future scenarios. Although individuals realise that potential economic benefits go hand in hand with environmental policy (Bührs and Bartlett, 1997).

The concept of Natural Resource Management has been the topic of concern for governments far longer than environmental policy, "this is especially true for Governments with resource-rich territory, and a significant proposition of economic activity accounted for by the resource sector" (Dryzek, 1997, p 64).

I think that we understand today that sustainable development is about much more than environment policy defined in terms of departments, ministers and white papers. It requires a mosaic of institutions, policies and values. Mosaic may even be too static a word for what is required; it is really a political eco-system that is needed to save the real one (Alexander, 2009, p 88).

Part of the political ecosystem, as Alexander (2009) puts it, is the role that business can play in environmental politics. Private firms are constantly engaging, whether directly or indirectly, in “the lion's share of the resource depletion, energy use, and hazardous emissions that generate environmental concerns. Corporate activity dominates every stage of the value chain" (Levy and Newell, 2005 , p 1). At the same time firms can act as engines of change through a system of business government relationships (Levy and Newell, 2005) towards a win-win discourse of 'ecological modernisation' (Hajer, 1997). Ecological modernization is a reform-orientated paradigm that surrounds ecological policy strategy (Mol, Spaargaren, Sonnenfeld, 2009). In Germany the environmentalists fought long and hard against a corporatist wall "yet once environmental values were taken on board, corporatism eventually enabled these values to be addressed in a particular fashion: that of ecological modernization" (Dryzek, 1997, p 141). 
A wide range of actors have caused an influential change in New Zealand's political arena eventuating from events such as the publication of the Brundtland report and issues brought up by the World Commission on Environment and development, climate talks at Copenhagen and Cancun. Environmental issues have slowly been working their way onto the political agenda of numerous parties within the context of New Zealand politics. The Green Party centres their left wing policies on the environment and social issues (South, 2009), while a much larger conservative right wing party 'The National Party' places a strong emphasis on economic rationale above anything else (South, 2009).

The Labour-Green coalition brought about some strong environmental change, particularly the passing of emissions trading legislation in 2008. The differing political parties can change the regulatory environment based on their perception of what their core constituents believe. Environmental regulatory measures will now be discussed with prominence placed on the Emissions Trading Scheme as it is vital to the Lake Taupo context.

\section{Regulatory Measures: Environmental Governance}

This piece of legislation is of significant importance, as the Emissions Trading Scheme (ETS) is an issue that many governments are either committing to or avoiding. It shows the concerns that firms and governments face "in the context of the pervasive and underlying issues of science, economics, and politics that are the phenomenon of global warming and its implications" (Grosse, 2005, p 153). Regulatory systems as stated by Grosse (2005) are said to be variable across all levels of governance: at the regional; national; multilateral; and bilateral levels; and they are variable over a range of countries and industries. 160 countries reached an agreement on December the $11^{\text {th }} 1997$ in Kyoto, Japan to stabilize emissions through measures such as legally binding targets and timetables. Levels from 1990 were set as a target over the period of 2008-2012 (Zhang, 2001). China and America are not included in the agreement and these two countries are two of the world's largest emitters. The Kyoto agreement is cited as "economically inefficient, unobjective, inequitable, and worst of all - ineffective" (Harvard Magazine, 2002). The Kyoto Protocol is an example of variability across countries as the United States of America did not make any commitment in the 
first period and countries do not seem to want to continue to commit to reduce emissions from 2012 under Kyoto (Brewer, 2003). Countries are now struggling to create a new agreement to collectively fight climate change.

Zhang (2001) identifies some important requirements that need to be considered when setting up an emission trading scheme. Firstly any targets set at a national context need to be legally binding and have a timetable. An inventory needs to identify the emission sources and there needs to be a system of monitoring and reporting. Finally enforcement needs to be in place for non-compliance "this requirement is of particular importance to emission trading because, under an emissions-trading scheme, firms that operate in a country without adequate enforcement can emit without handing over their permits" (Zhang, 2001, p 124).

The European Union approved its ETS in 2002 and emissions trading started in January 2005 (Grosse, 2005). New Zealand has since revised the ETS through an act passed on the $25^{\text {th }}$ of November 2009 which has reduced the financial impact on households and jobs while maintaining a responsible commitment to reducing the countries greenhouse gas (GHG) emissions (Young, 2010). A diverse range of tools are needed to achieve economic change as no one single measure will stabilise New Zealand's future of being a low carbon country. It is about "New Zealand doing its fair share" (Young, 2010, p 1) and honouring the commitment to voters and to the international community. Other regulatory initiatives include the New Zealand energy strategy, the sustainable land management plan and the New Zealand conservation strategy (Climate Change information, 2010). Along with an ETS, these initiatives "will provide New Zealanders with a flexible way of reducing their carbon footprint at a minimum cost to the economy and society" (Climate Change information, 2010, p 1). It does not help when Australia, New Zealand's closet trading partner is pulling away from its commitment to trade emissions (O'Reilly, 2010) as it sets the stage for uncertainty (Fallow, 2010). As Grosse (2005) pointed out the variability is of concern across countries and industries as agriculture has been excluded from the European Union's ETS and yet agriculture is the biggest emitter of GHG in the New Zealand system so it needs to be included as long as it does not hinder international competitiveness.

The Brundtland definition as a diagram in Figure 1, illustrated intricate relationships that occur between a range of stakeholders in terms of sustainability. 
Entities in environmental politics also need to be consulted as Government's should be representing the diversity of society. They are considered to be stakeholders and come from many different areas within society and this next section will go on to define stakeholder management and multiple stakeholder collaborations.

\section{Stakeholders: who and what are they?}

Sustainability and stakeholder engagement are closely interrelated; the former is virtually unachievable without the latter

(Strand, 2006, p 23).

A refined definition by Mitchell, Agle, and Wood (1997) alludes to "the notion that corporations have an obligation to constituent groups in society other than stockholders and beyond that prescribed by law or union contract, indicating that a stake may go beyond mere ownership" ( $p$ 59). The emphasis placed on 'stockholders and beyond' illustrates the fact that individuals were questioning the assumption that a business's sole purpose is to its stock holders and a lack of capital investment in the organisation does not necessarily mean you are not a stakeholder. Stakeholder theory has a history set in economic theory as Adam Smith argued that "societies function best when economic interests and ethical interests coalesce; [he] established the notion that economic and ethical arguments share a symbiotic relationship (Andriof, Waddock, Husted, and Rahman, 2002, p 10). Business has an integrative relationship with society as they are part of and not separate to communities.

Today the phrase leading companies are using to define their relationship with the wider society is 'corporate citizenship'. It implies a responsibility to provide useful goods and services while operating legally, acting ethically, and having concern for the public good. Corporate Citizenship is a multi-faceted concept that brings together the self-interest of business and its stakeholders with the interests of society more generally. (Androif and Waddock, 2002, p 23).

Freeman (1984) identifies a broader but classic definition of a stakeholder group as "any group or individual who can affect or is affected by the achievement of 
the organization's objectives" ( $\mathrm{p} 46)$. The theory of stakeholders is a concept that is now embedded in a $21^{\text {st }}$ century managers' thinking (Kolk, and Pinkse, 2007). The interconnected relationships include such a wide range and diverse web of entities that managers need to understand the business impacts from potentially every source (Saint, 2005). Many authors create a hierarchy of stakeholders identifying primary and secondary stakeholders (Gable, and Shireman, 2004) with some being placed higher in priority than others (Arnstein, 1969: Reed, 2008). It comes down to the specific context of engagement as some situations will require different levels of engagement (Tippett, Handley, and Ravetz, 2007) with Reed (2008) discussing a 'wheel of participation' as a metaphor in favour of a stakeholder hierarchy.

There are many factors surrounding stakeholder engagement that are contextual and businesses today are a lot more connected with their stakeholders due to the changing conditions of society. Businesses are faced with the challenge of accepting the perspectives of such diverse stakeholders. No longer can they ignore what is occurring in the outside world.

The general trend, worldwide, seems to be that the responsibility of each and every business to reduce its impact on the environment is gradually being accepted.

(Corporate Sustainability, 2008, p 24).

As mentioned above businesses are exposed to a range of stakeholders. A number of entities can be listed as stakeholders ranging from employees, customers (Gable and Shireman, 2004), suppliers (Gao and Zhang, 2006), shareholders, competitors (Everett and Jamal, 2004), communities (WBCSD, 2002), local governments, future generations (Gago and Antolin, 2004), and even the environment (Saint, 2005). Mitchell, Agle, and Wood (1997) identify the natural environment as a stakeholder, particularly if it is affected by corporate activity. However the environment is not necessarily considered a stakeholder if it can influence an organisation in reaching its own objectives (Kolk, and Pinkse, 2007).

Organisations tend to address specific stakeholder claims based on their view as to which one is the most significant (Mitchell, Agle, and Wood, 1997). In such a 
diverse world "remote groups at the fringe of a firm's current operations can find common cause, exerting increasing pressure and calling into question the firms legitimacy and right to operate" (Hart and Sharma, 2004, p 7). It is possible that even stakeholders on the fringe "-the poor, weak, isolated, non-legitimate, and even non-human" (Hart and Sharma, 2004, p 7) can be extremely useful in terms of identifying new business models and can aid in managing disruptive change. An alternative view is that businesses have to take into account the influence of each stakeholder group and consider their position based on influence (Clulow, 2005). Androif and Waddock (2002) identify three sets of criteria being influence, impact and alignment. Mintzberg (1983) states that "influence is the equivalent of power, as power that is not exercised is insignificant, and influence is a materialization of power" (as cited by Roome and Wijen, 2005, p 236). When it comes down to collaboration with a range of stakeholders it is power that can be the most important dimension (Hardy and Phillips, 1998). This often results in a trade-off between conflicting stakeholders and their viewpoints which the organisation in question has to consider as some entities will have more power than others. Stakeholders can then be classified by their possession of the following attributes: “(1) the stakeholder's power to influence the firm, (2) the legitimacy of the stakeholder's relationship with the firm, and (3) the urgency of the stakeholder's claim on the firm" (Mitchell, Agle and Wood, 1997, p 853).

Table 1: Typologies of participation and collaboration

\begin{tabular}{|c|c|}
\hline Table 1: adapted from Reed (2008) & $\begin{array}{l}\text { Typologies of Participation and } \\
\text { Collaboration }\end{array}$ \\
\hline Basis of Typology & Example \\
\hline $\begin{array}{l}\text { Different degrees of participation } \\
\text { based on a continuum. There are } \\
\text { different terms based on the } \\
\text { different rungs of the ladder (Biggs, } \\
\text { 1989; Farrington, } 1998 \text { as cited by, } \\
\text { Reed 2008) }\end{array}$ & $\begin{array}{l}\text { Arnstein's (1969) ladder of } \\
\text { participation. A newer form is } \\
\text { suggested by Davidson (1998, as cited } \\
\text { by Reed, 2008) as a wheel of } \\
\text { participation }\end{array}$ \\
\hline $\begin{array}{l}\text { Based on nature of participation in } \\
\text { alignment with } \\
\text { communication flows }\end{array}$ & Rowe and Frewer (2000) \\
\hline $\begin{array}{l}\text { Based on objectives for which } \\
\text { participation is used }\end{array}$ & 2007) \\
\hline $\begin{array}{l}\text { Based on a transformative approach } \\
\text { that inspires and empowers } \\
\text { communities and gets them } \\
\text { participating and collaborating }\end{array}$ & Lawrence (2006) \\
\hline
\end{tabular}


Table 1 showcases a range of typologies differentiating the degree of stakeholders being engaged. Arnstein (1969) distinguishes between two types of engaged stakeholders in the form of a 'ladder of participation' with the lowest form being passive dissemination to the highest form being active engagement. However Biggs (1989) describes stakeholder engagement as a "relationship that can be contractual, consultative, collaborative, and collegiate" (as cited by Reed, 2008, p 2419). This is further built upon with Lawrence (2006) identifying transformative participation as a substitute for the term Armstein (1969) created at the top level of the ladder which was termed active engagement. This transformative approach leads to the idea that empowerment will occur in communities that are involved through engagement (Lawrence, 2006; Reed, 2008).

There is a negative side to stakeholder engagement surrounding sustainability relating to identity and a stakeholders overall reputation. An entity who is actively involved in the stakeholder process opens themselves up to judgement from others who are involved "as more or less competent, as sufficiently or insufficiently knowledgeable about the issue at hand, as appropriately open- or close-minded and so forth" (Collins and Kearins, 2007, p524). There is also the issue of stakeholders not having the same ideals when it comes to engagement and sustainability. Often the minds of business people see it as sustaining the business which is very weak sustainability (Collins, et al., 2005). It also leads on to the issue of unexpected outcomes that eventuate from the process and that these outcomes are not in favour of sustainability.

There are examples of entities who engage with stakeholders for the publicity rather than genuinely communicating with stakeholders (Collins, Kearins, \& Roper, 2005). The identification and selection of entities to engage with are subject to business interests (Banerjee, 2000). The danger in this is for selfinterested stakeholders to dominate in discussions and give little benefit to the greater group. Particularly when it comes to resource use where decisions are set around the short to medium term, the self-interest of stakeholders emerge which can be detrimental to a sustainable situation. If "all stakeholders pursue a selfinterested approach to conflict management, working towards common good, sustainability-orientated resolutions become impossible" (Collins, et al., 2005, p 
13). Selfish parties who engage are often reluctant to agree on making significant changes because it could impact on their profitability. Collins et al., (2005) recognizes this behaviour is the expectation of "higher costs being incurred by covering what had traditionally been conceived of as externalities" (p 8).

So far stakeholders that are specifically situated around one organisation have been discussed. The matrix of multiple stakeholder engagement is examined next as it is important to recognise some stakeholders work with others towards a collective outcome. The stakeholder matrix does not necessarily focus on one organisation in the centre, it has many stakeholders networking with a range of entities (Roome and Wijen, 2005).

\section{Multi Stakeholder Collaboration}

Kia ata whakatere i te waka.

Kei pariparia e te tai, kei monenehu te kura.

Whakamarotia atu ano, mea hoki mai kit e kapua

whakapipi.

Be careful when launching your canoe

Lest it be overcome by the tide and its plumes be drenched

It is all very well that we go our separate ways but our strength is in working together.

(Tamamutu, Tupuna of Ngati Tuwharetoa, Towards 2019, 2010, p 48)

Collaboration between stakeholders is evident in corporate environmental management where it is not a single organisation working towards one outcome but rather a range of actors bringing about knowledge and ideas beyond business organisations (Rome, 1994). As the Maori quote by Tamamutu Tupuna from Ngati Tuwharetoa suggests, the 'strength is in working together'. This is an important theme that has emerged between interactions of companies and other stakeholders in environmental management (De Bruijin and Tukker, 2002; Roome and Wijen, 2005; Sharma and Vredenburg, 1998). Different perspectives surrounding particular issues, options and outcomes are beneficial from discussions with a diverse range of stakeholders (Carroll and Buchholtz, 2008; Roome and Wijen, 2005). Collaboration occurs, according to Wood and Gray 
(1991), when "a group of autonomous stakeholders of a problem domain engage in an interactive process, using shared rules, norms and structures, to act or decide on issues related to that domain" ( $p$ 14). Networks of stakeholders are developing into a significant and influential form of social organisation. A shift in stakeholders views, as seen in Figure 3, shows a paradigm shift from the organisation centric view to a network focused view where different stakeholders engage with one another. This changes the interaction to a collaborating and accommodating approach with the external environment (Svendsen and Laberge, 2005). The engagement between parties is a symbiotic relationship with the longterm in mind (Andriof and Waddock, 2002). This means that the interdependency between parties is not a short-term arrangement, it is dependent on the long-term wellbeing of the system (Svendsen and Laberge, 2005; Post, Preston, and Sachs, 2002).

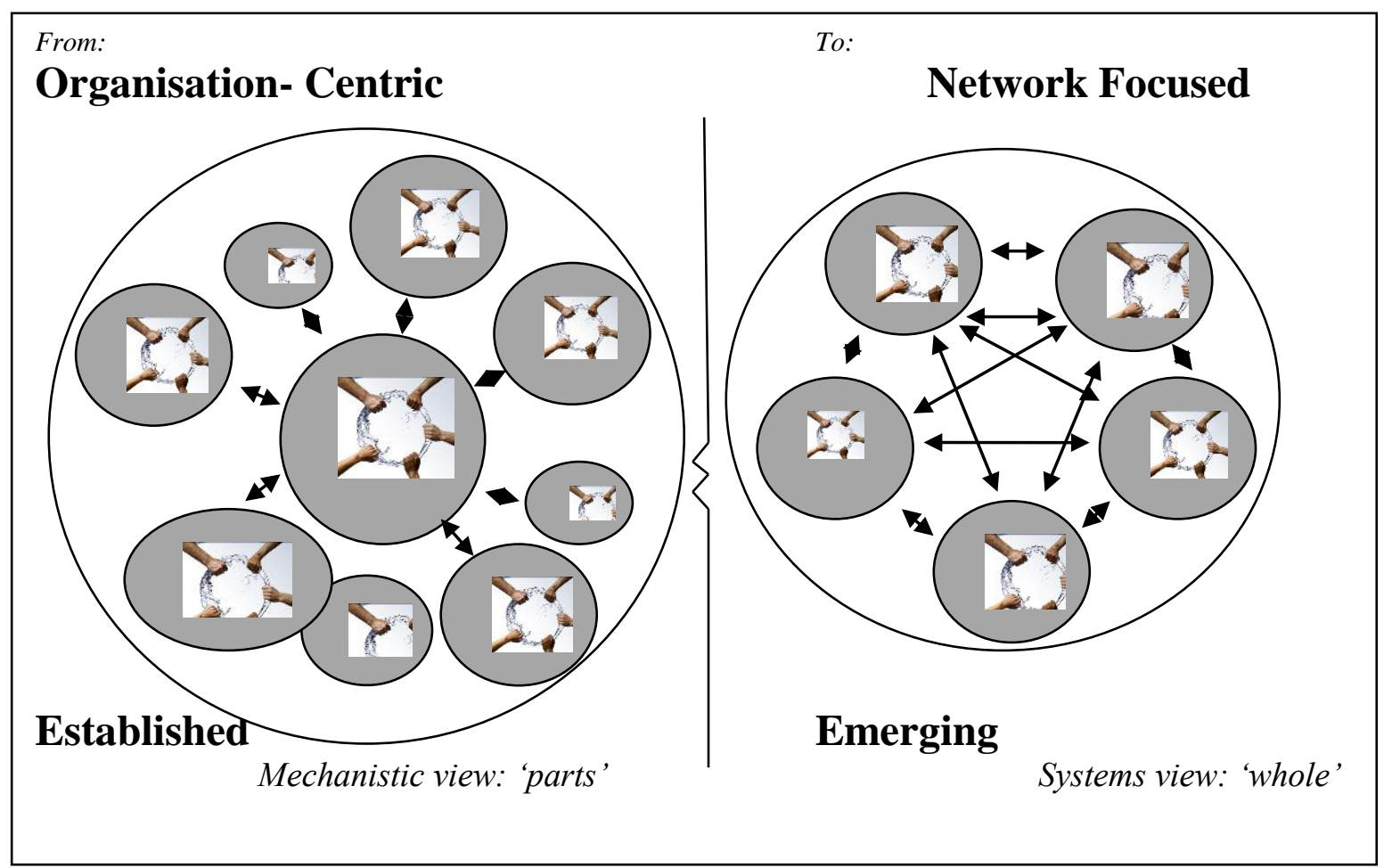

Figure 3: Shift to systems view in stakeholder engagement Adapted from (Svendsen and Laberge, 2005, p 97)

Collaboration between diverse stakeholder groups is extremely important in an environmental context with scientific and management discourse as it brings information into a setting that is easier to comprehend (Everett and Jamal, 2004). Within environmental discourse, ecological issues can be explained as meta- 
problems or problem sets that are interconnected, the actors in the set who deal with issues generally affect the set as a whole (Chevalier and Cartwright, 1966: Roome and Wijen, 2005). Roome (1994) finds if a group of stakeholders are to discuss a solution to that problem then it needs to address the whole problem set, "involving multi-actor cooperation designed to assess problems, find solutions and evaluate outcomes" (Roome and Wijen, 2005, p 267). This is due to many environmental problems being unstructured, complex, and multi-scale so the decision making process needs to be transparent and flexible to change (Reed, 2008). Such environmental problems are now involving a range of stakeholders due to an increasingly sceptical public who are more educated regarding the environment (Irwin, 1995, as cited by Reed, 2008). Companies and even governments get a sense of social legitimacy through interaction and engagement with a variety of groups (Hoffman 1997, as cited by Roome and Wijen, 2005).

It has been suggested that the process of group learning and action from a stakeholder setting comes down to a range of factors (Clarke and Roome, 1999) such as "organisational antecedents, market positioning, technology, access to stakeholder networks, sensitivity to multiple perspectives and ability to facilitate inputs from different internal and external stakeholders" (Roome and Wijen, 2005, p 238). Engagement and collaboration with a range of entities means there are a number of risks that need to be considered for a successful outcome to eventuate.

There are some negatives that can eventuate from engaging with a range of actors. Reed (2008) finds that marginalised groups in society can have unfavourable interactions with the power structures throughout the process. Minority groups that are represented in a situation can also become discouraged from sharing their unique perspective and this is a negative as these minority groups often have insights which are extremely important (Hart and Sharma, 2004; Nelson and Wright, 1995). Authors also argue that consultation fatigue or burnout can occur as stakeholders are constantly asked to participate in a setting in which they feel their opinions and involvement are not influential towards a final outcome (Burton, Goodlad, Croft, 2004; Duanne, 1999; Payne and Calton, 2002; Reed, 2008). The facilitators are also seen as potential abusers in terms of unrepresentative selection of stakeholder groups. A common perception is that stakeholder engagement is classed as a 'talking shop' that creates "ambiguities and delays decisive action" (Vedwan et al., 2008, as cited by, Reed, 2008, p 2420). This is further developed upon by Fischer and Young (2007) who identify the fact 
that some stakeholders do not have the expertise to engage in highly technical discussions. However the benefits far outweigh the negatives when it comes to engagement (Reed, 2008).

It has been argued that the benefits of involving multiple stakeholders in any decision means increased quality and durability of the solution is greater (Fischer, 2000). Although Reed (2008) questions the validity of this claim as it has not been tested, he does suggest that environmental managers have learnt valuable lessons and consequently develop more constructive post-participative approaches to ensure a durable solution occurs. Outcomes can fall into inertia if the goals are not clearly set out and followed in an inter-organisational agreement (Huxham and Vangen, 1996). That is why trust, commitment and co-operation are key drivers in any arrangement. While they are generally considered to be included in any forum regarding stakeholder engagement, they somehow seem to be excluded in many environmental engagements (Gao and Zhang, 2006). Trust is very important when parties include government entities who are collectively trying to develop policy. Improving stakeholder engagement means risks are reduced and opportunities are increased (Strand, 2006). Reed (2008) also notes that participation among stakeholders increases the uptake of interventions and technologies in a local social and environmental setting. This means that initiatives will be adopted by targeted groups if they are consulted at an early stage in the process (Reed, 2007). The process can change relationships as Reed (2008) argues through "establishing common ground and trust between participants and learning to appreciate the legitimacy of each other's' viewpoints, participatory processes have the capacity to transform adversarial relationships and find new ways for participants to work together" (Reed, 2008, p 2420). As different stakeholders often have conflicting interests it is important for open discussion to occur throughout the process and overcome the hurdles that they may face in a collaborative manner (Stringer, Prell, Reed, Hubacek, Fraser and Dougill, 2006).

The public and private relationship needs to embrace participatory decision making throughout the process for a successful initiative (Van Nijnatten, 1998). When relationships are formed between NGOs, corporations and other entities it can create new demands and new opportunities for all parties therefore averting the disastrous impacts on the environment prior to them actually occurring 
(Rondinelli and London, 2002). Some companies have adopted a tactic of sitting back to see the government's approach, relying on regulatory implementation of policies and procedures and not actively getting involved and engaging with stakeholders (Kolk and Pinkse, 2004). Historically the purpose of business was the maximisation of shareholder wealth and this primarily was the sole motivator. They did not engage with other entities unless they were the stock holder (Friedman, 1970). This is contrasted by other companies who are more proactive and enact initiatives "specifically for emission reduction to anticipate future policy, societal or competitive developments" with the stakeholders involved (Kolk, and Pinkse, 2007, p 370). There are a number of multinationals who are self-regulating and promoting themselves as showing a collective approach to economic, social and environmental issues through collaborative stakeholder

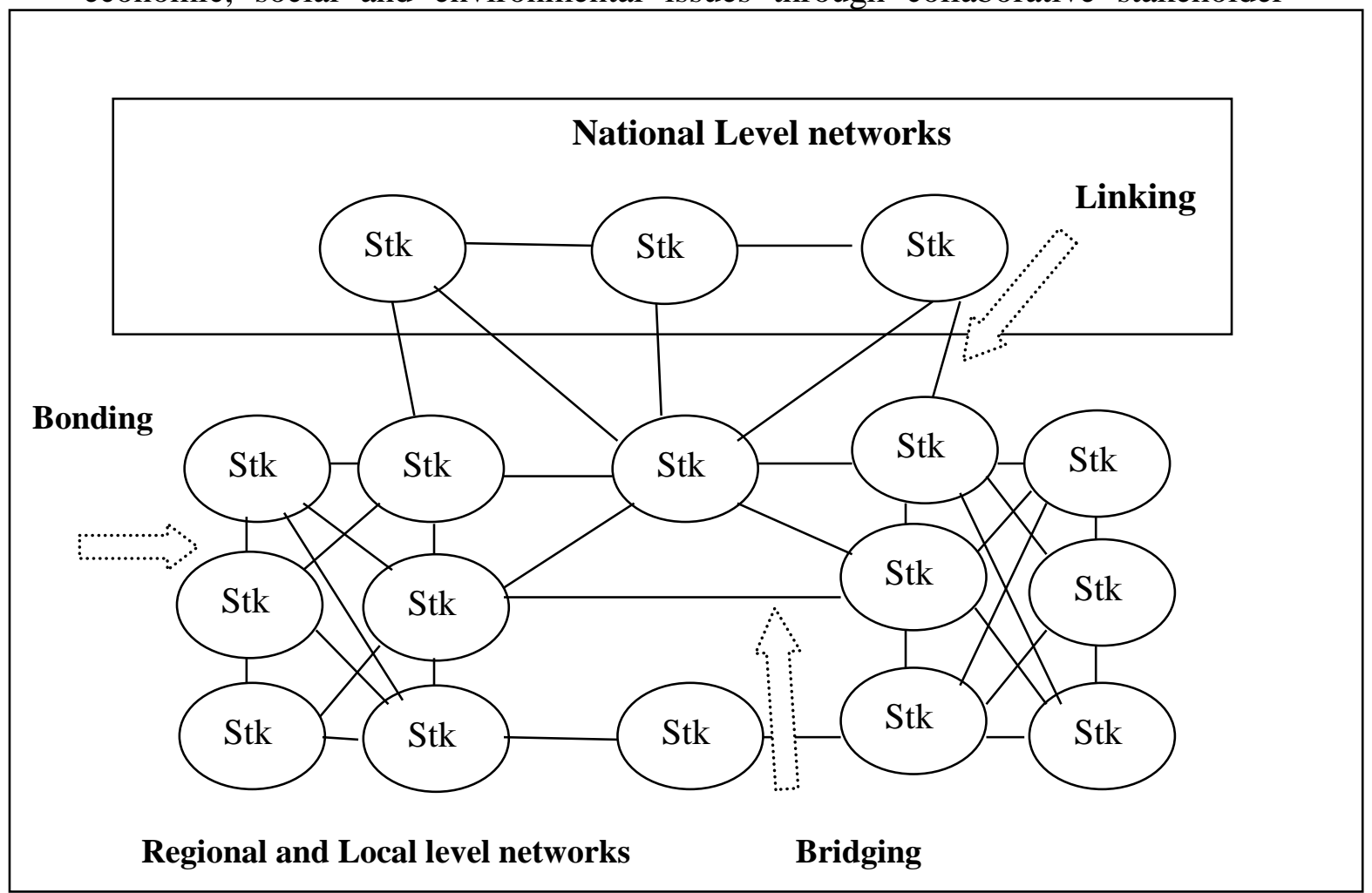

Figure 4: Networks and their ability to generate social capital Network depiction of social capital. Adapted from (Boutilier, 2009, p 60)

Social Capital is a concept that is core to multi-stakeholder collaboration. It is essentially a network approach to thinking, combining support, cooperation and collaboration. "Social capital is the goodwill available to individuals or groups. Its source lies in the structure and content of the actor's social relations. It's effects flow from the information, influence, and solidarity it makes available" (Boutilier, 2009, p 59). Netwroks and their ability to generate social capital, as seen in figure 
4, demonstrates the three forms of social capital that include bonding, bridging and linking. Bonding social capital is the link between two actors and is normally measured based on the level of communication that occurs. Bridging social capital is when a relationship is bridged, an actor that can bridge or a gap that is bridged. In essence it is when someone has their 'foot in both camps'. If there is a structural hole, such as a lack of communication between two sets of stakeholders, then bridging social capital is reinforcing communication between all actors. Linking social capital is a unique form of bridging as it sees hierarchical levels among stakeholder groups so linking is creating vertical bridges and is very important for sustainable development. Multi-sector stakeholders and their social cohesion is fundamental and illustrates how they interact within complex systems and form lasting relationships. A complex system as a concept is addressed next as an extension of multi-stakeholder collaboration.

\section{Complexity Theory:}

The world is uneven. We exist in an environment that continually presents us with change and variation in multiple manifestations: sunlight and shadow, day and night, hills and valley, town and country,

(Cumming, Barnes, and Southworth, 2008, p 15).

The theory of complex systems through such systematic unevenness is demonstrated in the above quote by Cumming, Barnes, and Southworth (2008). Our environment presents itself as a complex system that is constantly changing. Linear approaches to management of ecosystems, of business environments and of single stakeholders as isolated and independent are no longer sufficient (Norberg and Cumming, 2008). A new approach is emerging where "nonlinear interactions within coupled natural and socioeconomic systems are changing the nature of the game" (Norberg and Cumming, 2008, p X). Systems and the way that they nonlinearly interact is fundamentally shifting and changing the management of the Structure. Particularly in a network system where all the entities are interrelated, adaptive management seeks to change the original practices. This is due to increased knowledge on how the system as a whole interacts (Webb and Bodin, 2008). Increasingly stakeholders are becoming ever so important in complex systems. 
Much emphasis is put on stakeholders at different levels and their involvement in the management process. Knowledge and information from the natural systems responses to (current) management practices are critical assets that must be transferred through communication links on different levels to provide for evaluation and possible adjustments of practices in use, (Webb and Bodin, 2008, p 107).

This means that networks can provide unique and valuable channels in sustaining policy. This illustrates more of a bottom up approach and Webb and Bodin (2008) state that sound ecological and scientific knowledge and its distribution to all actors in a timely fashion is imperative for successful policy acceptance and implementation. Governance also plays an important part in managing the networks and the whole system as "governance addresses the broader social contexts of creating the conditions for social coordination that enable eco-systembased management" (Hahn, Schultz, Folke, and Olsson, 2008, p 119). In a complex environment where a range of entities exist, governance is a form of feedback and facilitates direction towards the vision of sustainability. A “convincing vision: as well as good social links and trust with fellow stakeholders may mobilize several interest groups at several organisational levels and start a self-organising process of learning and social capital generation of management of complex adaptive ecosystems" (Hahn, Schultz, Folke, and Olsson, 2008, p 119). With so much uncertainty in complex systems, management can work in collaboration with a wide net of stakeholders towards a common vision. A collaborative approach in terms of stakeholder engagement has illustrated that numerous networks can pool together to beneficially work towards a common solution and act as a whole system. But if the economics of the situation are not sustainable, then is the project viable? The business case for sustainability is a term that is increasingly being used by managers that will now be discussed. Businesses need to understand that economic, social and environmental integrity are important for sustainability and they can work simultaneously to enhance the bottom line. 


\section{Business Case for Sustainability}

Business as usual, government as usual, and perhaps protest as usual are not giving us the progress needed to achieve sustainable development. Let's see if we can't work together to find better paths forward,

(Hemmati, 2002, p 1).

Doing well by doing good is a mantra that society views as imperative (WBCSD, 2002), and many organisations see sustainability as a responsibility and opportunity (White, 2009), others see it as a moral, ethical, or even religious cause (WBCSD, 2002) However there are some see it as a hindrance to business as it increases costs (Preston and O'Bannon, 1997). There are a number of companies that still think addressing sustainability is not in their strategic interest and scrutinise the implications of sustainability with great scepticism (Berns, Townend, Khayat, Balagopal, Reeves, Hopkins, and Kruschwitz, 2009; Preston and O'Bannon, 1997). Steger (2004) states that companies will, "miss the boat if they do not immediately transform themselves to suit the 'new age'. But few if any companies are doing this" (p 67). The role that business plays in our society can be traced back to the 1960's as concerns were raised surrounding corporate responsibility. Individuals could see a correlation between corporate responsibility and employee recruitment, retention, improvements in profitability and the overall reputation of the business (Davis, 1960).

A sustainable business excels on the traditional scorecard of return on financial assets and shareholder and customer value creation. It also embraces community and stakeholder success. It holds its natural and cultural environments to be as precious as its technology portfolio and its employee's skills. (WBCSD, 2002, p 7).

In trying to integrate the term sustainability with the bottom line, many businesses, academic scholars and consultants have focussed on the 'business case' for sustainability. The World Business Council for Sustainable Development emphasises the fact that it is not only about financial returns but a rounded perspective. This angle specifically asks firms how they can drive their economic sustainability through their social and environmental performance (Dyllick and Hockerst, 2002) for value creation (WBCSD, 2002). It has been identified by 
Carroll and Buchholtz (2008) that companies should invest in corporate social responsibility initiatives "as part of their business strategy to become more competitive" ( $p$ 52). The Vice President at Dupont for health, safety, and the environment changed the terminology to sustainable growth due to the controversy it created.

Growth was very important. I tried sustainability and the business leaders saw it as status quo. I tried sustainable development and they viewed it as environmental sustainability. I tried sustainable business [but] growth is what organisations want- either you're growing or you're not and not growing is not a very good sit. (Holliday, Schmidheiny, and Watts, 2002, p 15).

The business case is broken down into three activities according to Csutora and Szerenyi (2008). Firstly, the business needs to realise they have to voluntarily incorporate societal and environmental solutions above and beyond regulation. The next activity "must create a positive business effect or effect on corporate success which can be measured or argued for in a convincing way" ( $p$ 7). Examples can be increases in profitability or cost savings due to sustainable initiatives. The business effect cannot be speculative, it therefore must be based on sound logic in a business argument. Third and finally, Csutora and Szerenyi (2008) state that a "clear and convincing argumentation must exist that a certain management activity has led or will lead to both the intended societal or environmental effect, and the economic or business effect" (p 7). Holliday, Schmidheiny and Watts (2002) identify the context as an interesting point to consider as "good sustainability practices are increasingly being associated with good management practices, the business case also varies by country and region" (p 28). Management needs information based on the business case and a sound understanding of the links in the relationship between economic success and social and environmental activities (Berns, et al, 2009; Csutora and Szerenyi, 2008; Epstein and Roy, 2003; Hopkins, 2009).

Eco-efficiency is a concept that business tends to associate with sustainability and it is defined as the "delivery of competitively priced goods and services that satisfy human needs and bring quality of life; reducing ecological impacts and 
resource intensity throughout the life cycle, to a level at least in line with the Earth's estimated carrying capacity" (WBCSD, 2002, p 5). This form of management strategy seeks to intertwine economic with environmental performance in a more efficient manner so resources are not wasted along the value chain (Dyllick and Hockerst, 2002; WBCSD, 2002). A leadership team who incorporates this mindset into their strategy learns to think ahead with social and environmental value while at the same time not compromising their concentration on financial and economic realities (WBCSD, 2002).

Yet in the end, sustainable development is not a fixed state of harmony, but rather a process of change in which the exploitation of resources, the direction of investments, the orientation of technological development, and institutional change are made consistent with future as well as present needs... Painful choices have to be made. Thus in the final analysis, sustainable development must rest on political will,

(WCED, 1997, Our Common Future).

Depending on the context, some businesses are incorporating sustainability because legislation is forcing them to adapt (Berns et al, 2009; Epstein and Roy, 2003). The successful organisations that are one step ahead and incorporating sustainability into their corporate agenda before legislation forces them to, are generally more successful with a first mover advantage (Berns, et al, 2009; Epstein and Roy, 2003; Hopkins, 2009), however many businesses do not have the adequate systems to measure and evaluate the impact that initiatives have on their overall financial performance and the trade-off that occurs (Epstein and Roy, 2003). The greatest benefits to all managers, as seen in figure 5, illustrates the factors addressed by top managers, in an American context, as the most important for a business case for sustainability. Among the factors top managers who had an expertise in sustainability emphasised the need for a broad range of initiatives that would create added value and leads to a business case for sustainability (Berns, et al, 2009). The biggest among all factors for the business case was the improved 
company image or brand that eventuated.

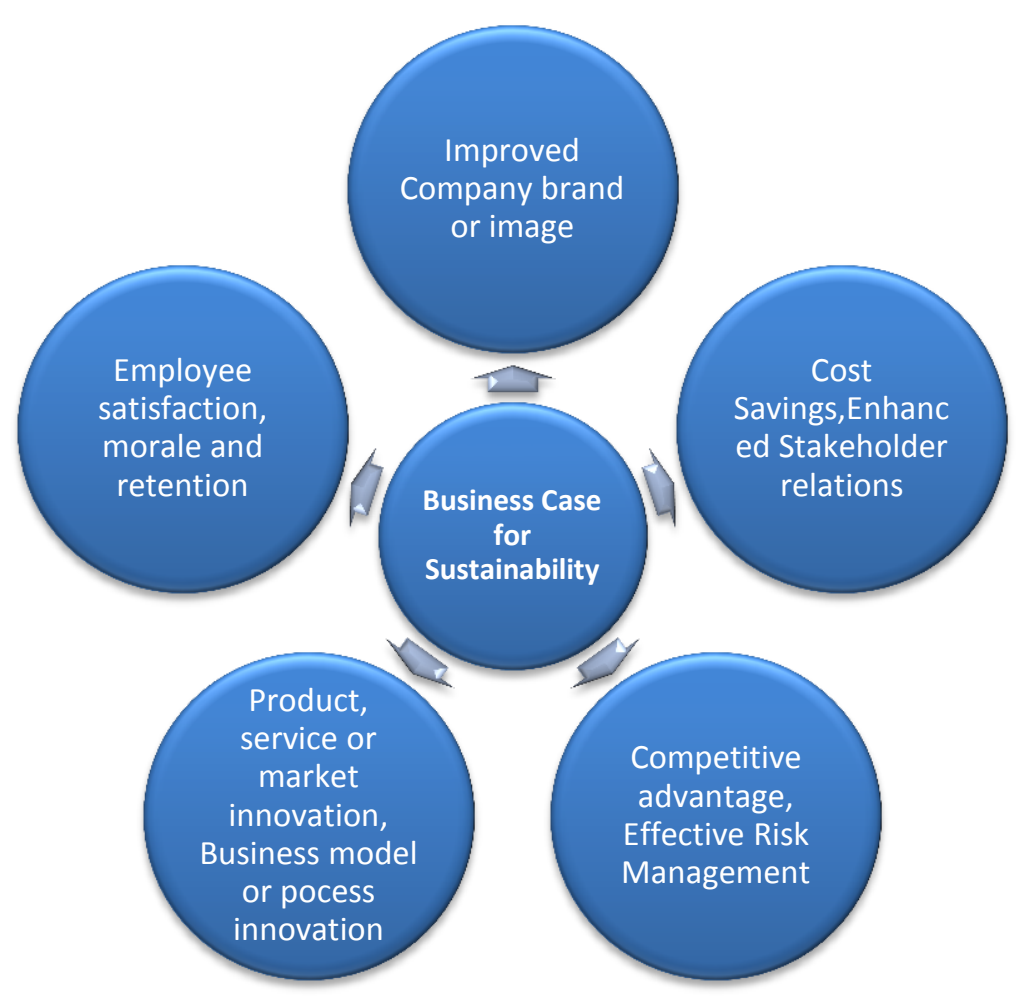

Figure 5: The greatest benefits to an organisation in regard to sustainability (Adapted from Bern, et al, 2009)

Business is often viewed as the problem in terms of social and environmental degradation, however they need to be viewed as the solution (Bansal and Roth, 2000). Businesses are viewed in this respect because they have a "primary focus on continued growth and financial viability" (Collins, Lawrence, Pavlovich, and Ryan, 2007, p 729).

A wrestling match occurs where,

the balance of power shifts one way or the other depending on the prevailing political winds: The need for regulation to protect the environment gets widespread but grudging acceptance: widespread because everyone wants a liveable planet, grudging because of the lingering belief that environmental regulation erodes competitiveness (Porter and van der Linde, 1995, p 120).

There are barriers to adopting sustainability and many businesses see the following as hurdles to the business case. Companies and their managers struggle to understand the numerous investments of sustainable initiatives to ultimately 
improve shareholder wealth and find it difficult to select the ones that will provide a benefit to the business and to society (Epstein and Roy, 2003; Hillman and Keim, 2001).

The biggest barrier though is change (Brereton, 2003) and this is evident from the mind-set of traditional profit maximisation. A business needs commitment and meticulous attention to detail when seizing opportunities (Hopkins, 2009). Managers need to constantly evaluate the initiatives and measure the performance so they have tangible evidence to show that it is benefiting the organisation. When production is increased and continuously pushed to increase profitability from the senior management team with no consideration for the social and environmental impacts, then it is not sustainable (Brereton, 2003). Another factor that needs consideration is cost (Hopkins, 2009), many organisation find it too expensive in terms of management time and financial investment (Collins, Lawrence, Pavlovich, and Ryan, 2007).

Knowledge base is another issue that seems to be a barrier as individuals and company mind-set are often entrenched and feel that they do not have the knowledge capital to be able to effectively manage sustainability initiatives (Berns, et al, 2009; Brereton, 2003). Trying to change that strict historical model to a new way of thinking is often very difficult (Hopkins, 2009), but communities can influence businesses in the way that they operate (Collins, Lawrence, Pavlovich, and Ryan, 2007).

Some businesses are seeing the positives in adopting social and environmental practices that increase the bottom line. Stakeholders who see this positive move give the business a licence to operate, however there needs to be a commitment to change from the organisation otherwise they will be perceived by their community as being deceitful. Presenting the business to the world is cause to be labelled dishonest and that is currently what New Zealand is facing. The world is slowly awakening to the insincere branding of a country that prides itself as clean and green. 


\section{0 per cent Hype}

We come more and more to see through the follies and vanities of the world and to appreciate the real values. We load ourselves up with so many false burdens, our complex civilization breeds in us so many false or artificial wants, that we become separated from the real sources of our strength and health as by a gulf.

Burroughs, J. (1912) Time and Change, Boston: Houghton Mifflin. (Fennell, 1999)

The phenomenon of tourism in New Zealand is not a recent occurrence; wondrous destinations such as the pink and white terraces have been attracting tourists to this country since the nineteenth century (Patterson, and McDonald, 2004). The Department of Tourism was setup in 1901 to cater for the growth of the industry which significantly started to accelerate in the 1970's as technology in the aviation industry led to low cost travel, and disposable incomes increased, making New Zealand an attractive destination (Statistics New Zealand, 2000). With rising numbers of tourists, it was obvious that they brought with them economic rewards for the country resulting in increases in gross domestic profit (GDP) (Patterson, and McDonald, 2004), employment, individual income generation (Lim, 1991), and it caused a strong multiplier effect in local communities (McDermott Fairgray Group, 2001).

Growth in this sector not only creates economic benefits but also environmental costs (Becken and Simmons, 2002), which the Government increasingly has to consider in its decision making process (Patterson, and McDonald, 2004). In 1997 the Parliamentary Commissioner for the Environment investigated the environmental impacts on the New Zealand Tourism sector with one primary recommendation. This sole recommendation was to "facilitate and resource the development of a strategy for sustainable tourism in New Zealand" (Williams, 1997, p17). The New Zealand Tourism sector directly and indirectly contributes 9 per cent of GDP which equates to NZ\$21 billion dollars per annum (Gibson, 2010), and it therefore is one of the country's biggest contributors to the economy (NZTGBC, 2010). 
Sustainable tourism represents "a set of principles, policy prescriptions, and management methods which chart a path for tourism development such that a destination area's environmental resource base (including natural, built, and cultural features) is protected for future development" (Lane, 1994, as cited by, Hunter, 1997, p 850). In New Zealand's case it is imperative to market a sustainable tourism industry and is evidenced in the New Zealand Yearbook 2000 with NZ described as having natural beauty and natural assets (Statistics New Zealand, 2000). In 1999 this environmental emphasis was grounded in a worldwide marketing campaign by Tourism New Zealand, branding the country as ' $100 \%$ Pure'. For New Zealand to be perceived as credible the brand needs substance to showcase to the world that as a country New Zealand is in fact doing everything in its power to be clean, green, and sustainable (Patterson, and McDonald, 2004). A study by the Ministry for the Environment in 2001 identified the 'clean and green' image that New Zealand portrays has significant export value, even though this image is being tarnished by environmental problems (Chang and Kristiansen, 2006).

This ' $100 \%$ Pure' campaign continues today, however cracks are starting to emerge with worldwide attention illustrating NZ is not living up to its reputation. Realistically, 100 per cent pure is not going to be completely truthful comparative to the rest of the world and New Zealand seems to be supporting actions that go against the underlying notion of clean and green and leaning more towards economic growth (Hackwell, 2009; Cumming, 2010). In November 2009, before the Copenhagen talks in Denmark, The Guardian published an article ruthlessly attacking New Zealand and their rising emissions, rate of car ownership and the intensive agricultural sector. It was documented in a survey that showed tourism would be reduced by 68 per cent if the clean and green image was to disappear and dairy exports could halve (Pearce, 2009).

This claim was enhanced further when the current National led Government of New Zealand recently announced that it was going to open conservation land from the conservation estate for mining (Gibson, 2010). The Institute director from Tourism Research emphasised his concern being "people who have an eagle eye on our global image ... are going to say 'isn't this another case of something going on that doesn't match up with the national marketing campaign" (Gibson, 2010, p 
1). And right he was with The Economist writing a backlash to New Zealand's vow of purity, criticising the country on its green image and questioning its ability to balance economic growth with environmental responsibility. The comparison was made to other rich countries that are in the same position as New Zealand who are struggling to balance the same two factors. The difference is New Zealand is an economy reliant on the export of commodities and landscape tourism who sells itself as '100\% Pure' (The Economist, 2010).

A report compiled by the Cawthorne Institute found that the Manawatu River was one of the dirtiest in the Western World due to nitrogen and phosphorus from farm runoff and sewerage contamination (Cumming, 2010).

The focus on our environmental performance coincides with a global shift towards green and ethical consumption, fuelled by concern about global warming. Consumers are rejecting everything from pesticides and GM foods to cage-farmed bacon and choosing eco-tourism when they travel (Cumming, 2010, p 1).

As New Zealand's agriculture sector is one of the biggest exporters and contributors to the economy it is important to maintain positive economic and environmental perceptions. However this is not the case environmentally, with many New Zealand farmers failing to clean up their act. The Clean Streams Accord for 2008 to 2009 shows non-compliance rose 15 per cent, which is up 3 per cent from the previous year. The Dairying and Clean Stream Accord agreement signed in 2003 between "the Ministry of Agriculture and Forestry, the Ministry for the Environment, Fonterra and Local Government New Zealand; shows that full compliance rates with effluent disposal requirements fell dropping from 64 per cent in 2007/08 to 60 per cent in 2008/09 season" (Daniels, 2010). Noncompliance means that rules or resource consents are breached resulting in an increased risk for environmental degradation. Fonterra has threatened to stop collecting milk from non-complying farmers but at the moment reporting is done individually and relies heavily on farmers to make additions to their practices on their own, this is not enough of an incentive (Daniels, 2010). Bennett (2010) finds that the previous government "took advantage of clean and green as tourism boomed, but put up no fight to protect our rivers and lakes while 
those waterways were being overwhelmed by dairy effluent" ( $p$ 1). There was no concern for the adverse effects of mismanagement that would eventuate. Tourism is one of the main contributors to GDP within the Lake Taupo Catchment. Therefore it was seen as an imperative to protect the lake (Environment Waikato, 2003, B). Yet agriculture is another strong industry within the catchment so a trade-off occurs. Water quality and water management are seen as going hand in hand. The next section will discuss river and lake management cases from an international context and illustrate how a range of stakeholders can effectively manage water as a natural resource.

\section{Lake Management- Cases from all over the World}

Earth is a water planet on which the quality of water defines the quality of life, Good water, good life. Poor water, poor life. No water, no life

-Sir Peter Blake

Only 2.5 per cent of the water on this planet is fresh water (United Nations, 2009). It is perceived as an inalienable right that is a necessity of life, however water resources are increasingly coming under pressure from anthropological factors (MFE, 2006) and effects from industrialisation and agriculture (Beacon, 2009). These resources are under a huge amount of stress (Nakayama, 1997) and billions need to rely on fresh water for ecological and societal activities (Gleick, 1997). The water needs of nature and humans seem to be viewed as competing with each other (Richter, Mathews, Harrison, and Wigington, 2003) when in fact this should not be the case.

Ecological sustainable water management is viewed as protecting,

the ecological integrity of affected ecosystems while meeting intergenerational human needs for water and sustaining the full array of other products and services provided by natural freshwater ecosystems. Ecological integrity is protected when the compositional and structural diversity and natural functioning of affected ecosystems is maintained (Richter, Mathews, Harrison, and Wigington, 2003, p 207).

Governance is essential in ensuring that water systems are adequately protected and monitored for future generations. Yet there does not seem to be any 
agreement on best practice regarding water management (Rieckermann, Daebel, Ronteltap, and Bernauer, 2006). The best approach to solving issues surrounding water management is a consensus based process, even though critics argue that partnerships take up a huge amount of time and effort (Leach, Pelkey, and Savatier, 2002). It has been identified that partnerships look at the more serious problems in a very attentive manner which is contrasted by the view that a consensus approach is unable to form a binding agreement between parties (Kenney, 2000). To gain a more insightful understanding into governance structures and the way stakeholders collaborate regarding water management, a range of cases will be illustrated which will allow reliable inferences to be made surrounding the success and failures of such initiatives. Letcher and Giupponi (2004) find that catchment management involves intricate interactions between social, economic and environmental sources. Therefore management need to take into account how impacts of their decisions will influence these systems.

Bernauer (2002) discusses a context that incorporates international river management. River management relies heavily on the community and other local stakeholder groups to advocate for protection, particularly for these groups to be proactive in gaining the attention of the national government, "river management problems are, in the absence of concerted political pressure by locals, often not at the top of national governments' political agendas" (Bernauer, 2002, p 13). There are some interesting observations that can be taken from this 'river management' context and used for the purpose of this study. River management issues can potentially be solved if all parties involved have common perceptions regarding the problem. It is viewed that if a solution is put forward where all parties can benefit and if national leadership is going to commit to solve the problem then the uptake of collaboration among stakeholders is higher.

Bernauer (2002) finds social concerns surrounding the catchment area need to be defined and included in the early planning stages along with the cost of consequences and any alternate strategies being detailed. This is so stakeholders are involved and their ideas are included whilst brainstorming alternative options from the start to create an inclusive culture. The author argues that cooperation is more successful if the process is open to flexibility and can adapt to the parties changing values. Bernauer (2002) does find that upstream and downstream 
problems are the most difficult to deal with in an engagement process. This is due to the wide variety of stakeholders who need to be engaged from such a vast area. Water management issues have been the source of many disputes on an international stage. One such example illustrated by Nakayama (1997) is the 'Indus Water Treaty' that was established in 1960 between the countries of India and Pakistan. This is an international based case that concentrates on water rights rather than ecological management with countries acting as the stakeholders. The process of how the parties eventually came to an agreement is interesting to observe and briefly described.

The World Bank facilitated the agreement as a mediator and a neutral party throughout the process and even invested capital and sourced capital from other countries. The parties involved took a path of problem solving and collectively working together to collaborate and solve the problem. High level representatives from both of the Governments involved brought in outside individuals to view the issue who saw it as a top priority for both of the countries to be involved. Through engagement with a third party, the countries were able to identify problems and felt more comfortable with the overall result due to constant communication (Nakayama, 1997).

Bernauer (2002) proposes a general water management structure, as seen in figure 6, which enables individuals to analyse the process in environmental management. This is used as a framework which describes three forms of variables during engagement. These variables are the structure of the problem, the tools that need to be employed and the institutional properties.

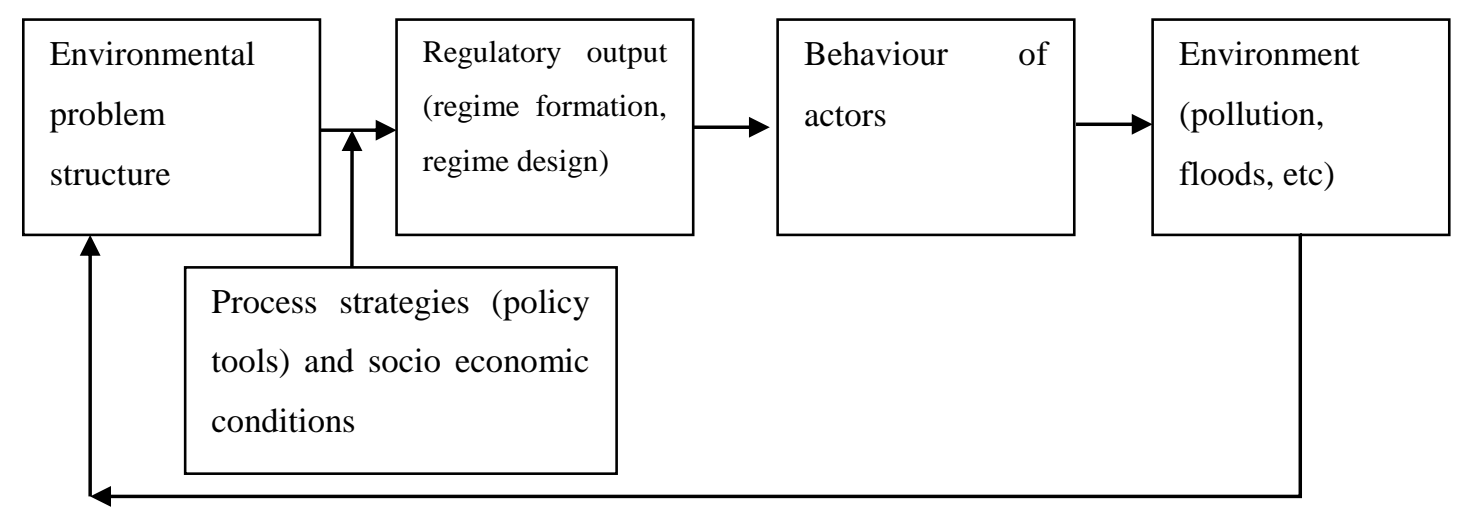

Figure 6: Water Management Structure (Adapted from Bernauer, 2002). 
This framework illustrates the successes and failures of river management, with some of these now being discussed. The success or failure of environmental policy can be measured using Pareto-efficiency (Valente, 2008) compliance and or problem solving (Bernauer, 2002; Sprinz and Helm, 2000). Pareto-efficiency is when all parties involved in a situation are not made worse off by other members' activities (Valente, 2008). In this context it is applied to policy and can be hard to measure, as determining Pareto-efficiency in economic terms through policy development would be comparing policies that were never created. "Paretoefficiency involves counter-factual elements; namely, showing whether or not other policies, which did not materialise, would have made one or more other players better off and no one worse off' (Bernauer, 2002, p 4). It is often easier to "instead focus on behaviour; that is the degree to which the existence and operation of an agreement has changed the behaviour of key players" (Bernauer, 2002, p 4). This is taking a look at policies once they have been implemented and initiated, concentrating on compliance. However compliance through regulatory means can be viewed as a "poor indicator for success" for a project (Mitchell, 1994, as cited by, Bernauer, 2002, p 5) as it does not determine how parties involved went about solving the problem. Problem solving is another measurement tool that can be used to determine success or failure of a project, however a vague tool compared to the other two devices (Young, 1999). Interesting though, this approach enables the researcher to understand the connections between entities involved, "more precisely they [the researcher] can ask how institutions that riparian countries create in order to solve a problem actually cause changes in behaviour that help to solve the problem at hand" (Bernauer, 2002, p 5). In the context of this study it would not be riparian countries but rather riparian entities or stakeholder and how they have influenced behaviour.

In a problem solving context the following steps have proven to produce relevant results that are significant and reliable in terms of measuring the success or failure regarding environmental management (Bernauer, 2002; Sprinz and Helm, 2000).

Clearly delineating the problem (e.g., pollution by specific substances, decline of biodiversity in specific forms) 
Choosing a starting point in time and establishing the state of affairs at that time. Measuring whether and to what extent the problem has increased or decreased over time, whether and how far the outcome (e.g., the level of pollution) has moved towards what experts would define as desirable, and what the outcomes would have looked like without policy intervention (Bernauer, 2002, p 5).

In a context surrounding environmental management this problem solving structure can work with the above framework to determine the problem and implement tools in a regulatory manner to change behaviour and solve the problem.

The following are a set of international lake cases that illustrate different approaches to managing the lake as a resource. The lakes range from Lake Titicaca in South America to Lake Ulubat located in Turkey. Each showcases a different perspective of how lakes are managed with a range of actors involved.

\section{Lake Titicaca basin}

In the South American Andes near the border of Peru and Bolivia lies Lake Titicaca. At an altitude of 3810 metres above sea level this lake is said to be the highest in the world while delivering freshwater to over 3 million people (Rieckermann, Daebel, Ronteltap, and Bernauer, 2006). However there are problems that arise such as unsustainable water use and local water pollution. A joint agreement between the two countries sought to effectively manage the lake, drafting specific initiatives in a collaborative approach. Accelerated eutrophication was mentioned as a future challenge but currently it does not significantly affect the lakes biodiversity (Borre et al, 2001, as cited by, Rieckermann, et al, 2006). Pollution mainly comes from untreated sewerage near populated areas. Developing more sewerage treatment plants with consistent monitoring and restricting the amount of water for irrigation were some of the management initiatives put forward to protect Lake Titicaca. From the master plan that was created 8 years prior to this article, only 4 out of 10 initiatives were considered successful. However the author does argue that the creation of such an agreement between two third world countries can be considered a success. With 
international exposure comes increased attention and a diverse range of international entities are interested in assisting the project to create environmental standards worldwide (Rieckermann, et al, 2006).

\section{Lake Chapala}

The third largest lake in Latin America, Lake Chapala is 80 kilometres long and covers an area of 1120 square kilometres. The region relies on tourism and fishing for economic stability (von Bertrab, 2003). Over a short space of time, irreversible actions have occurred that has been detrimental to the lake and its health. Pollution from industrial activity, agricultural waste and municipal activities along one of the lakes river inlets has seriously impacted the biodiversity. Erosion through deforestation has led to increased sediments flowing into the lake, increasing turbulence which limits the ecological production of the lake and has decreased the depth resulting in increased temperatures and more evaporation (von Bertrab, 2003). With a range of multiple factors impacting on the lake, a species of plant that feeds on nutrients that flow into the waterways, the "lirio Acuático exacerbates the loss of water through evaporation, limits light penetration into the water and constrains the free movement of boats, thus having an impact on fishing and recreational activities" (von Bertrab, 2003, p 132). This has culminated in an endemic species nearly becoming extinct and as this fish population is slowly contaminated and consumed, it poses a health threat to the two thousand local residents who rely on fishing for income.

Public awareness surrounding the lake and its management has led to environmental groups, non-governmental organisations, chamber of commerce and civil society working together to form proposals to recover the lakes health. However problems surrounding who makes the final decisions and the differing levels of authority within the group means the project is highly politicized (von Bertrab, 2003). Processes to decentralise decision making and increase the social inclusion of groups to create "innovative cooperative mechanisms" (von Bertrab, 2003, p 135) have been occurring for many years. The National Water Commission set up 26 water councils all over Mexico which decentralised decision making and created unprecedented participative engagement, an illustrative example of the breakdown of the River Basin Council is seen in figure 7. The law behind these local water councils is stated by von Bertrab (2003) as 
instances of coordination and orchestration between the three levels of government (federal, state and municipal) and the representatives of water users, with the objective of formulating and executing programmes and actions for a better management of water bodies, the development of the hydraulic infrastructure and of the respective services, and the preservation of the basin's resources (p 135).

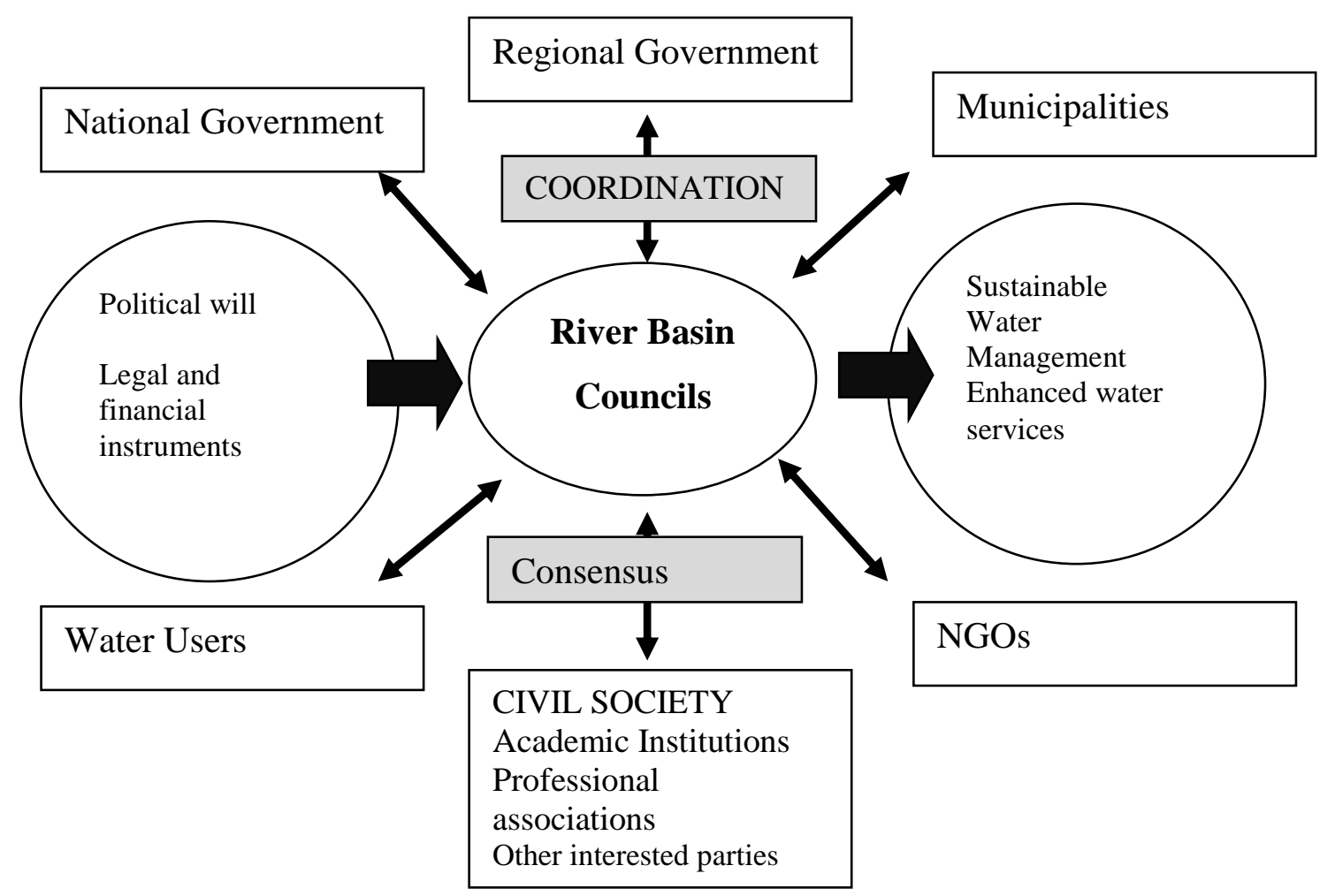

Figure 7: River Basin Councils in Mexico (Adapted from von Bertrab, 2003, p 136)

One of the main challenges that von Bertrab (2003) discusses is the complicated transition of changing the mind-set from centralisation to decentralisation. Interestingly, even though decision making is easier due to the increased power that these councils have, a negative has eventuated where the water councils are not meeting the needs of the poor. "The council needs to seriously start considering how to safeguard and improve the access of the poor to water, and how to combat the current de facto concentration of water rights in the hands of a few" (von Bertrab, 2003, p 138).

This case illustrates institutional mechanisms through a partnership with a range of actors to integrate sustainable development in the form of water management practices. What the Lake Chapala case shows, is that the rate of solving such 
ecological problems lags far behind environmental degradation if they are not identified early on (von Bertrab, 2003).

\section{Lake Uluabat}

Located south of Marmara Sea in north western Turkey, Lake Uluabat is a fresh water lake that is deemed one of the most important in terms of wetlands and plant diversity covering 135 to 155 square kilometres. An array of plant life attracts migratory birds and other forms of wildlife but eutrophication from domestic and industrial waste is affecting the water quality of the lake (Salihoglu and Karaer, 2004). The main forms of pollution are from sewerage water, agricultural fertilizers, animal waste and other forms of industrial waste from local businesses in the catchment area. This resulted in the development of a plan to address the environmental issues with Turkeys Ministry of Environment, NGO's and other societal groups jointly working together. Relationship building at the start of the process was identified as a crucial step in: reducing conflicts in authority; effectively managing responsibilities; and reducing insufficient coordination and cooperation problems. A wide range of environmental management processes were examined in the Uluabat case (Sewell, 1975; Barrington, 2001; and Bernauer, 2002).

The problem formulation structure, in Figure 8, illustrates the integrative approach that should be upheld in lake management cases. Salihoglu and Karaer (2004) have adapted a range of problem formulation tools but found this integrative model reflected the Uluabat process. It shows that a lot of research was undertaken in the problem formulation phase which involved a wide range of stakeholders and took into account all stakeholder interests when formulating objectives. However there were instances when some stakeholders were offended when they were not considered or represented within workshops or at meetings. An example of this is when academics who were involved in undertaking research on the lake were not invited to planning meetings, or a former mayor who had worked hard to protect that lake had not been invited but the new mayor had. This illustrated the fact that the 'partnership building' process is crucial at an early stage. 


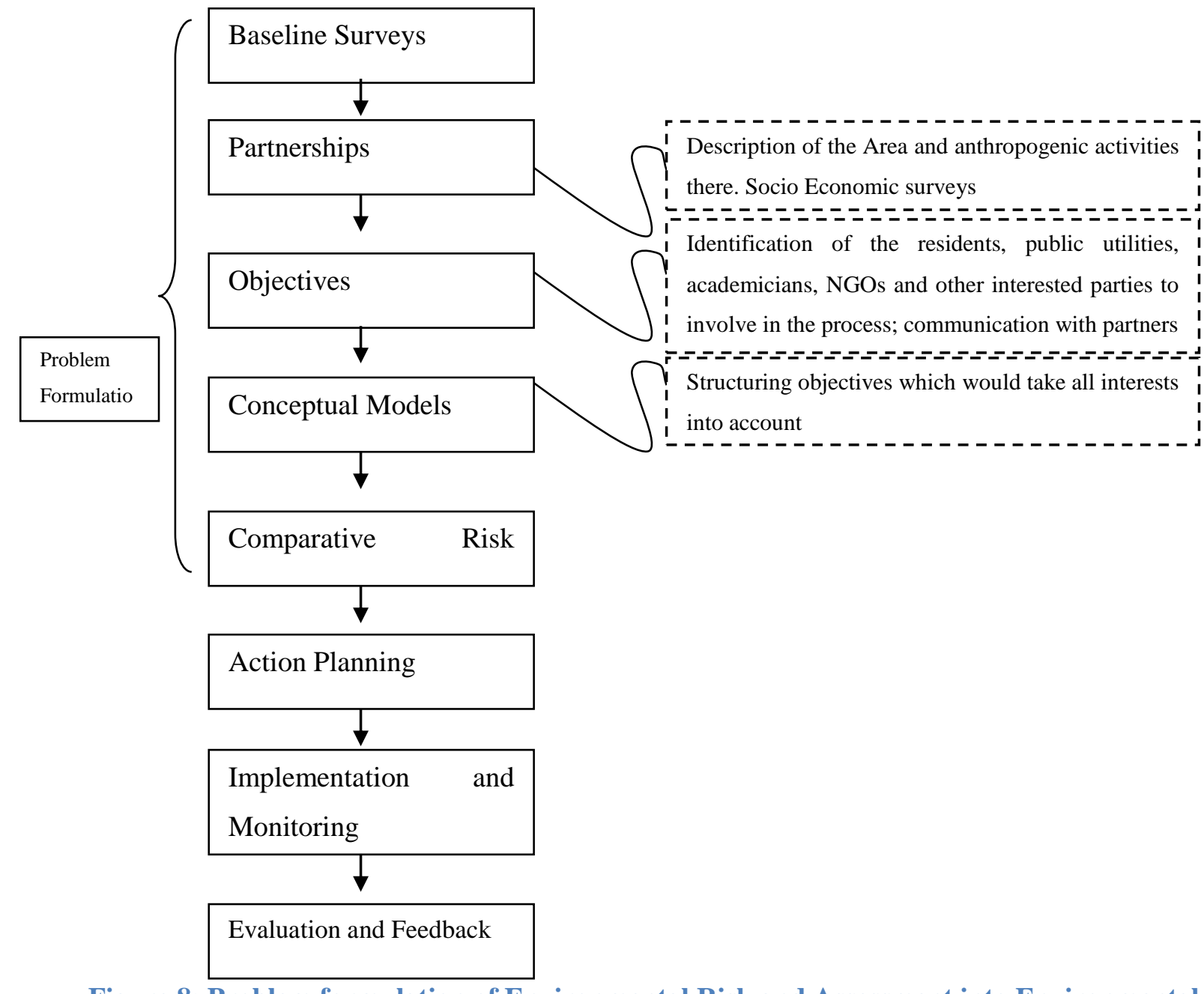

Figure 8: Problem formulation of Environmental Risk and Assessment into Environmental Management Plans Towards Protection of Ecological Resources.

(Adapted from Salihoglu and Karaer, 2004, p 907).

Communicating and creating objectives were strong foundations throughout the process, as the achievement of these objectives acted as important motivators for the actors involved. The Uluabat case demonstrates that even when there is no dominating regulatory input into the process, informality in terms of coordination between actors exists, which seems to only strengthen the overall process. The Uluabat approach shows that designing an environmental management system with public and private actors can work for the betterment of ecological resources. 


\section{Summary:}

This research seeks to understand stakeholder collaboration at multiple levels with a wide range of groups aiming to protect Lake Taupo and the health of the region. Sustainability is an important aspect to the project and in essence, the conservation of Lake Taupo is about "meeting the needs of the present without compromising the ability of future generations to meet their own needs (WCED, 1987, $\mathrm{p}$ 43). There is a need for intricate relationships when it comes to collaborative public and private stakeholder management (Van Nijnatten, 1998) as trust (Gao and Zhang, 2006), setting objectives, ensuring continued commitment (Stringer, Prell, Reed, Hubacek, Fraser and Dougill, 2006) and communication (Reed, 2008) are crucial components.

Protection of the lake as a resource for current and future needs is important as business, government and society can greatly improve environmental solutions to sustain future growth through a participatory process (Roome and Wijen, 2005). Governments, it seems, need to assimilate and integrate environmental policy that prevents from an early onset (Bührs and Bartlett, 1997; Hajer, 1997). Business can then act as engines of change in business government relationships with the perspective of a business case for sustainability (Csutora and Szerenyi, 2008; Levy and Newell, 2005). Even though business has often been seen as the problem when it comes to environmental and social degradation, it needs to be seen as part of the solution through a collaborative approach (Bansal and Roth, 2000) and this study aims to determine how the business case is affected with so many stakeholders working towards a common purpose.

The lake management cases illustrate a range of contexts all over the world and how a variety of stakeholders collaborated to try and determine solutions to environmental problems. Some of the initiatives in these international cases illustrated success in how a range of stakeholders can protect a resource. Some showcased the disappointment that stakeholders felt when successful outcomes were not apparent. These cases enable a comparison to be made with the Lake Taupo context as the business case will be able to be referenced for future environmental engagement projects. In saying this, the Lake Taupo Protection Project presents itself as a unique study that is innovative in its carbon and nitrogen reduction strategies. This innovation conducted by a myriad of entities 
consequently changes the collaborative process among stakeholders and therefore current literature does not sufficiently build on multi-stakeholder collaboration with so many stakeholders engaging from multiple levels of government, society and business.

The set of questions developed in the next chapter flow from the reviewed literature and aid in gaining an understanding of the networks and collaborations that are occurring in the Catchment area. It is hoped that observing the multitude of actors working with one another, this thesis will add to existing knowledge within the field of sustainability and stakeholder collaboration. The next chapter will discuss the qualitative approach undertaken to explore these questions to formulate a case study. 


\section{Chapter III: Method}

A qualitative research approach has been employed to answer the following research question: How does a multiple stakeholder perspective affect the business case for sustainable development? Qualitative research observes the context as interconnected and complex, giving rich understandings (Cavana, Delahayne, and Sekaran, 2001). The focus is on a case study to build theory and essentially capture the lake Taupo context (Maykut \& Morehouse, 1994). The reason why a qualitative approach has been employed is the fact that it allows the researcher to answer questions surrounding the "why" and "how" of the context (Yin, 1994) and understand the business processes involved (Maxwell, 2005). The view that is taken is a perspectival approach and consequently this cannot be further probed through a survey (Cavana, et al., 2001). Causation relies heavily on "the description of a visualizable sequence of events, each event flowing into the next" (Maxwell, 2005, p 23). To observe these events the researcher looks to the "human-as-an-instrument; as only a human can be responsive, adaptable, and holistic" (Cavana, et al., 2001, p 135) when observing the responses that eventuate through communication with the interview participant. In using a qualitative approach the research is theoretically generalizable as the processes developed can be replicated and will be relevant (Green, 1999) beyond the lake Taupo context.

This chapter will firstly outline the reasoning behind the case study approach. It will then discuss best practice of case study research and outline ethical considerations before finally concluding with a section on the analysis of the data and limitations of the research.

\section{Case Study:}

Cases are individual experiments that can stand on their own as distinct "analytic units" (Eisenhardt and Graebner, 2007, p 25). The word case or 'casus' is Latin and translates to "occurrence" (Easton, 1992). A case "captures an entity, whether it is an individual or an organisation, as they experience their natural, everyday circumstances" (Feagin, Orum, and Sjoberg, 1991, p 1) and can be compared to other case study's (Yin, 1994) that have been illustrated in the literature to serve as "replications, contrasts, and extensions to emerging theory" (Eisenhardt and Graebner, 2007, p 25). A single case study has been chosen rather than using a 
range of cases as "a single case represents a single set of empirical circumstances, as does a single experiment, and the findings of a single case are generalizable to other empirical settings when additional cases test and confirm those findings in other settings" (Darke, Shanks, and Broadbent, 1998, p 278). The reasoning behind choosing one case as Benbasat, Goldstein, and Mead (1987) state is the fact that it is; "a revelatory case; and it is a unique or extreme case" (p 373). As such, theory can then be divulged from the Lake Taupo case as comparisons and contrasts can allow the question of 'why' and 'how' to be addressed (Yin, 1994). Searching for the 'why' behind relationships through a case study method, will build on the internal validity of the research (Eisenhardt, 1989). Benbasat, Goldstein, and Walton (1992) finds case studies are one of the best producers of theory.

Mead (1987) discusses a range of key characteristics that need to be considered when utilising a case study approach. The main points that should be noted include the collection of data from multiple means, no manipulation or coercion occurs, and that results are dependent on the integrative manner of the researcher. A case study approach also provides a platform to recognize interrelating causal factors (March, 1979), when identifying what the factors are for a multistakeholder impact on the business case for sustainability (Roome and Wijen, 2005).

Utilizing a case study process enables the researcher to view the processes "indepth using a variety of data gathering methods" (Cavana, Delahayne, and Sekaran, 2001, p 112) and observe how they have occurred and the dynamics that are at play between the range of stakeholders. It is crucial to ensure that the case study is "understanding and correctly translating the dynamics" as this is "critical for successful problem solving" (Sekaran, 2003, p 36). The strengths from a case study approach allow "novelty, testability, and empirical validity, which arise from the intimate linkages" (Eisenhardt, 1989, p 548). As a phenomenon is being researched it is important to observe the occurrence in its natural context and illustrate the various conditions and factors that are currently or have previously influenced the phenomena (Cavana, Delahayne, and Sekaran, 2001; Yin, 1994). It is even more important that there is no explicit control or manipulation over 
variables and to ensure that the researcher is un-bias throughout the process (Darke, Shanks, and Broadbent, 1998).

Data for the case study has come from a range of sources including minutes from meetings, newspaper articles, annual reports, attendance at a range of stakeholder meetings, policy documents, with interviews being the primary data collection method which will mean "the resultant interpretations can be compared" across all mediums which are discussed further below (Cavana, et al, 2001, p 136).

\section{Best practice of case study research}

It is important to ensure that all information collected throughout this study is valid, relevant and accurate. To aid in verification of this, a range of mediums have been used in accordance with the technique of triangulation which "entails using more than one method or source of data in the study of social phenomena and comes from navigation and military strategy, it refers to the process whereby multiple reference points are used to locate an objects exact position" (Bryman and Bell, 2003, p 291). This aids in accuracy and completeness of the overall findings (Jones, and Bugge, 2006). The variability of results using a single method of research is lessened through the use of complementary methods (Jones, and Bugge, 2006) to pick up on when and why differences occur (Mathison, 1988).

In this thesis, the methods utilised for the case study include interviews with a range of participants, and analysis of newspaper articles and other related policy documents, and attendance at stakeholder meetings. Interviewing participants from a variety of organisations who are involved in the protection of Lake Taupo has been the primary data source as these interviews have aided in gaining diverse perspectives. Follow-up interviews have been used if required to further clarify points or to probe insights in gaining further understanding to formulate an overall picture for the case study. Interview transcripts that were utilised in the study were sent out to those who have requested, after their interview, to verify that they are in agreement with what was recorded. Respondent validation ensures that the information collected is valid and consistent with what the participant said (Cavana, et al, 2001, p 136). 
Another practical approach towards validation of the research is the utilisation of archival analysis. Hill (1993) defines archival analysis as "observing trends by looking through material such as letters, memos, annual reports, minutes from meetings, lecture notes, transcripts, and other organisational files" (p3). Archival analysis for the purposes of this study will involve two separate forms of medium. Newspaper articles will be a valid source to compare participant's thoughts and views. Newspapers are a publicly available source so they can aid in validation by comparing and contrasting the perceptions of the documents that are circulating in the media with the discussions from interviews. Policy papers and analysing various reports from organisations such as Taupo Lake Care, Lakes and Waterways Action Group (LWAG), EW, the Yurex (2010) and Arunachalam (2010) case studies, and meeting minutes will be the final area that will add to triangulation of the overall data. Collecting an assortment of documents has helped in comparing and contrasting perspectives that emerge in these documents with the perspectives that were apparent in the interviews (Mathison, 1988). This has assisted in transparency and accuracy of the overall research through the use of a range of mediums (Jick, 1979, p 602). Utilizing multiple forms of research helps to increase the construct validity of the research (Yin, 1994) and grounds the theory through evidence (Eisenhardt, 1989).

All data has been collected and stored in a case study database holding transcripts, interviews in mp3 format and other documents as a formal presentable database during the collection phase. The creation of such a database is not only for security reasons, it is valuable for future researchers to independently analyse the data in terms of secondary or further analysis if the need arises (Darke, Shanks, and Broadbent, 1998; Yin, 1994).

Interviews can give rich qualitative insights to form a case study and it is important to discuss the strategies utilised to gather relevant information during the interview process.

\section{Interviews:}

Qualitative interviews have operated for us like night vision goggles, permitting us to see that which is not ordinarily on view and examine that which is often looked at but seldom seen (Rubin and Rubin, 2006, P vii). 
Interviewing was one of the main research methods to gather information from participants in this thesis. Rubin and Rubin (2006) state interviewing gives the ability to see what is not ordinarily on view. It is a conversational approach between two parties where an effective interview utilises an organic style with the interviewer having an adaptive approach (Dean, 2007). Webb (1995) defines an in-depth interview as "an unstructured personal interview which uses extensive probing to get a single respondent to talk freely and to express detailed beliefs and feelings on a topic" (p 121). Weinreb (2006) identifies through numerous cultural studies the fact that if the interviewer is not known by the participant, this can then have an impact on the results of the study. It is interesting to note that participants are more likely to "discuss deep issues with strangers" ( $p$ 1017). In this case the interviewer used an unstructured interview approach using an interview checklist, as seen in appendix 4, to stimulate discussion with open ended questions in order to probe with further questions if needed. These questions relate to the literature that was identified in the previous chapter and subsequently arranged into broad themes.

The ability for the interviewer to relax the participant at the start, lowering the defence barriers, is imperative to develop trust (Goulding, 2002) and intimacy, to be able to gain reliable and rich information throughout the rest of the process (Cavana, Delahayne, \& Sekaran, 2001). Stokes and Bergin (2006) elaborate on a range of the advantages when conducting in-depth interviews. The actual choice of the sample is more accurate and the careful selection of the individuals interviewed will give rich answers due to the ability of the interviewer to follow up on questions. Interviewing is also beneficial for the case study because the face to face component of the physical interview allows greater flexibility when inquiring about specific content and the researcher can read the body language of the participant (Stokes and Bergin, 2006). However there were instances when interviews were conducted over the phone due to clashes with interviewees schedules.

Listening to a participant answers allowed the individual to feel a sense of empowerment and establish rapport which led to the participant espousing a higher degree of trust (Berent, 1966). Interviews were generally held at the place 
of work as the work environment is said to be the best place to uncover information regarding a particular phenomenon (Maykut and Morehouse, 1994). All interviews were recorded with permission from the participants for transcription and analysis subsequently undertaken at a later stage.

With a wide range of stakeholders collaborating in the Lake Taupo Catchment area it was important to include individuals from as many of the acting organisations as possible to build a sound case study. Eisenhardt and Graebner (2007) state that the research needs to demonstrate "very clear pattern recognition of the central constructs, relationships, and logic of the focal phenomenon" ( $p$ 27). Participating organisations were selected based on their involvement even if they were from differing industries or areas outside of the catchment area. There was one criterion that needed to be fulfilled to participate, that being actors must be involved in the protection of Lake Taupo in some way, shape or form. Case study actors were selected based on the assumption that they would be able to explain and expand on the relationships that exist in that Lake Taupo Catchment area and how they evolved over time. A list of the individuals and their organisations that were able to participate and were involved in this thesis can be seen in appendix 5 . Interviewing a range of external entities means that ethical issues need to be considered and these issues are addressed in the next section.

\section{Ethical considerations}

It can be said that "ethical dilemmas and concerns are part of the everyday practice of doing research - all kinds of research" (Guillemin and Gillam, 2004, p 262). Due to the fact that this study involves human participants, all of the information that was collected from interviewees was done so with the approval of the Waikato Management School Ethics Committee, see Appendix 6. Participants were invited to be involved in the research, see Appendix 7- Letter of invitation, and given documentation of what was involved in the research, see Appendix 8- Participant information sheet. Interviewees were also informed of the expected commitment, outcomes that would subsequently eventuate and the ability to ask questions or opt out of the research at any time and asked to sign a consent form, see appendix 9. Once all data has been collected the process of analysis can begin which is discussed below. 


\section{Analysis of the Data}

Qualitative research is fundamentally interpretive. This means that the researcher makes an interpretation of the data. This includes developing a description of an individual or setting, analyzing data for themes or categories, and finally making an interpretation or drawing conclusions about its meaning personally and theoretically, stating the lessons learned, and offering further questions to be asked

(Creswell, 2003, p 182).

Transcription of the oral data is important to transform the information into a manner in which it can be analysed (Kvale, 2007). This then allows the information to be displayed in a way that enables the researcher to observe themes through interpretive data analysis (Clandinin \& Connelly, 2000). Qualitative methods are diverse and complex and thematic analysis is seen to be a foundational approach in qualitative research (Braun \& Clarke, 2006). Content analysis is "a narrative approach for understanding the meaning of an individual's stories (Ollerenshaw, and Creswell, 2002, p 330). As part of this content analysis technique, a more focused approach is thematic analysis which "is a method for identifying, analysing and reporting patterns (themes) within data. It minimally organizes and describes your data set in (rich) detail” (Braun \& Clarke, 2006, p 79). However, thematic analysis can be extended to delve further into an interpretation of a range of aspects surrounding the topic that is being researched (Boyatzis, 1998). Themes can eventuate from a range of areas within the data set such as "conversation topics, vocabulary, recurring activities, meanings, feelings, or folk sayings and proverbs" (Taylor and Bogdan, 1989, p 131). Some authors argue the broad nature of thematic analysis as a constraint as it is vague in nature (Antaki, Billig, Edwards, and Potter, 2002; Boyatzis, 1998). However a theme is described as "something important about the data in relation to the research question" (Braun \& Clarke, 2006, p 82). That said, a theme is not given prominence when analysing the research just because it appears in many instances throughout the data set, it comes down to researcher judgement to determine what a theme is and how important it is (Braun \& Clarke, 2006).

From the transcribed interviews, themes of common patterns or ideas can be listed. The coding process "involves recognizing (seeing) an important moment 
and encoding it (seeing it as something) prior to a process of interpretation" with a "good code as being one that captures the qualitative richness of the phenomenon" (Fereday and Muir-Cochrane, 2006, p 83). The researcher then compares all data that relates to the pattern to combine and catalogue similar patterns into sub themes (Aronson, 1994). It is bringing together ideas or patterns that would be insufficient or meaningless on their own but form a theme when pieced together (Leininger, 1985). When patterns are forming, feedback can be gained from the participants which can then be incorporated into the theme analysis (Aronson, 1994). A legitimate argument for choosing themes can be presented by incorporating relevant literature that has been identified earlier in the literature section.

When literature is interwoven with the findings, the story that the interviewer constructs is one that stands with merit. A developed story line helps the reader to comprehend the process, understanding, and motivation of the interviewer

(Arson, 1994, p 3).

A sample of interview transcripts illustrates themes that have emerged and coded can be seen in appendix 10. This will then allow the story of the Lake Taupo Catchment area to be told through a case study approach. Limitations of this study are examined in the following section.

\section{Limitations}

Cavana, Delahaye and Sekaran (2001) state that 100 per cent accuracy is not always possible as there will always be limitations that are apparent in any form of research. Trade-offs are expected in research design and there is no perfect research process (Patton, 2002). Participant and researcher biases, the size of interview transcripts and the number and selection of interviews undertaken generates drawbacks in this thesis.

The fact that there is only one researcher analysing the results means there is the potential for researcher bias. As an individual I am a strong supporter of sustainable development and I do not want this to impact on my resultant interpretations of the research, particularly if a participant does not share my 
thoughts. Throughout the research process, and to avoid the bias towards verification, if an observation or particular thought that is contrasting to my own opinion occurs during the collection phase I will document it and attempt to discuss it in the results. Flyvbjerg (2006) states that this is the process Charles Darwin undertook in his studies to avoid researcher bias, "owing to this habit, very few objections were raised against my views, which I had not at least noticed and attempted to answer" (p 234).

Having human participants involved in this study means subjectivity in the areas of feelings, and perceptions are to be expected and this can cause irregularities in data collection and analysis. Having 68,000 words of interview transcripts to analyse suggests that there is the potential for one researcher to misinterpret forms of information through the analysis process. The use of triangulation as a technique has been utilised to try and limit such influences, discrepancies and participant ideologies.

To mitigate against the issue of only having one researcher analyse the data, a research database has been created to store all transcripts and documents that will be utilised from the case study for future research analysis once this thesis is completed. A secondary researcher can bring a different perspective in terms of interpretations (Cavana, et al., 2001), however Flyvbjerg (2006) does find that due to the researcher being immersed in the context of the study, they are more likely to pick up on themes and divulge them in the findings compared to an external researcher scouring the hard data for themes.

The case study contains no greater bias toward verification of the researcher's preconceived notions than other methods of inquiry. On the contrary, experience indicates that the case study contains a greater bias toward falsification of preconceived notions than toward verification (Flyvbjerg, 2006, p 237).

Communication with supervisors and their ability to observe progress through regular meetings enabled ongoing reviews, ensuring the research was on task with appropriate interpretation. 
Another limitation is the sample of organisations and individuals within this thesis. Approaching organisations that have been involved in the protection process or collaborated over the past 10 years has led to recommendations of other individuals to interview. The protection of Lake Taupo is an evolving process and this seemed to reflect in the people who were interviewed. As interviewing proceeded a range of individuals were recommended but, due to time constraints, this was concluded to enable analysis of the transcripts.

Another factor that is a limitation is the Taupo protection process has been occurring for the last ten years. As a researcher I am trying to understand the process over that time period so there will be a certain degree of comprehension through documents and case studies illustrating the process from the year 2000 2010. Understanding these limitations and how they will impact on this study was beneficial for the researcher.

The methods chapter has documented the case study approach and discussed how interviewing was the predominant source of data collection. The subsequent chapter will overview the themes that have developed through analysis in a case study format. 


\section{Chapter IV: Findings}

\section{Taupo-nui-a-Tia-}

\section{Multi-Sector Collaboration for Sustainable Development.}

Taupo is so big and so deep that it was probably seen as being bullet-proof (John Kneebone, Chairman of the LTPT).

The task at hand was an enormous challenge. As outlined in the introduction, the environmental Protection Project that occurred from 2000 to 2010 has been the biggest within New Zealand and the lake is definitely not bullet proof. Taupo is the largest lake in Australasia, and there was a perception that due to its size, nothing could upset the complex system. This could not be further from the truth and the community understood that water quality was central to the sustainable development of the region. Visibility of the problem (or the lack of) was an inhibiting factor as many stakeholders said the science stated nitrogen could take 30-80 years to flow into the lake and will continue to degrade before it gets better. So the visuals of a clear lake and the possibility of it getting worse were not consistent with the urgent need for action.

Justine Young the Senior Policy Advisor at EW said "the issue in Taupo is nitrogen and you can't see it." This was reiterated by Graeme Fleming, CEO of the LTPT who found the sheep and beef farmers who were in the catchment but were " $4-5$ kilometres from the lake couldn't even see the lake and thought how is it our problem?" The lack of visuals negatively impacts the lake and influenced how stakeholders felt about the problem- was there even a problem?

\section{Perceptions of Sustainability}

Stakeholders knew that the protection of the lake was imperative and the science could demonstrate that water clarity was decreasing and nitrogen leaching was increasing. The sustainability of the lake was crucial to all stakeholders in the 
region and this consequently led to EW creating a policy called RPV5. The innovative policy was created to protect the lake for future generations whilst enabling all industries to continue within the catchment. Justine Young from EW recognised the importance of the lake for policy development.

The lake is an amazing icon that draws people's attention, so from a policy point of view that was incredibly helpful. A bucket of blue lovely water with land around is a focus of attention. When you look across to the lake, across to the mountains, it's such an iconic view, then that's something that is very visible.

For the CEO of the LTPT, Graeme Fleming, sustainability was fundamentally about people, "our motto is te wai te iwi, [the water the people] essentially it's about the waterways, but it's about dealing with people in a fair way."

The definition of sustainability fits uniquely with each individual and even though sustainability was the ultimate goal for the lake, it was interpreted differently by many stakeholders. The multi-sector perspectives gave interesting insights when it came to stakeholders engaging around water management.

The following section will explore how stakeholders, mainly the forestry and farming sectors, perceive sustainability. The definitions from these two industries are interesting because they are the main landowners affected by policy. The interactions of multiple stakeholders and their ability to see each other's perspectives will be reviewed before the business case is analysed. An element of uncertainty and inequality around environmental regulation is discussed from the perspectives of farmers and foresters before examining leadership and governance within the catchment and how this has impacted on the Protection Project. The findings chapter will finally conclude with the dynamic nature of societies changing opinion before heading into the discussion chapter. 


\section{Foresters: In it for the Log Haul}

Lake Taupo Forest Trust (LTFT) and Lake Rotoria Forest Trust (LRFT) operate for the benefit of their land owner members who are in Ngati Tuwharetoa. George Asher, who is the CEO for the LTFT talks about his understanding of the term sustainability:

To the Trust- one of our missions is to ensure Kaitiakitanga ${ }^{4}$ over assets of the trust and I guess we have an understanding of Kaitiakitanga where the rest of the world is still coming to understand, certainly a holistic approach to it, in that is not just about looking after a certain sector of an ecosystem it is a total ecosystem. Tuwharetoa has maintained that its Kaitiaki has enabled it to bring into the modern world natural assets that were totally unspoilt. The basis on which these forests were established was a recipe for sustainability.

Sustainability was a fundamental choice for the Tuwharetoa forestry trusts as it is about the people and protecting the whole ecosystem. The long-term vision and stability of land ownership means forestry has a low impact and was the preferred route rather than converting large amounts of land into farming.

Because of the issue of sustainability we have water resources, forestry resources, landscape resources that are better served by forestry than by farming and that has been proved by the nitrates issues.

Geoff Thorp the Forest Operations Manager from the LTFT illustrates that sustainability for landowners incorporates a holistic approach and the lake "is their central Taonga [gift] of all things and they are particularly concerned about the lake and it's well-being, it's whole role is in their very being just like the land." Even though Forestry releases less environmental pollutants than farming, the interest that foresters show for the land is similar to how farmers respect their land. Farmers have a strong connection to their land and see it as a means of creating economic opportunity but also in the aesthetic value.

\footnotetext{
${ }^{4}$ Kaitiakitanga- is a Maori term referring to guardianship over natural resources 


\section{The Passion for Farming}

We sell ourselves as one of the cleanest and greenest in the world. The lake can be fixed it's a matter of leadership and education around nitrogen. Farming can continue to farm around the Lake No problem (Dave Staite, Organic Fertilizer rep).

In the farming sector the link to the land was a strong motivator to protect the lake. The economic aspect of sustainability resounded strongly as the continued ability to generate profits was paramount, particularly when farmers felt like a cap was effectively a cap on income. Sue Yurex, a sheep farmer and founding member of Taupo Lake Care (TLC), describes the holistic picture of sustainability that incorporates,

...economic aspects as you want to try and make a living. Every farmer has a very keen environmental sense of protecting their property for future generations. Sustainability in my eyes is sustaining the life-blood of the community, and it is about sustaining the farm, the people, the environment and the stock.

Sue has holidayed around the lake and has a historical connection which means she would feel uncomfortable to do anything other than protect the lake. Another sheep and beef farmer and current member on the board of TLC was Alex Richardson. Alex finds that the environment has not come into his approach to sustainability, "it's probably more the economic sustainability that worries us, to remain economically viable." However, their farm overlooks the lake and this consequently was a main driver in purchasing the farm as "the lake means a lot to us and we are prepared to work to keep it healthy." The link between farmer and land is a very emotional connection as many farmers commented that they were passionate about working the land which drew them to farming. Mike Barton a former chairman of TLC and Sheep and Beef farmer talks about his attachment to the land, "the land and the environment is very important. Taupo is somewhere I have been coming since I was 5 years old." Farming is a business and that emotional connection in protecting the land for social, environmental and economic value is important to many farmers. 
The emotional drive to protect such an important public and private asset was shared by many stakeholders within the catchment. The process, spanning from the year 2000-2010, has seen a variety of entities coming together to interact with each other. These relationships are discussed in the ensuing section.

\section{Multi-Sector Stakeholder Interactions}

Once you can put yourselves in other people's shoes it helps to move forward and design workable policy (Sue Yurex, Sheep farmer and founding member of TLC).

The 10-year process of setting up strategies to protect the lake with workable legislation has been an intensive one, not only financially but also time-intensive. Nick Carroll, Manager of Strategic Environmental Policy at TDC, sees stakeholders as having always recognised that the community view the lake "as sitting at the heart of the district, the one symbol of Taupo and the Taupo district." They see it as "a precious natural asset but also as an economic asset." Even though the end vision and goal of protecting the lake was shared by all parties involved, there were tensions in relationships along the way.

Graeme Fleming, CEO of the LTPT identifies the driving force is "looking after the lake" and EW compared the failure of the lake and how this would impact tourism being that "farming is a very marginal income generator to the region," which meant the lake needed to be protected no matter the cost. However farming felt that the finger was being pointed at them with no incentive to change.

The cost-benefit analysis outcome was that the lake needed to benefit the wider public. The economic, social and environmental impact that regulation would have on the farming sector was taken into consideration according to EW. Economic studies were conducted in 2001 by Tharrold and Findlayson, but farmers felt this was not enough. Mike Barton remembers when the 2001 economic analysis was presented within the Environment Court and states EW, under the RMA section 30, was required to model the economic impact that any policy would have on stakeholders. "I raised this in court and the judge asked to see it. It was a document produced very early on in the process and you could drive a truck through it," he explained. Mike Barton consequently did his own 
economic analysis as part of his MBA and modelled the worst case scenario which would see farming unviable over the next 10 years, post 2010, in a society of rising costs. This was not taken into consideration by EW according to Mike as "the RMA says you cannot put people out of business. It has to look at economic and social implications." Sharon Barton felt that within the word sustainability "we saw the economic aspect as being left out." However Anne Mcleod the Deputy CEO from TDC acknowledges that it is not pushing one cost over another,

It's more about the long-term rather than the short-term view. And I don't know how I would argue one cost over a range of other costs. It's about sustainable development not about one single aspect.

EW did take into account the impact that potential legislation could have on stakeholders, and farmers were one of those groups. According to Justine Young this was evident in EW's decision to choose grand-parenting rather than averaging, as averaging would make farming "unviable within the catchment." However that went against what the forestry sector were arguing for, being in favour of averaging. Justine states the "bigger issue was - will the pastoral farmers go out of business? That was well up on the council's agenda."

Farmers were concerned about the social impacts of how policy will affect their community in the long term. Alistir Robertson, owner and operator of Cascades Lodge within Taupo wondered about the landscape changes with a large amount of farmland converted to forestry. Alex Richardson also expressed concern regarding the changing landscape to trees. Justine comments on whether or not landscape changes should have been something that EW was concerned about, "what's the bigger concern? For me the biggest concern is the outcome of the lake and the outcome for the farmers in the lake."

The Farming sector also worried about how they could continue to make an economic profit under a cap and Justine comments,

I guess the question is.. is it EW's core activity to find alternative economic pathways for people that are affected by policy interventions? To achieve a public net benefit of lake water quality being protected there 
will be private costs- does EW need to address all those private costs? After all, it is the public net benefit that we are all about.

Mike Barton would tend to agree with this point as he sees it as an individual farmer's job to decide on their own economic opportunities. Mike states "to have governments tell me what's good or bad for me economically is a frightening thought. People need to take responsibility for their own economic health, or sustainability." It is his view that farmers must realise the implications of carbon and nitrogen markets on their own and determine a course of action that suits them best.

Taking into account different stakeholders viewpoints when determining policy was a learning experience for all. Including local, regional and central bodies with private interests was a balancing act and the ability to see each other's perspectives was crucial as Geoff Thorp from the LTFT states "it's been useful to break down barriers to see other peoples' point of view." Common areas of interest were extremely important as Sue Yurex describes,

The expectations were always just to try really hard to establish common ground and establish where everybody was coming from. And that we could establish some form of trusting relationship to work towards a policy.

The friction between farmers and policy staff during engagement was another issue according to Sue as,

people who design policy don't have an understanding of on farm practices and don't understand how it will affect you financially. A bureaucrat's mind-set and a farmer's mind-set, who has their skin in the game, are different.

Justine Young from EW realised there was tension in the relationship with farmers from the very beginning because of the initial approach taken by EW in saying 'this is the problem and here is the intervention'. EW had a minimal relationship with farmers prior to this and Justine recalls that "we took two steps 
back in our relationship." EW then had a lot of work in rebuilding those relationships.

Sue commented on farmers fighting for their livelihoods whereas some staff were there working and being paid to consult. She recognises the mediation role that Bruce Tharrold from Ag Research played in the early stages, between EW and Farmers, was instrumental as "he did a lot of interpretation and took the emotive language and tried to explain where each side was coming from." The relationship between EW and farmers from the beginning was rocky, due to EW labelling farmers as polluters from the outset. However according to Sue, over the years EW staff have been developing a working relationship, primarily through TLC which has eventuated through "open dialogue, trust and honesty."

The working relationship that EW cultivated with the farming sector and other stakeholders was instrumental. The ability to communicate with diverse groups to see their views is described.

\section{Standing in someone else's shoes}

If you want a win-win for everybody then you cannot move forward without understanding each other and their perspectives. I found the Environment Court very interesting because I was able to see the issues from the forestry perspective because I was only thinking from a farming perspective (Sharon Barton, Farmer).

One of the most important aspects of engagement in the case of Lake Taupo was the ability to sit down in discussion and see other stakeholder angles. Sue Yurex points out,

It was important for EW and TDC and some of the central government personnel to see actually from a farmer's perspective.

Anne Mcleod, the Deputy CEO of TDC became involved in the process after EW decided to bring in TDC. Representatives from EW, TDC, TMTB, LTFT, LRFT, MfE and TLC met on a regular basis which was an intensive process. Time was 
an important factor as it let everyone come to terms with the policy and as Anne recalls,

One of the things that everyone had to get over - was to come to an understanding of what it was like to stand in someone else's shoes. Originally everyone took the position of what was our corner. And then we needed to take the position of what was common, and the particular needs that each of those partners needed.

George Asher from the LTFT argues that at times people were not listening to those who were in the room,

With the issue of sustainability you have to front up to everybody and you have to be there to listen and to hear everybody on the issue. Rather than just take a track and create a perception of what you want. You have to deal with who is in the room.

The banding of individuals from varied public and private entities in groups such as LWAG was seen as a beneficial way to transfer information to diverse stakeholders. Natalie Haines from MRP is one such member who recognised the value in having a diverse group of people meet as it "is really positive, even if you can't tangibly measure the positive outcome, it's getting people thinking about things."

Not all members have similar goals as Paul White the chairman of LWAG points out, when defining sustainability some members do consider economic and social aspects above anything else, however the environmental interest towards the protection of the lake is the common purpose which unifies the group. The ability to work with the productive sector and generate sustainable innovative solutions is important and as Paul says "you never do that unless you are actively engaged with them. We try to set up projects that aim to help the productive sector work alongside environmental aims in the Taupo Catchment." The ability to identify the opportunities and weigh them against costs is something that a range of stakeholders had to consider. Seeing the trade-offs eventuated from being able to 
see stakeholder perspectives and the perceived impact is discussed in the following section.

\section{The Trade-offs}

The farming sector as Sue Yurex puts it, wanted to be involved in the process and realised that if they locked their gates and did not engage then "we weren't going to be part of the decision making process and we could not input what we wanted to which was an understanding of what these rules would mean, practically, financially and socially." EW is the regional governing body and they realised they had to be pioneers in their regulatory approach for the protection of Taupo. The conflict that aroused is described by EW's Justine Young who states,

A traditional cost-benefit analysis was done in-house that said what's the value of a clean lake? You can't value the lake with a monetary value, but they used the value of tourism as a proxy and said if the lake stays as good as it is, tourism will grow and tourism is worth this much to GDP versus the cost to the individual farmers.

The community is another stakeholder group that have had a role to play in the protection of the Lake. A survey that was sent out to the community in the late 90's sought public opinion on particular values with a resounding response in protecting the lake. However some stakeholders feel differently about the urban community and their perception of what had been occurring from 2000-2010. Alistir Robertson, from the Cascades Motor Lodge comments from a local perspective that he has been "surprised there has not been more about what has gone on in the last 12 months." However as Graham Law the current chairman of TLC states this year [2010] has been calmer "after all those years of intense activity, this year has been a quieter year while the last bits of wording of RPV5 were sorted." Farmer Sharon Barton feels as though the community were pointing the finger at the rural sector to clean up the mess. Deputy CEO of TDC Anne Mcleod has a contrasting view, she states: "there is no kind of feeling that this is solely a pastoral land issue and it should be the farmers who have to stump up." Not all parties felt like their voice was being heard in the early engagement stage. One such group was the forestry sector. The forestry entities of Tuwharetoa 
decided many years ago that forestry would be the best productive use for land due to their Kaitiaki (guardianship) philosophy. In their view, forestry respected the whole ecological system that encompassed the lake while generating a financial return for their Tuwharetoa landowners. In reference to the argument of averaging nitrogen across all landowners (compared to grand-parenting, which is the method adopted at the Environment Court) Geoff Thorp from LTFT understands that forestry's

Point of view was heard and understood but not accepted. They [EW] had a difficult job, farmers are a hard bunch to herd, sole operators who work hard, that's their life savings, and it's harder to come down on them than to come down on forestry which tends to be more corporate big outfits.

Averaging the nitrogen across all landowners would give forestry and farming an NDA of $5 \mathrm{~T}$ per Ha compared to grand-parenting which would give farming the possibility of an NDA of $15 \mathrm{~T}$ per Ha and forestry an NDA of $3 \mathrm{~T}$ per Ha. Mike Barton explains how the averaging method would cripple the farming sector in the catchment,

Forestry argued under a NDA of 3 they would be stuck in forestry forever, we argued that it was disingenuous that one day you might want to be farmers. Giving foresters 2 extra Tonnes from 3 to 5 and all farmers having 5T meant farmers would have to purchase extra tonnes of nitrogen from foresters. Every farm would have been gone just like that. So it would have been a cap and a reduction. Economically farmers would not have been able to survive.

The trade-off between the two stakeholder groups was intense with the future of each sector uncertain, engagement with the appropriate decision makers was crucial. EW faced a dilemma in balancing the needs of all stakeholder groups.

Geoff Thorp from the LTFT noted that it was a learning curve in seeing "where the weight of influence is in terms of rural land use, the sheer strength of the farming lobby. They have been lobbying for 150 years." The farming sector have been a powerful lobby sector in New Zealand's history, but there are only a small 
number of farmers within the catchment. Geoff's perception is contrasted with that of Mike Barton who states that in the Taupo Catchment there were "only 110 farmers. It is a large contributor to GDP in the catchment but comes from a low voter base, the biggest voter block is the tourist industry." Which is interesting as tourism was not specifically represented through the engagement process and Natalie Haines from MRP acknowledges that "our tourism industry wouldn't be here if it wasn't for the nature of that lake."

From a regional council perspective, Justine Young recalled the forestry groups having the perception that the decision to go with grand-parenting over averaging had been made by council and there was no point in engaging with EW and consequently "that relationship didn't really progress until the negotiations after the appeals were all in."

I know throughout the forestry groups they felt like their perspective was not properly considered. That was also the perspective of the farmer groups. I do vividly recall in these partnership meetings we had reps from EW, Central Government, TDC and Tuwharetoa, the forestry and farmer reps were excluded so a lot of the time they felt like they were not included.

CEO from the LTFT, George Asher comments on the lack of a sustainable outcome "they have actually not encouraged a sustainable solution they have avoided that." He refers to the RPV5 rules and that there "is no built-in incentive. If we look at nitrates the real incentive there is a commercial incentive." Geoff notes the difference between the mind-set of foresters and farmers in their business thinking as it appeared that farmers did not "have a real commitment to the lake itself. They were looking at the impact on their own lands, whereas Tuwharetoa people thought about the concern for the lake."

The commercial incentive of the farming sector to continually maximise production and increase profits was contrasted with the forestry sector and their choice of an environmentally benign land-use. The choice of forests compared to farms, for land-use, was Tuwharetoa landowners' way of respecting their 
environment. The Forestry sector, particularly the Tuwharetoa foresters, felt punished for their environmental stewardship in choosing forestry. The differing perspectives between forestry and farming with the governing bodies choosing grand-parenting over averaging continues to be a controversial issue. Geoff Asher from the LTFT comments on the final decision as,

The major concession seems a bit out of proportion when it's the forestry and undeveloped land that is saving the lake. Forest and undeveloped landowners' job is to protect the lake in perpetuity, while the farmers job is to continue to make money and pollute the lake. That's how we saw it and that's how we still do see it today.

The Lake Taupo Protection Project demonstrates multiple stakeholder interactions and the impact that this had on stakeholders, some positive and some negative impacts. The process illustrates the balancing act in creating legislation and the need for policy to be encompassing of diverse industries, in the end some tradeoffs had to be made. It was beneficial for stakeholders, particularly regulators and other governing bodies, to see the perspectives of stakeholders to understand their positions. Relationship building was crucial in developing trust throughout the process and the relationships between stakeholders and the LTPT is now reviewed.

\section{Stakeholders Relationship with the Lake Taupo Protection Trust (LTPT)}

The Trust was set up formally in 2007 to reduce nitrogen entering the lake by twenty per cent. The Trust worked toward this goal even though the legislation was not yet final. The main entities that the LTPT worked with were farmers and Tuwharetoa trusts. They participated in innovative initiatives such as purchasing and selling land with covenants ensuring low nitrogen intensive uses, or purchasing nitrogen off farmers. Utilising public funds to protect a lake that is a public and private asset was truly an innovative mechanism. The clear distinction between EW and the LTPT was another important step as farmers saw a clear delineation between the two. John Kneebone, Chairman of the LTPT, talked about the public perception of the trust and states "if you're a farmer, then the LTPT are seen as bastards, but the other people in Taupo think what the LTPT are doing is 
great." However some do not see the trust's involvement of purchasing farms and nitrogen in a positive light with Sue Yurex stating "there are people who are not satisfied with that." Because the Lake Taupo Protection Trust was one of the only buyers of land within the catchment, Sue states that from a private farmer's perspective the trust was "going to come in and rip you off as they will be the only buyers in the market" and as some farmers wanted to get out of the catchment, they felt like it was not going to be good. She goes on to describe the point of view of farmers seeing their relationship as "probably something of distrust." In the beginning, the "Maori farmers saw the LTPT as a bit irrelevant until the whole evolution of nitrogen and Graeme Fleming deciding to couple nitrogen and carbon together, so then there was a valid role for [Tuwharetoa forestry and farming] trusts and corporations."

Farmer Alex Richardson discussed the impact of losing four neighbouring farming properties. "I don't think it was necessary to remove my neighbours from farming, but you have to give the trust credit for giving those farmers the opportunity to get out of farming." As a farmer the trust is viewed solely as a driver to reduce nitrogen entering the lake by 20 per cent. Alex recalled the comments from a trust member that were "hardnosed and rubbed farmers up the wrong way back then. Basically it's been pretty hard to recover from that." Sue Yurex remembers those comments where "a trust member got up and said 'life is not fair and we can't change anything.' He got slattered for that. And someone needed to be honest."

The engagement that the LTPT has been doing with Tuwharetoa farming trusts has been more successful than with the majority of individual farmers. The work conducted by the LTPT is satisfying as Tuwharetoa trust farmers are being rewarded with nitrogen payments and in some cases carbon payments with MRP. Graeme recalls one of the Kaumatua ${ }^{5}$ from Ngati Tuwharetoa who said,

we will give you any bit of support you need to, we really like that you are actually trying to not only improve the environment and look after taonga

\footnotetext{
${ }^{5}$ Kaumatua is a Maori term for a respected tribal elder who is chosen to lead the tribe and future generations
} 
${ }^{6}$ of the lake, but you are actually trying to introduce some financial benefits for our people.

The relationship between the small number of dairy farmers within the catchment and the LTPT is one of competition. The sale of large Landcorp blocks of land going to a dairy farmer enabled a corporate way of farming to enter the catchment and one such dairy farmer purchased nitrogen off sheep and beef farmers, effectively competing with the Trust in buying nitrogen which was something that Sue Yurex did not foresee, where "one of the largest dairy farmers in the country would come and compete with the trust for purchasing nitrogen." Due to the funds being drip fed from local, regional and central government the trust was only able to drip feed payments to the nitrogen sellers. Whereas the dairy farmer had cash in hand and was purchasing nitrogen to increase their on-farm NDA so they could leach more N. Justine, from EW recognised that,

they are a buyer as anyone else is. That is the thing when you set up a market you have to have competition so the farmer is getting the best price and best deal. So that is a success as far as an economic instrument goes. Nitrogen is going to the person who gives it the highest value at the time.

For some farmers the decision was not an economical one, but they phrased it as a moral one. There was a moral decision made by some farmers to see the value in selling nitrogen to help the LTPT reach its aim, in saying that the financial driver of cash upfront was enticing for many. There is the question that Justine raises of whether or not "we [EW] are paying the least amount that we could possibly pay in using public money?" Justine goes on to say the fact is, this was the first time trading from diffuse sources had occurred in New Zealand, and the world, so there was learning involved throughout the process.

Promoting the business case was instrumental in Graeme's approach to initiating land change within the catchment. The next section goes on to detail how such a business case was formulated and the range of community groups, private and

\footnotetext{
${ }^{6}$ Taonga is a treasured thing in Maori culture
} 
public entities sought to have low nitrogen leaching land use whilst still being able to generate a profit.

\section{The Business Case}

We have to look at farming in a new way. For the last 20 years we have been pushing production up and up and up and we cannot do that any longer. We need to look at a new business model and what is that new business model, and what does it look like?

(Mike Barton, sheep and beef farmer).

The Lake Taupo Catchment in 2011 was an environment that encouraged low nitrogen intensive land use through new regulation. Individuals and businesses increasingly realised that it made financial sense to operate in a manner that respected the great lake. As Graeme Fleming stated, "I think the government and even individual catchments can take that lead by looking at the big picture. It's about business; it's about actually making some of the business equations work." Farmers were the main target group to reduce nitrogen leaching into the lake and it has been this group that has struggled with change the most. The land was balloted to farmers so the Government sold the land at a very low cost. It was after the Second World War when soldiers were offered ballot farms. John Kneebone describes how these farms were small blocks of land in the catchment that could be converted from scrub land into pastoral farms. In many cases the balloted farmers were farming the land for decades and they then had the government state they were polluting the lake and their farming practices had to change. RPV5 has enabled that fundamental land use change within the farming community.

Derek Ryan, an Agricultural Advisor at EW, has been working in Taupo with the implementation of RPV5 and breaks the farming community down into four groups. These categories include; Entrepreneurs, Positive conservatives, Negative conservatives and Laggards. Originally when EW told the farming community that they were responsible for polluting the lake the farmers did not want to change their management style and the majority of farmers were classified as negative conservatives. Over time with engagement, EW has built a report with 
the farming community and the bulk of the community in 2010 are made up of Entrepreneurs and Positive Conservatives according to Derek Ryan.

The Entrepreneurs have embraced it all, they see opportunities that others do not, they know the rules and they see the opportunities. After they [the Positive Conservatives] see what these guys have done, they sell and trade nitrogen and get into carbon farming. One of the positive spin-offs of RPV5 is people in the catchment start to rationalise their land and they have actually got a better bottom line profit.

These entrepreneurs were being leaders and influencing others within the community, to not only showcase their business and the positive impact that it was having financially, but that it was better off for the health of the lake.

You can actually improve the environment and get an economic return at the same time (Graeme Fleming, CEO LTPT).

Graeme was a driving force behind positive land use change and convincing land owners to see the business case. Working as the CEO of the Lake Taupo Protection Trust (LTPT), Graeme managed to create deals with individual farmers and Iwi to couple nitrogen and carbon as lucrative business opportunities.

We are creating sustainability; it gives farmers a whole other business philosophy and model. Take your land, convert some to forestry, moderate or change you're stocking levels, get a nitrogen payment from us, and you are going to have an income from your forestry.

Graeme talked about a new dynamic where landowners are looking at the business paradigm and that is how Graeme pitches it -- by not approaching landowners and saying "do this for the good of the lake. What I am trying to do is provide people with a good business opportunity."

There are also community groups that have recognised some farmers within the catchment are not seeing the business case and want to help out. LWAG is one such group with a diverse collection of individuals from a range of industries 
within the catchment consisting of individual farmers, councillors, MRP representatives, fertilizer companies, scientists to name a few. Paul White the Chairman of LWAG recognised the group had a varied nature and some see the economic drivers whereas others see the environmental and social factors above anything else. Primarily the group was focused on lakes and waterways so an environmental focus was inevitable. The group wanted to be engaged with the productive sector and in 2011 were working with the farming sector. Paul states,

For many farmers in the lake Taupo Catchment the Lake Taupo Protection Project looks like a stick. If you do not do what you are told then we will punish you. So you look at the question, where are the carrots? What is the incentive for Farmers to change? And so what we are trying to do is develop a set of carrots for farmers. We have had a few sessions called carrots for farmers. It's to do with incentives for farmers to get alongside the lake Taupo Protection Project.

The LWAG group persisted to enhance the knowledge of members in their group alongside the productive sector to ensure future viability of the farming and other productive industries within the catchment. Organisations have encouraged other organisations within the catchment to move toward a sustainable future which was beneficial for the district.

The entrepreneur farming types identified the carrots and engaged with the LTPT and entities such as energy generator Mighty River Power (MRP), had in some cases, agreed to contractually purchase carbon credits. This combination of selling excess nitrogen and planting land in forestry to sell carbon was, according to Derek Ryan from EW, "a huge incentive for them [farmers] to get on-board." Receiving an annual income from carbon sales "is a much better business model than farming sheep and beef and that is driving change" according to farmer Mike Barton. The coupling approach in 2010 and 2011 had an uptake from large Tuwharetoa Trusts and corporate farmers as they had the capital and large scale areas of land to convert. This uptake received a large amount of media publicity which was good for the district. Sue Yurex identified the reason why nitrogen and carbon need to be factored into the farming equation, because "in the dry stock industry we have to listen to our consumers, and we have to produce an 
environmentally sustainable product and part of that is carbon and animal welfare and sustainability." Sue talked about retaining the industry as it was important for New Zealand's reputation. Not only was it beneficial for the image of the catchment, but protecting the lake was a matter of sustaining the image of the industry on a national and international level.

As one of the largest companies operating in the catchment, Mighty River Power realised the long-term benefits of working collectively with stakeholders in the Taupo Catchment. The lake was the primary water supply for the company generating hydroelectricity and used $1 \%$ of the lake's surface, or 1.4 metres, in an operating range. Resource consents for MRP last for 35 years so it made sense to form lasting relationships to continue to successfully gain resource consents for the next 35 years. Natalie Haines, an Environmental Advisor at MRP stated, "we want to be able to show we are operating with total regard for the environment, and total regard for the communities that we are operating in." For MRP it is about developing a standard so that the community and stakeholders give the company "the license to operate". Natalie referred to MRP working with Tuwharetoa and the carbon agreements and how it was important to manage the lake which is so central to operations, as "it is the water source for the whole of the hydro operation so it is highly valued." Even though an element of uncertainty surrounded the New Zealand ETS and RPV5 was not set in legislation, MRP took charge to ensure security for a range of businesses such as farmers and Tuwharetoa trusts. Adam Smith, a carbon trader at MRP, recognised the importance of being leaders in this area and "for us [MRP] to stand up and actually invest in it and say we support the emissions trading scheme and actually start trading is a big plus. We've got international exposure." With the license to operate, MRP saw the business case and reduced the uncertainty for themselves as a company moving forward and for other businesses within the catchment.

Entities such as the LTPT, LWAG and MRP initiated positive land use change within the catchment and as more landowners managed to see the business case, the levels of nitrogen leaching into the catchment decreased. Being able to demonstrate the economic value in sustainable land use enabled the creation of a new business model which coupled nitrogen and carbon for farmers. The next section describes how not all organisations responded to the regulatory 
uncertainty in the same way as some stakeholders could not see a viable future within the catchment.

\section{Creating Environmental Stability and Uncertainty}

The Taupo Catchment and communities were functioning in a manner in which they thought was normal prior to 1999. Governing bodies alerted urban and rural communities that it was time to change if the lake was going to be protected. The proposed change brought about an aspect of uncertainty. Uncertainty shrouded regulation, livelihoods, and future industries within the catchment.

\section{Regulatory Uncertainty}

The purpose of RPV5 was to ensure that land intensification did not continue within the catchment so the lake was maintained at 2001 water quality levels. This was the largest environmental Protection Project in New Zealand and a learning process for all involved. The catchment "is the very first time in New Zealand and in the world that trading occurs from diffuse source to diffuse source" says Justine Young a Senior Policy Analyst from EW.

Paul White from LWAG recognised the need for policy to create certainty for the future.

You need policies for the long term. The Lake Taupo Protection Project is 50 years and that's not long in environmental timescales you might be looking at multiple decades or hundreds of years for some environmental cycles. You need that certainty and purpose in policy.

Some suggested that voluntary compliance was the way forward but also realised that government involvement was essential in some circumstances. Sue Yurex, one of the founding members of TLC, described the ideal future for TLC,

We were always hoping for more voluntary compliance. We always asked for an incentive rather than a stick. I think that's the way to change behaviour... but there will always need to be regulation to pull in the nonconformers. 
Justine Young, from EW, commented on the fact that farmers do love the lake but questioned whether or not "they would choose to voluntarily cap their nitrogen emissions? No. So unless there is an intervention then they won't change their behaviour."

A two-tiered approach occurred in the catchment with a local nitrogen trading scheme and a national emissions trading scheme (ETS) which aimed to reduce the uncertainty about the future of the lake. However the certainty surrounding the ETS as a regulatory instrument was unclear, particularly for the implementation of a national and international ETS. Alex Richardson was one such farmer who was interested in selling carbon under an ETS but he was concerned about the stability and reliability of such a scheme as it "may not be there in two years or 10 years." Sue Yurex also noted that in terms of an ETS and "farming, it's a big unknown. No farmer knows what the cost will be for their business." Illustrating that it potentially was profitable to farm carbon, but with agriculture being phased into the ETS, the true cost to the farming sector was uncertain.

The investment cost of planting trees was a capital intensive decision as John Kneebone, chairman of the LTPT points out: "You've got the establishment costs of the trees and you've probably got 7 or 8 years of no income. The potential for carbon to provide income is enticing in the long term. Short-term, people cannot sustain themselves on that." Combining the high investment with limited income and an ETS that was not set in legislation added to an uncertain environment. Adam Smith, a carbon analyst from MRP recognised the predicament that landowners were in when trying to make the decision to invest in forestry as "you need income certainty to get finance to plant those forests so there is a huge upfront cost of buying land and planting trees." The challenge was how to get around the large initial capital investment. It therefore was important for the business case to be successful, nitrogen and carbon trading had to be combined. This combination was profitable as Sue Yurex notes, "coupling carbon and nitrogen is a huge win-win." This was evident in the agreements between LTPT, Tuwharetoa Trusts, farmers and MRP. MRP saw the positives in being the first mover and taking a leadership role when it came to the ETS. 
With the ETS coming into effect, it makes sense for us [MRP] to invest within the local communities that rely on the lake, it's good to protect the lake, it's meant to be protected.

Adam acknowledged that MRP were reducing the uncertainty of future carbon incomes for farmers, but it was also securing a position for MRP in the market for the continued purchase of carbon into the foreseeable future. This multi sector partnership was mitigating the risks that many parties would face working in such a market-based scheme if they were alone.

In regards to local legislation, there was an evident amount of certainty surrounding RPV5 as it was in the final stages of mediation between stakeholders regarding wording before being passed into legislation. Derek Ryan from EW who had been involved in benchmarking farms commented on the challenges included "the fact that we have not got any rules yet. You know, I have been waiting nearly 3 years for the rules to be finalised." The process over the past 10 years and its creation was the underlying contributor for uncertainty for stakeholders as Sharon Barton expressed, "people were scared in the lead up to the legislation coming, what are the implications RPV5. No one wanted to touch Taupo land, it was something to be feared, and if people buy into it, they were weary." Her husband, Mike Barton suggested with RPV5 nearing completion in 2011 and engagement refined the issues "we have more certainty in terms of how we farm than anywhere else in the country." This was not always the case and the uncertainty for farmers over the 10 years prior to 2010 was a gruelling account.

\section{Farmers' Uncertainty}

Farming has never faced a problem like this before. The hardest aspect has been having it hang over us for 10 years and not knowing. It took away a lot of enjoyment and incentive for farming. (Alex Richardson, sheep and beef farmer)

From 2000 to 2010 stakeholders worked toward one common purpose, the protection of Lake Taupo. Farmers, in particular, had to come to terms with their sector being labelled polluters and wanted to determine a workable policy whilst 
continuing to make a living at the same time. Many farmers felt that the economic modelling of the impact of RPV5 or the social implications were not taken into consideration by EW. Mike Barton described how the community felt throughout the process.

Putting a group of farmers under a cloud for 10 years has hugely negative effects such as stress, marital problems, and relationships between farmers were damaged. When people see one farmer is capped higher than the other, jealousy comes out. There are people who see the glass as half full, and there are others who are stuck and that is tragic for them as they cannot move on.

The uncertainty of the future was very concerning for many farmers placing strains on relationships within the community. Alex Richardson thought that the government "didn't appreciate the emotional issues involved, they are changing the social fabric of the community." With a low return on investment per annum for sheep and beef farming in 2010, the real capital gain was in selling the property. The uncertainty for the future saleability of their farms within the catchment was described by Sharon Barton:

Some were stuck or feeling threatened, especially people who were reaching retirement felt very threatened, the uncertainty of retirement, they suddenly felt like it was eroding and feeling like they have no control, it was a scary time. For some it was a very threatening process and it brought out the very worst in human nature. The farming community have had to try and understand it and some of them still do not understand it because they have been living it and breathing it but because of their emotions, they have got incredibly confused about it.

This concern was reiterated by Alex Richardson who thought that "most of the farmers felt the pressure to sell because of the variation. The uncertainty surrounding the future was pressure to sell."

The formation of Taupo Lake Care (TLC) in the early stages of 2001 was a defining point for all farmers involved. The ability for a non-governmental entity 
to disperse information and updates regarding RPV5 was seen as a success. Farmers notably preferred to communicate and receive communication with TLC compared to other government entities. It meant the sector had a collective voice and were lobbying for a single purpose as Sharon Barton puts it, there was a lot of "social cohesion in the early years, there was a united purpose." Once the discussion turned from defining parameters of a workable policy to implementation, that is when a division occurred between the farming community and relationships started to fray as Sue Yurex stated,

I think it has ripped the community apart. In some respects it [being a part of TLC] made us stronger and people were unified with a purpose but there were some people who were left behind in the process and as a result we do have some people who feel hard done by and were never comfortable with any form of working with anybody, they wanted to lock the gate. It is a community that still feels that the urban community points the finger and says it is your problem so sort it out.

Alex Richardson found that the motivation to continue farming disappeared and as a farmer who lived in an area where surrounding properties were purchased by the LTPT felt that,

they did not appreciate the impact it [land use change] has had on people's lives. I don't think EW looked at the social impact, to me removing these neighbours is quite a loss and that is a huge loss when we do not have many neighbours in a remote area, your neighbours are quite important.

Sharon Barton notes the impact on individual farmers' motivation levels and the difference that it had on men and women farmers.

For men in the catchment we saw de-motivation and depression was a real battle, not only the pressure of their wives on the retirement figure, from a daily point of view a lot of them were de-motivated. They lost their sense of challenge, and it affected different age groups in different ways. 
The flow on effect of RPV5 and the sale of some farms impacted businesses that relied on the farming sector. With a bulk of farm sales from the LTPT, Jocelyn Reeve who is the current secretary of TLC and a farmer just outside the catchment stated, "our vet has already lost $25 \%$ of their traditional sheep and beef farmers with the LTPT farm purchases. It's had a major impact on farmers, if only we had the solutions to change."

The social aspects were the biggest factor that threatened farmers and the impact that RPV5 had on their retirement and the future of farming in the catchment meant they felt insecure about their future. It was not only the farming community that had uncertainty shrouding their sector. The foresters were in a similar situation with the RPV5 locking them into forestry perpetually.

\section{Foresters' Uncertainty}

We do look at forestry as adding positives to this catchment. One of the phases that forestry has gone through in New Zealand over the last 10 years is it has gone from a strong forward looking sector to one that has incurred a number of uncertainties, (George Asher, CEO LTFT).

The uncertainty for foresters laid in the ultimate decision of a NDA allocation. As a collective they argued for averaging $5 \mathrm{~T} \mathrm{~N}$ per ha across the whole catchment, which would give them a degree of certainty in how they could utilise their land for the future. Under grand-parenting, forestry was given an NDA of $3 \mathrm{~T}$ per ha, which meant they were effectively locked into forestry. The principle of making their own choices of land use was the issue, Tuwharetoa forestry land owners wanted to be able to make decisions on future land use as Geoff from the LTFT pointed out,

The big thing for Tuwharetoa is that their asset is their whenua ${ }^{7}$, it's not the forests on it, in all likelihood most of the forestry land will be forests for as long as anyone can see. But we don't want to be locked down to that.

\footnotetext{
${ }^{7}$ Whenua is a Maori term for Land
} 
For businesses like Carter Holt Harvey $(\mathrm{CHH})$, the uncertainty led to them selling out of the catchment before the Environment Court proceedings. However they were involved in the appeals and discussion at the Environment Court due to the occurrence of possible precedent setting outside the catchment for other foresters.

The fact that RPV5 potentially was a form of precedent was on the minds of not only forestry groups but also the farming sector. EW maintained that there is a 'no precedent clause' section in the RPV5 policy that says this legislation is not intended to be precedent setting.

The Objective, Policies and implementation methods contained in Variation Five - Lake Taupo Catchment have been developed to address the decline in Lake Taupo water quality in the context of the unique set of circumstances which apply in the Lake Taupo Catchment. In doing so the Waikato Regional Council does not intend to create a precedent, either direct or indirect, for any other catchments or water bodies and does not consider that any precedent is created, (Berry, 2008, p 2).

However farmer Jocelyn Reeve pointed out in the hearings committee the following statement could be precedent setting for other regional councils to take on board for future policy,

One of the goals in managing non-point source discharges is a change in farmer and regulator culture and norms from telling farmers they must undertake or cease some particular activity, to developing an understanding of the complexity and drivers of nitrogen leaching in the Taupo Catchment. To accomplish the necessary change requires a strategic and co-ordinated approach that encompasses consultation, education, policy development, regulation and enforcement,

(Hearings Committee Section 32 analysis, Doc 1093829, p 128).

Foresters and farmers negotiated at the Environment Court stage with many new stakeholders getting involved for fear of the legislation spreading throughout the country. Even so, the project was observed by a range of other regional councils 
within New Zealand and on an international level. So there was ground for the legislation to be picked up for similar future protection projects.

The subsequent section describes the inequality that stakeholders felt while engaging from 2000-2010 and discusses the main discrepancy between foresters and farmers where the grand-parenting method was chosen by EW.

\section{Inequity}

An interesting finding was the perceived inequality between some stakeholders, even within their own sectors. In any situation there are going to be trade-offs to find common ground for an ideal outcome to eventuate. This was demonstrated in the above stakeholder interactions section with the inequality between the farming and forestry sector. Forestry felt as though farmers were being let off lightly according to Geoff Thorp. Too much nitrogen was entering into the system:

To counter that they wanted to lock us down into forestry. It didn't seem to be a logical answer. So the $20^{\text {th }}$ century was the opportunity to get up the ladder with your nitrates (or intensity your land use) and if you missed out then you are locked down and it perpetuates that position in life.

Geoff had concerns surrounding the rules of the policy and decided to go and talk to the EW councillors in Hamilton. After the meeting it was clear that Geoff's talk was the first time EW councillors thought forestry had concerns "I was pretty pissed off cause the EW officers that I had been talking to had obviously not passed on our concerns. They thought it was just a farming issue." Tuwharetoa has forestry and farming trusts so they "have a role on both sides of the fence" which resulted in a divide between the two sectors. The LTFT was acting on behalf of the Tuwharetoa Maori Trust Board (TMTB) to represent a unified Tuwharetoa. With the LTFT arguing for an averaging approach they soon realised that if averaging were to go ahead then:

The allowable amount [of nitrogen] might need to reduce in the future, and if that reduced, we [Tuwharetoa] were setting ourselves up for some internal fights as to who would get that scarce amount of nitrogen. Even 
though we were trying to work together [farmers and foresters within Tuwharetoa], such a scenario could be quite divisive as we would have our own 'within Tuwharetoa' fight.

Geoff states that the averaging method "didn't persist and in hindsight the risk of nitrates becoming a scarce resource would have led to a difficult scenario for us." It was agreed that the Tuwharetoa entities would continue to represent their own interests rather than try for a whole Tuwharetoa approach. From the perspective of a farmer, Sue Yurex could see how the forest trusts were treated inequitably.

The inequity of the whole policy in that the lake was Maori owned and was used in reserves since the 60's and as guardians of the lake bed they were being asked to commit more. So when the LTPT could offer a winwin situation [for Tuwharetoa farming trusts] and MRP, it was hugely rewarding.

One of the peculiarities of Maori land is that they intend to retain the ownership of the land in perpetuity. George Asher recognised the fact that if Maori cannot use the land in a profitable manner under a regulatory regime then they had to live with that forever. Maori land is not sold for capital gains like other farmers within the catchment. He said there was a

whole lot of factors that work against you as a perpetual owner of the land so you need the flexibility over a long term. How does that relate to sustainability?.. one of the things that a perpetual owner can bring is stability, it could be economic stability but it could be eco system stability. So again going back to the need to work through this is the need to find solutions which are long term and meet a number of long term objectives not just short term objectives of government.

When the engagement process shifted from discussions surrounding the NDA cap to an implementation phase, farmers started being capped at their highest year between 2001 and 2004. Throughout this process different farmers were capped with a higher or lower NDA and this caused friction between farmers who realised that their NDA had a dollar value. 
This jealousy was prevalent between large and small land block owners within the catchment as the larger farmers generally had more land area in which they could retire for forestry or other uses. The larger farmers are categorised as corporate farmers and as Graeme Fleming found, the larger players can take a thousand hectares and convert it into forestry and receive a return "which is higher than sheep and beef, and get a nitrogen payment from me."

The difference between Tuwharetoa land and private farmers from Graeme's perspective was with the Tuwharetoa land you were buying the future use, whereas "with private owners, they were simply in it for land value. As soon as I [the LTPT] put a covenant on the property for 999 years saying it can only be used for this, it is having a big effect on their potential value."

The future value of land was something that devastated the farmers and Derek Ryan from EW saw a change in some of the farming community who originally felt that the situation was totally inequitable. Derek tells the story of a farmer who was one such example.

When I first met him, I could only talk to his wife, he would sit in the background, he was miserable. Now he is just happy as Larry, he has got nitrogen to sell and he can see money in it. So he is one person who has shifted and that is really quite satisfying.

Compared to the corporate farms, Alex Richardson had 310 ha of land and was a comparatively smaller farmer. He saw the inequality between farms within the catchment and those that are outside.

All these things we are putting in they are still an added cost to our farm that other farmers do not have to bear at the moment, although they are positive. It's a cost no one else has to bear. To me if not financially fair.

The fact that landowners varied in size and make-up, with diverse land uses such as forestry and farming land, meant trade-offs had to be made. EW had a duty to protect the public and create a net benefit for all stakeholders and sometimes 
stakeholders were impacted more so than others. The biggest inequity was between the farming and forestry sector with the grand-parenting and averaging arguments respectively. EW did their best to balance stakeholder needs to reduce such inequity.

The engagement process that occurred in the Lake Taupo Catchment from 20002010 was being watched by regional councils in New Zealand and worldwide. Leadership was seen to play an instrumental role in such an intensive policy development and implementation process. However there was a lack of industry leadership, particularly from the farming sector.

\section{Governance and Leadership}

I think over time government policy and industry leadership is now starting to believe we need to maintain our clean green image, as a brand. I think you will start to find that other regional councils are looking at some degree of environmental protection through rules and regulations. It certainly won't be like this, because this is quite a unique situation where you've got one lake, one regional council, one Iwi, and one district council, (Derek Ryan, Agricultural Advisor EW).

The role that the TDC, TMTB, EW, and CG played in setting up strategies and legislation along with other key stakeholders was crucial to the success of this project. Many of the stakeholders recognised the impact that a change of leadership within local, regional and central governments had on the process. The loss of half of the EW councillors to a new rates control team who did not have a proper understanding of the Lake Taupo Protection Project was seen as a big risk. Sue Yurex comments, "you do need continuity in leadership in any project that is quite complex." Anne Mcleod from TDC aligned with Sue's comment in that EW, TDC and the TMTB had a consistent point of view whereas MfE "tended to send a different representative every few months and that lost the intellectual property and continuity throughout the process." This added to a difficulty in people not understanding what had previously occurred. It is hard to "embed the long term thinking in what councillors do when they have that three year election cycle" according to Nick Carroll from TDC. 
In saying that Justine Young from EW commented on the fact that consistent political will to proceed with policy intervention over three election cycles "is quite heartening." In spite of this, the consistent leadership of the farming industry was another story.

\section{Where Was Leadership From the Farming Industry?}

Industry need to ensure that their suppliers conform, because they can wield the stick much more than central government can. (Sue Yurex, Farmer)

It was extremely positive when businesses such as MRP came into the equation and offered to purchase carbon from farmers and Tuwharetoa trusts to encourage stability in an uncertain environment. However there were a range of large entities such as CHH, Federated Farmers, Fonterra, Meat and Wool and Landcorp Ltd who left the catchment or were not actively involved in engagement until it was too late.

For the farming community, the lack of involvement from Federated Farmers early on was disappointing. Many farmers pay a sub to the organisation to represent them as their collective political voice on issues relating to farming. Farmer Alex Richardson observed that they were missing from the start as they were "notably absent and had a lack of presence until the Environment Court procedure." Federated Farmers had ring fenced what was going on in the catchment and left it at that. It was not until five years later in 2008 that Sue Yurex remembers "feds had woken up that they missed the boat on this one. That they should not have let it get swept under the carpet and let the Taupo farmers get left out to dry." The lack of leadership from Federated Farmers, according to Paul White from LWAG "did not do his organisation [Fed Farmers] any good." The strong lobbying for "economic issues and bugger the environment" was not consistent with what the productive sector needs. Those needs are land and customers to purchase their product. Paul explained that "if New Zealand wrecks its environmental profile by going pro farming and bugger the environment then the customers will disappear and where have we got to?" 
Justine Young from EW recalled Federated Farmers were so late in the piece that they missed making a submission to the Environment Court so they joined onto other submitters "yet the process had been working for 5 years. You cannot get much more late than that."

The reason why Federated Farmers along with $\mathrm{CHH}$ entered into the discussion was due to the fact that this would become precedent setting for the rest of New Zealand. Interestingly, Sue Yurex stated that the late intervention was more of a hindrance than a positive occurrence because:

They had stopped the process by hassling around the edge in the Environment Court and that was not good for anybody. We wanted people around the catchment to understand and get on with it.

The Farming Industry should have been leading the way years ago, according to Alistir Robertson. Further leadership in this area would have sped up the, "voluntary process. Unfortunately central government may still have to put in nationwide policies to bring about the required change."

Landcorp Farming Ltd is an organisation who strives to lead the way in improving the sustainability and productivity of farming. As a state-owned enterprise they were required to return a profit to the government. The idea was put forward to have the Landcorp land within the catchment converted into low intensive land use to help alleviate the amount of Nitrogen entering the lake. However the CEO Chris Kelly ${ }^{8}$ stated that they wanted to keep the land in production if they sold it. The minister of the MfE, then Marion Hobbs, stated that converting the Landcorp land was not an option as they wanted to take a whole government approach to change behaviour. In October 2007, Landcorp, who owned 20 per cent of the pastoral area within the catchment, sold up and left the community. Farmer Alex Richardson found "it was a bit of a slap in the face when Landcorp sold out.

${ }^{8}$ See the Yurex document for further detail into Landcorp Farming Ltd's reasons for exiting the catchment. Yurex, S. (2010). Protecting Lake Taupo: The strategy and the lessons. New Zealand: Environment Waikato. 
Landcorp bailed out and sold off to big farmers and washed their hands and left." According to Yurex the fact that Landcorp disappeared from the catchment means,

they let down the whole country, Lake Taupo and the Taupo farmers by not being proactive for longer. But he [Chris Kelly] was doing it purely for commercial reasons. He felt his land was going to de-value and they thought they should move on. To me that is not part of Landcorp's charter. Landcorp's charter was to be leaders for New Zealand farmers, and that was not bailing on an area that was about to be capped. The fact they sold and got out really gutted the community and I do not think they will get over that.

Large players within the farming industry should have engaged earlier on in the project and the farming and forestry stakeholders recognised this. Farming bodies have significant influence in representing industry and Federated Farmers, Fonterra and Landcorp Ltd failed to represent their key stakeholders and their interests.

\section{Summary}

The perception of farming and the impact it has on the community has become consciously talked about since the year 2000. That is apparent as a result of the RPV5 legislation seeking to change intensive land use. Farming is a large contributor to GDP for New Zealand and it was hard for the farming sector to come to terms with this new paradigm change. Geoff Thorp from the LTFT recollected when he was growing up "you never heard a bad word said against a farmer, there was no reason to. You certainly do now and it is generally about their impact on the environment." This was in line with John Kneebone who can see a huge swing in individuals being concerned with pollution.

The leaching of excess nutrients from landowners had an impact on how the community sees the productive sector, particularly when it has a visual impact such as algal growth in waterways. Justine Young observed the farming community in New Zealand was, 
producing more contaminants than is acceptable to the community valued water bodies and therefore the community has rights above the farmers rights. I think that is becoming more explicitly talked about in regional councils around the country.

Justine Young talks about how New Zealand allowed the sector to farm "regardless of what they discharge into the environment and this has been an accepted part of New Zealand for decades despite the RMA and I think that is changing." The legislation that EW developed through engagement, RPV5, brought in a range of stakeholders from public and private sectors who sought to protect Lake Taupo for future generations. The definition of sustainability illustrated self-interested needs where some stakeholders identified economic drivers over and above the environment. However many stakeholders identified Taupo was central to the regions prosperity and protecting the lake was the 'right thing to do'. A multi-sector group of entities engaged where these stakeholders collectively worked together and created innovative business models, ensuring the Taupo Catchment was a low nitrogen and carbon economy. This business case enabled a reduction in farmers' uncertainty regarding future incomes and increased the viability and certainty of farming within the Taupo Catchment. Inequity was perceived between landowners and EW ended up balancing the needs of diverse stakeholders with trade-offs occurring. Ultimately EW had to create a net benefit for the wider public and they created this in the form of an innovative piece of legislation.

The following discussion chapter will apply the Lake Taupo 'Taupo-nui-a-tia' case to theory and formulate key findings from the research question and aims of this thesis. These themes will be applied to the literature identified in chapter two and analysed so similar environmental protection projects can benefit from the Taupo case. 


\section{Chapter V: Discussion}

\section{Understanding the Lake Taupo Project}

In the previous chapter, the findings illustrated an integrated web of stakeholders engaging to protect a crucial resource for the region and the nation. The findings showcased multiple stakeholder perspectives and how they impacted on the business case for sustainable development. The interpretations of sustainability that each stakeholder espoused gave an insight into their motivations to protect the lake and demonstrated the differences that exist among stakeholders in a collaborative setting. In this final chapter, perceptions and interactions will be analysed whilst linking in theory to document learning's for similar environmental engagement initiatives. The structure of the discussion chapter is based on the themes identified in the preceding findings section. Each theme is examined and in some cases two themes are combined, compared and contrasted with current literature. Themes flow in subsequent order from the findings section initially starting with the perception of sustainability. Areas such as exploring multiple stakeholder interactions and understanding the business case are analysed and the ability to reduce uncertainty for a sustainable future is investigated. The themes of uncertainty and inequity are combined and explained before finally examining the governance and leadership of the Taupo Protection Project.

\section{Stakeholder Interactions and Their Perception of Sustainability}

Considering the stakeholders involved in the protection of Lake Taupo were engaging to protect their own special interest, evidenced by the forestry and farming sectors, it is intriguing to view stakeholders definition of the concept. The ambiguity of the definition enabled participants to conceptualize a sustainable future that was specific to their context (Collins and Zorn, 2007; Richardson, 1997; Rydein, 199; Vionoz, 2008). 


\begin{tabular}{|c|c|c|c|}
\hline Stakeholders & Industry & Idea of Sustainability & Ideal outcome \\
\hline $\begin{array}{l}\text { Tuwharetoa } \\
\text { Foresters }\end{array}$ & Forestry & $\begin{array}{l}\text { "A total eco-system } \\
\text { approach- } \\
\text { Kaitiakitanga" } \\
\text { "Sustainability is all } \\
\text { about the people" }\end{array}$ & $\begin{array}{l}\text { The protection of the } \\
\text { lake and treating all } \\
\text { stakeholders fairly. } \\
\text { Stakeholders polluting } \\
\text { should be penalised. }\end{array}$ \\
\hline Farmers 9 & Farming & $\begin{array}{l}\text { Primarily economic } \\
\text { (but concerned about } \\
\text { social aspects and } \\
\text { protecting the lake) }\end{array}$ & $\begin{array}{l}\text { Continue to farm } \\
\text { economically and have } \\
\text { high quality water } \\
\text { within the lake. }\end{array}$ \\
\hline $\begin{array}{l}\text { Governing } \\
\text { bodies }^{10}\end{array}$ & Government & $\begin{array}{l}\text { Social, Economic and } \\
\text { Environmental aspects- } \\
\text { Trying to retain a } \\
\text { balance between the } \\
\text { three factors. }\end{array}$ & $\begin{array}{l}\text { The lake is protected. } \\
\text { Industries can continue } \\
\text { to operate within the } \\
\text { catchment. }\end{array}$ \\
\hline MRP & Electricity & $\begin{array}{l}\text { Economic, social and } \\
\text { environmental. } \\
\text { Relationships were } \\
\text { crucial for resource } \\
\text { consents Lake is } \\
\text { central to hydro } \\
\text { generation. }\end{array}$ & $\begin{array}{l}\text { Recognised protecting } \\
\text { the lake was important } \\
\text { to the region. MRP } \\
\text { were not directly } \\
\text { involved in the } 10 \text { year } \\
\text { engagement process } \\
\text { however they do have } \\
\text { a member in LWAG. }\end{array}$ \\
\hline Community ${ }^{1}$ & - & $\begin{array}{l}\text { Stop land } \\
\text { intensification for the } \\
\text { protection of lake } \\
\text { water quality. }\end{array}$ & $\begin{array}{l}\text { Water quality levels } \\
\text { consistent with } 2001 \\
\text { levels. }\end{array}$ \\
\hline
\end{tabular}

The differences in understanding the fundamental concept of sustainability led to outcomes that were inconsistent with what stakeholders perceived for the sustainability of the lake. The table titled the Main Stakeholder Groups Perceptions of Sustainability details a range of stakeholders and their views and definitions of sustainability. Many of the farmers interviewed noted how important the lake was to them individually because they had a historical connection with the region from their childhood. Many grew up or holidayed near the lake which played an important part in sustaining the recreational and aesthetic value. However the economic aspect of sustainability was the most important aspect in continuing to remain profitable. This aligns with the view of Collins et al., (2005) focusing on a weak framework for sustainability.

\footnotetext{
${ }^{9}$ The Farming sector includes individual farmers, Federated Farmers, and TLC.

${ }^{10}$ Include EW, TDC, TMTB, CG, and the LTPT.

${ }^{11}$ Community encompasses individuals interviewed such as Alistir Robertson (Cascades), Dave Staite (Organic fertilizer sales rep), and Paul White (LWAG).
} 
The forestry sector viewed a holistic approach to the term as they referenced a 'whole ecosystem' structure. To foresters, sustainability is incorporating an aspect of protecting the whole system but also in sustaining the people. This indigenous philosophy that the LTFT is aligned with is the theory of complex systems and similar to recent scholars identifying management of ecosystems and their interconnectivity (Norberg, et al., 2008). A linear approach in only focusing on sustaining one sector, when in fact all industries must interact and rely on the environment, is not consistent with a whole perspective on sustainability (Webb et al., 2008). Throughout the engagement process, this was something that foresters felt was lacking, particularly with the farming sector who were only seeing the cost on their operations and not the true opportunity in protecting the lake.

From the farmers' perspective, they felt that sustainability needed to incorporate the economic implications, and for them, that was not considered or modelled during the engagement process. EW's view was solely directed towards the protection of the lake, and under the RMA which incorporates social, economic and environmental factors, it was their responsibility to ensure that the goal of protecting the lake was achieved in manner that would not cripple the farming or any other industry within the catchment. However, EW and the LTFT had a stronger sustainability view in serving the wider societal and planetary interests (Collins, et al., 2000) culminating into a whole system perspective (Hahn, et al., 2008). The farming view did not serve the wider interests of society compared to the definition that foresters and EW put forward. In saying that, there were discrepancies between how the foresters and EW viewed sustainability. Foresters wanted everyone in the catchment to be treated equitably in a social system by way of averaging nitrogen across landowners. However EW saw that this would ensure the farming sector would crumble and were in favour of grand-parenting as a model. The ambiguity in definitions (Hull, et al., 2003; Richardson, 1997; Rydein, 199) saw tensions created in the relationships between the three stakeholder groups. 


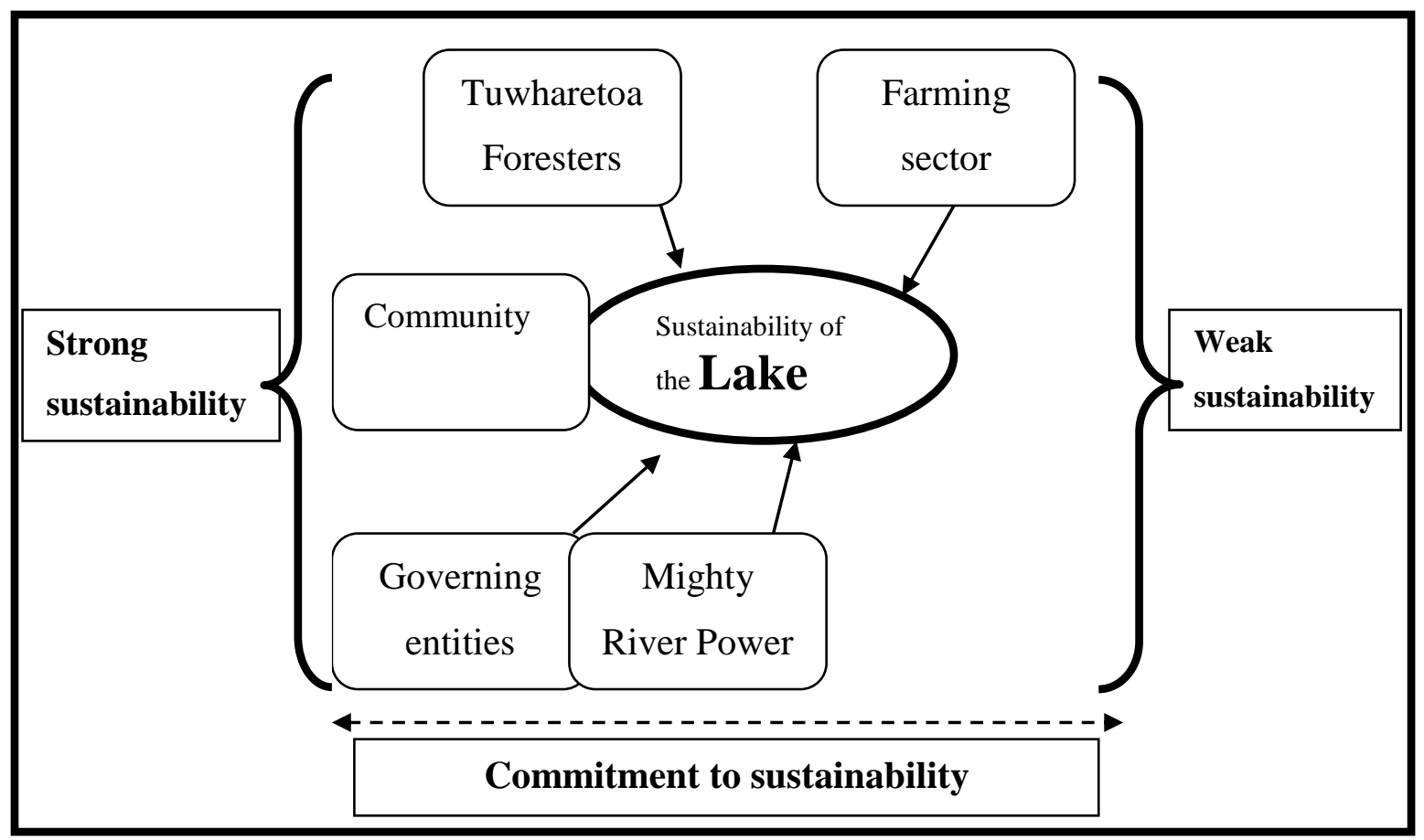

Figure 9 Stakeholders Commitment to Sustainability from Weak to Strong Sustainability

Stakeholders Commitment to Sustainability from Weak to Strong Sustainability in Figure 9 illustrates the differences between a selection of stakeholder groups and their positioning on a continuum of weak and strong sustainability. It can be said that even with entities positioned toward the strong sustainability end of the continuum, they all had different ideas on what sustainability meant to them (Collins et al., 2005). It is fascinating to view the positioning of Stakeholders Commitment to Sustainability from Weak to Strong Sustainability continuum in figure 9 with table 2 and the Main Stakeholder Groups perception of Sustainability. Obviously the Government entities had to consider their constituents needs, taking into account the benefits for the wider public enabling a strong sustainability mind-set. The farming community identified an ideal outcome of protecting the water quality in the lake, yet this still fits with a weak sustainability mind-set. The economic drivers to continue to increase profits on a farm do not align with a strong commitment to sustainability. Many farmers lived on the land and had a relationship with the environment in which they operated in, genuinely believing that their operations were in favour of strong sustainability. Comparing the farming view to that of the forestry sector and Tuwharetoa Foresters gives a stark contrast in mind-sets. The LTFT considered a total ecosystem approach which covered the people, planet and profit. As Maori stewardship, Kaitiakitanga, seeks to sustain: the people; the environment; and 
even though the foresters sought to generate profits on the land, this perspective still illustrates a stronger position on the sustainability continuum. The electricity generator MRP is positioned closer towards a weak sustainability mind-set as they are a company that utilised the environment to generate profits. The definition that they described incorporated the three tiers of sustainability being, economic, environmental, and social. However this mind-set is closer towards weaker sustainability even though they state that their definition is an all-encompassing sustainability.

The addition of Federated Farmers entering into the mix in the mid 2000's shifted the position of the farming sector more to the side of weak sustainability. The perception of sustainability that Federated Farmers held was purely a selfinterested position. The environment was not considered, it was purely the economics of the legislation and Federated Farmers mind-set was to fight the legislation that was developing within the catchment through the use of the media. This self-interested position halted the implementation of RPV5 and did not benefit their member farmers. Taupo farmers realised there was a problem with the lake, that was certain, and they wanted to find a workable solution. However Federated Farmers came into the situation in a corrosive manner. This division within the farming sector tore relationships apart within the rural community.

The first aim of this thesis was to determine the motivation behind stakeholders getting involved in the Protection Project and how they perceived sustainability. The individual perspective on how a stakeholder views the concept gives a good direction for the end goal for Lake Taupo. Some individuals saw the environmental aspect of sustainability ahead of any economic goals. It was evident that stakeholders were advancing their self-interested positions ahead of the interest of the lake. Having a multi-sector approach enabled a balanced view of sustainability to emerge, predominantly in the Environment Court setting when stakeholders heard the positions of other individuals and organisations. The majority of stakeholders from various industries ultimately demonstrated that their motivation to protect the lake was due to a connection with the area and it was the 'right thing to do'. In the end the reason to collaborate was to have their say, which is a form of self-interest. The regulation was in some way going to impact their business so rather than lock the gates they were prepared to have their say 
toward a workable policy. Even if that say was for the betterment of their individual benefit. Upholding the quality of the water in the lake was undeniably the motivation to collaborate for councils, Tuwharetoa trusts and groups such as LWAG. Diversity in stakeholders participating appeared in the literature as crucial for many environmental projects. These interactions are explored in detail in the following section.

\section{Multiple stakeholder interactions}

The involvement of so many stakeholders from a range of sectors posed various challenges and opportunities throughout the process. A hierarchy of stakeholders was evident in the engagement phase (Gable, et al., 2004) as CG, EW and TDC were the main funding partners along with TMTB who was the largest landowner. These parties were at the top of the hierarchy as the four partners had the authority to make final decisions and invested significant financial resources in protecting the lake. The power from these stakeholders had a huge influence in overall decision making (Mintzberg, 1983). 


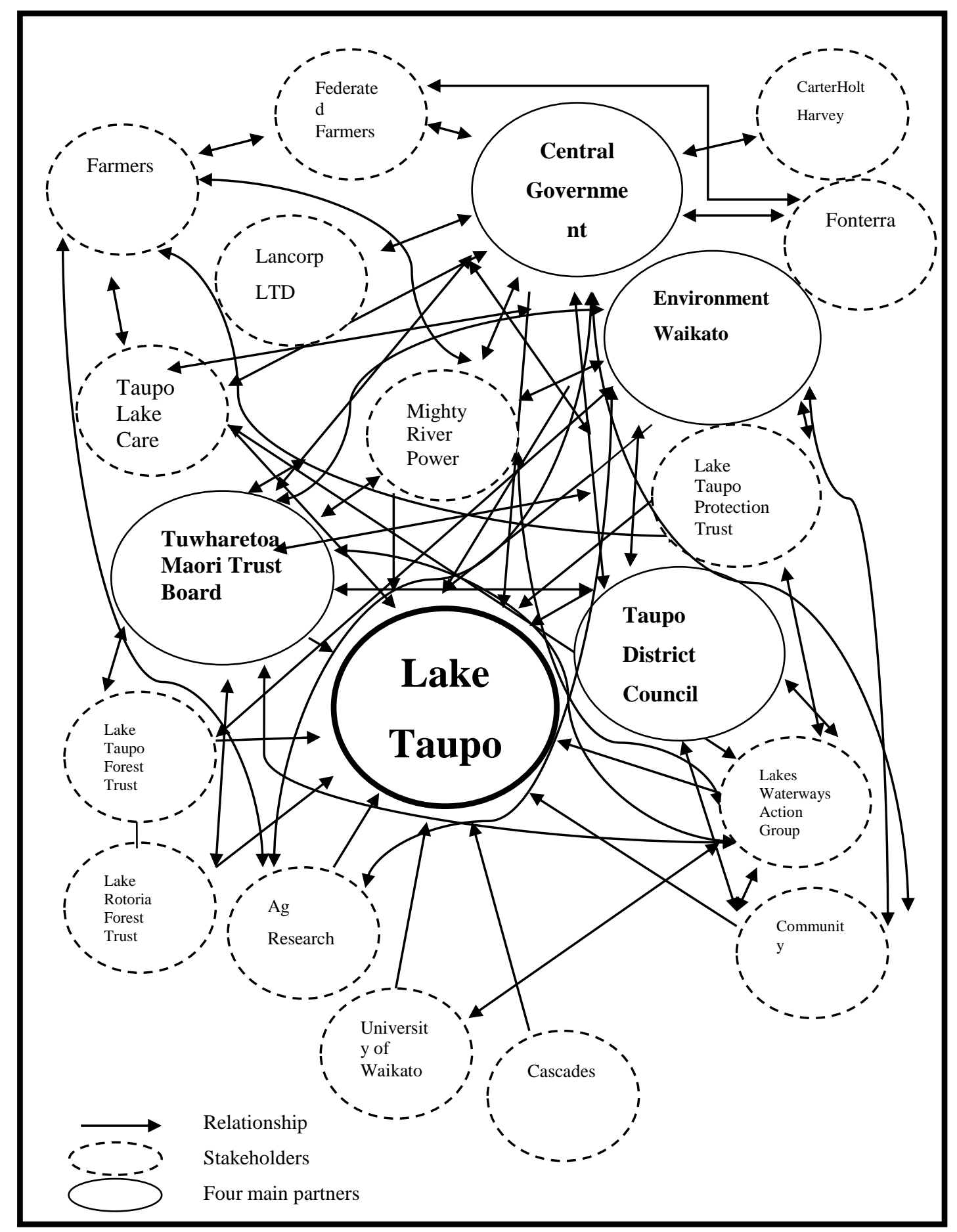

Figure 10: Lake Taupo Stakeholder Engagement Matrix

The interactions between the four partners and the diverse range of stakeholders can be seen in the Lake Taupo Stakeholder Engagement Matrix (figure 10). The intricate web of connections between all entities showcases who out of the stakeholders were working with each other and the nature of such a complex system. It was evident that some groups were given priority over others (Arnstein, 1969; Reed, 2008), mainly the farmers according to the LTFT. The challenge in trying to engage with so many stakeholders meant some felt left out. Many stakeholders commented on ideally having transparent and open dialogue 
throughout the decision making process (Reed, 2008) to ensure everyone is on the same page, even though in some cases a few stakeholders felt that this was lacking. The facilitators, as Fischer and Young (2007) point out, can have an unrepresentative selection of stakeholders. In this case farmers and foresters were not involved in the engagement process from an early stage and this was a detriment for progress in those early years to the on-going relationships. Over time EW worked on building trust through honest, open dialogue and this is particularly evident with TLC. This relationship came a long way since EW originally labelled farmers as the polluters early on in the process. However the relationship with foresters seems to be tarnished because the LTFT felt like they had not been listened to when it came to the 'averaging' argument. Foresters still feel that they were unfairly treated even though their actions were in favour of sustainable development and this is a view that they continue to hold.

The fact that so many public and private organisations were involved in the process (Leach, Pelkey, and Savatier, 2002) was a testament to the positive outcome of RPV5 and the creation of the LTPT. It means that the durability of the solution was far greater because of the large buy-in from stakeholders (Fischer, 2000). One of the strongest comments from many stakeholders was their ability to see others perspectives. Stepping out of their 'own shoes' and into 'someone else's' seemed highly valuable and enabled participants to see the legitimacy in others viewpoints (Reed, 2008). However this was not always the case and this was demonstrated by the sheer amount of time it took to create and implement a workable piece of legislation. In some cases seeing another stakeholders view point was very early on in the process, for others this did not occur until the Environment Court when they actually heard the perspectives of other stakeholders involved. Seeing the alternative perspective between farmers and foresters was noted as valuable insights for the two groups. This enabled groups to see where each other was coming from, even though both sectors stuck to their respective corners in the issue of grand-parenting versus averaging as a method.

The question needs to be raised, why did stakeholders not comprehend the perspectives of other stakeholders until the Environment Court? Numerous entities engaged in the years leading up to the Environment Court proceedings in 2008. Geoff from the LTFT commented on talking with officials about forestry 
concerns to then go to a meeting with EW councillors and be told that this was the first they had heard of any such concerns. Obviously there were breaks in channels of communication. The Lake Taupo stakeholder matrix visually documents the links between stakeholders and illustrates many channels of communication between entities. Yet stakeholders still did not understand the concerns of their fellow peers until the engagement process went into the court room. The lack of understanding demonstrates a failure in the engagement process in the lead up to the Environment Court. It seemed as though there were so many small clusters of stakeholder groups who were engaging separately which meant they were detached from the overall picture. This detachment meant entities in such small clusters were not able to gain a clear understanding of all stakeholder perspectives in the lead up to the Environment Court. So what could they have been done differently to avoid such a situation? The utilisation of external or even international mediators who could act as unbiased facilitators could have enabled an even platform for communication. The use of an Ag-research scientist to facilitate engagement between farmers and EW was viewed as a success in the early 2000's. Ensuring everyone was around the table, not just a select few who held the power over decisions, from the on-set with structured ground rules may have helped. This method certainly worked for small stakeholder groups such as LWAG who have a strong social cohesion within the community.

The bridging and bonding of social capital is evidenced in many groups in such a multi-sector environment (Boutlier, 2009). With stakeholders from central, regional and local government working with private organisations such as farmers and foresters, the ability to reduce hierarchical barriers and communicate as a group, built a strong foundation for social capital in such a complex system. The formation of TLC as a representative body for the farming community is an example of building and bonding such capital. The timeline in appendix one documents the creation of Taupo Lake Care as a community body to represent the farmers within the catchment in 2001. Having a collective voice as one organisation enabled streamlined communication. It also seemed that the farming sector was receptive when receiving communication from a community based farming organisation compared to communication coming from a regulatory body. Creating the group TLC, also built a social purpose for all farmers, rather than feeling like they had to engage as a private business individually. The group 
meant that they were able to gather support collectively which was beneficial for the farmers themselves.

There is also the example of a wider community group, LWAG, established to continue to educate and inform stakeholders primarily about environmental values, but also about economic drivers within the catchment. One such economic driver was the ability to assist in land use change. The uptake of groups such as LWAG trying to promote incentives was advantageous for the long term health of the catchment and added to the social capital between stakeholders. Examples of social bridging and bonding from LWAG included getting farmers alongside council to determine sustainable alternatives of land use to generate alternative income, to working towards promoting the tourism and heritage values of the farming community within the Catchment area. More investment such as financial or time resources needed to be given to entities such as LWAG who are fundamentally assisting in education of such a wide array of stakeholders as evidenced in their 'carrots for farmers' sessions. They are a group of diverse entities that were distributing information among stakeholders to help the productive sector move forward. This matrix of community based individuals should be seen as a model for further environmental management policies.

The modelling of economic, social and environmental implications and their impact on all stakeholders presented a complicated situation and the Taupo Catchment seemed to be complex system (Norberg, et al., 2008) because it was constantly changing and all the actors were interlinked (Kenney, 2000). The evolving situation was apparent in the realisation of having to increase nitrogen in 2010 from $153 \mathrm{~T}$ to $180 \mathrm{~T}$ due to the Environment Court. Tensions will be created in 2011 as the four partners determine where the extra funding will come from to reduce this extra amount entering the lake. Adaptive management sought to change the land use (Webb and Bodin, 2008) from intensive practices to more environmentally benign uses. As relationships formed between stakeholders they realised how the whole system interacts. Stakeholders were exposed to the perspectives off all the actors involved and this enabled a collective approach to policy development. The success seemed to be because policy development was brought down to a community level (Svendsen and Laberge, 2005). Including community based stakeholders enabled regulators to understand the perceived 
challenges that each sector was facing (Bernauer, 2002). Stakeholders who were going to be directly impacted understood how such a policy would affect them not only in the short term but in the long term as well (Androif and Waddock, 2002; Post, Preston, and Sachs, 2002). The community approach helped stakeholders to mitigate against the impacts as best they could during the short term so they could prepare for the future by looking at the business case.

\section{The Business Case - Reducing Uncertainty for a Sustainable Future}

An element of uncertainty was created because the two tiered regulation of an ETS and nitrogen trading scheme was not set in concrete, however a mix of businesses collaborating nonetheless was a positive step for the catchment. The matrix of business relationships included entities such as the LTPT, MRP and Tuwharetoa farming trusts who were promoting businesses as the 'engines of change' (Levy, et al., 2005) pushing toward a future of ecological modernisation (Hajer, 1997). The Taupo context suggests that businesses in an uncertain environment need to have the economic value of sustainable initiatives demonstrated. Sustainable business models are taken into consideration more so if they come from other businesses or parties that are seen to be detached from regulatory bodies. Uptake of such initiatives were aided by the LTPT and MRP promoting innovative business models for landowners.

As mentioned earlier, groups such as LWAG were also promoting talks such as 'carrots for farmers' for the productive sector to realise there were positive business models that were sustainable. A medium of community based communication is instrumental in transferring knowledge regarding sustainable land use. Community based communication was a beneficial initiative for EW when interacting with the farming community. Engaging with the community led group, TLC, enabled communication to diffuse out to all farmers. It would have been a lot harder for EW to communicate with farmers on a one-to-one basis. Engagement between EW and farmers enabled a new business model to be created (Hart and Sharma, 2004). Driving the economics of land use change is something that Derek Ryan from EW did not think was possible. 


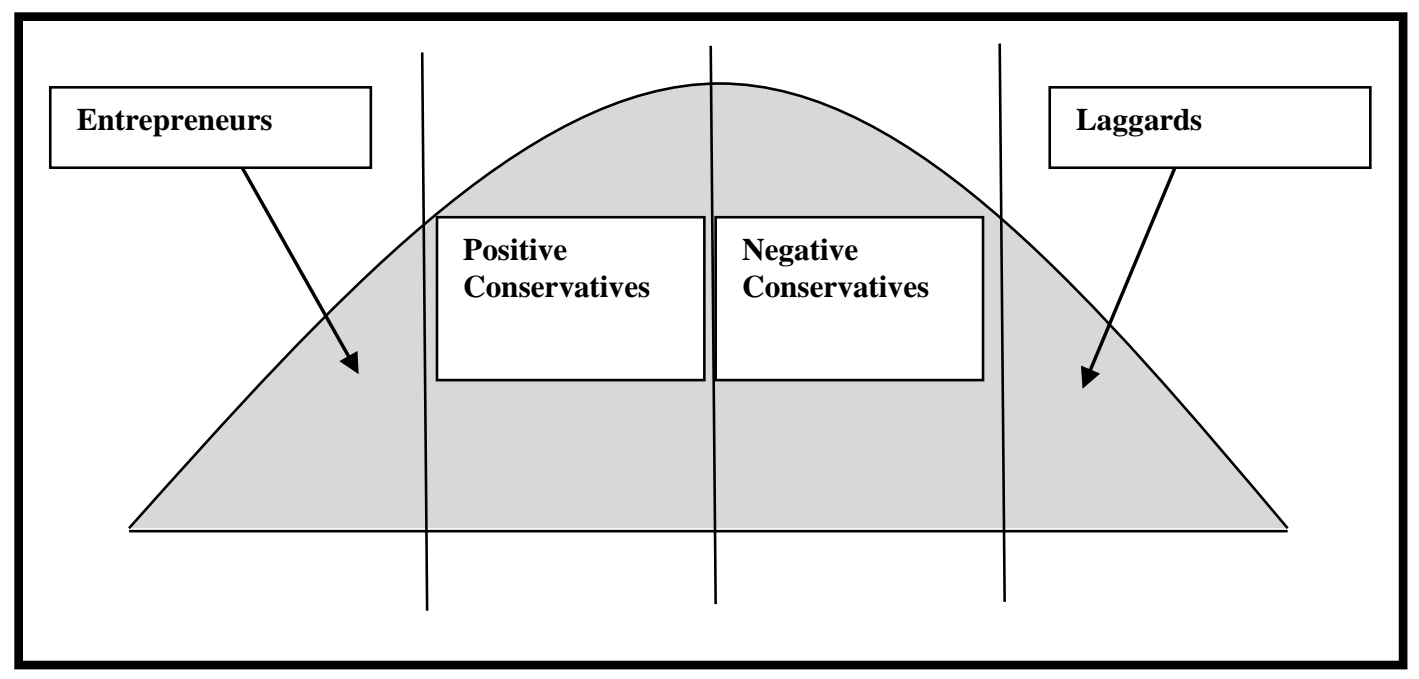

Figure 11 Bell Curve of Landowner Mind-sets within the Taupo Catchment

Yet the 'entrepreneur' type farmers recognised the opportunities to be made in innovative land use changes. As seen in the Bell Curve of Landowner Mind-sets within the Catchment (figure 11), the entrepreneurs were seen as first movers and acted as role models within the community. As more and more farmers saw these entrepreneurs generating higher revenues from sustainable initiatives, the positive conservatives and negative conservatives wanted to imitate so they too could increase their bottom line. Some farmers noted they would have liked to have seen voluntary compliance, however for the most part stakeholders felt legislation was required to force change (Berns, et al., 2009; Epstein and Roy, 2003) and the majority of the farming sector complied with the regulation.

The involvement of Graeme Fleming and MRP in coupling carbon and nitrogen trading for farmers was the biggest step forward for the catchment in reducing uncertainty. It was so significant in that it was the first time such an initiative had been utilised. The use of trading diffuse sources was a New Zealand and world first. Innovative uses for land were strategically going to be examples of positive land use for the rest for the country. These farmers were first movers and were voluntarily going above and beyond regulation (Csutora and Szenrenyi, 2008) while being able to mitigate against risk which was sound business logic (Berns, et al., 2009). The business case promoted was not just changing on-farm practices, it was causing a fundamental shift in the mind-set of farmers and the way they conducted their business. 
The biggest barrier was change (Brereton, 2003) and entities such as the LTPT communicated the benefits directly to farmers, Tuwharetoa trusts and other interested parties. The LTPT found they could educate stakeholders through the use of business terminology and knowledge transfer (Berns, et al., 2009; Brereton, 2003; Hopkins, 2009) by showing them how they could increase profits through alternative land uses.

Some farmers identified that it was in their best interest to satisfy customer needs, those needs related to a sustainable product that reflected New Zealand's pure reputation. Ensuring that a sustainable product was produced, incorporating animal welfare and carbon and nitrogen trading, reflected on a world class industry nationally and internationally. National and International market demands illustrated the pressure for New Zealand to produce an environmentally benign product and that it was consciously on producers minds to address that concern. RPV5 as legislation was helping farmers to achieve that goal and alleviate customers concerns, to a certain extent.

Sustainable business models for landowners in Figure 12 demonstrate how MRP and the LTPT were working alongside farmers to reduce the uncertainty under RPV5 legislation that was yet to be finalised. The retiring of farming land to plant in forestry meant the farmer received a payment from the LTPT and they could generate income from forestry. In addition to uncertainty around the regional legislation, it is also notable that MRP were creating long-term carbon contracts with large scale farmers, considering the uncertainty surrounding the ETS legislation on a national and international level, such contracts were unprecedented and MRP were first movers. 


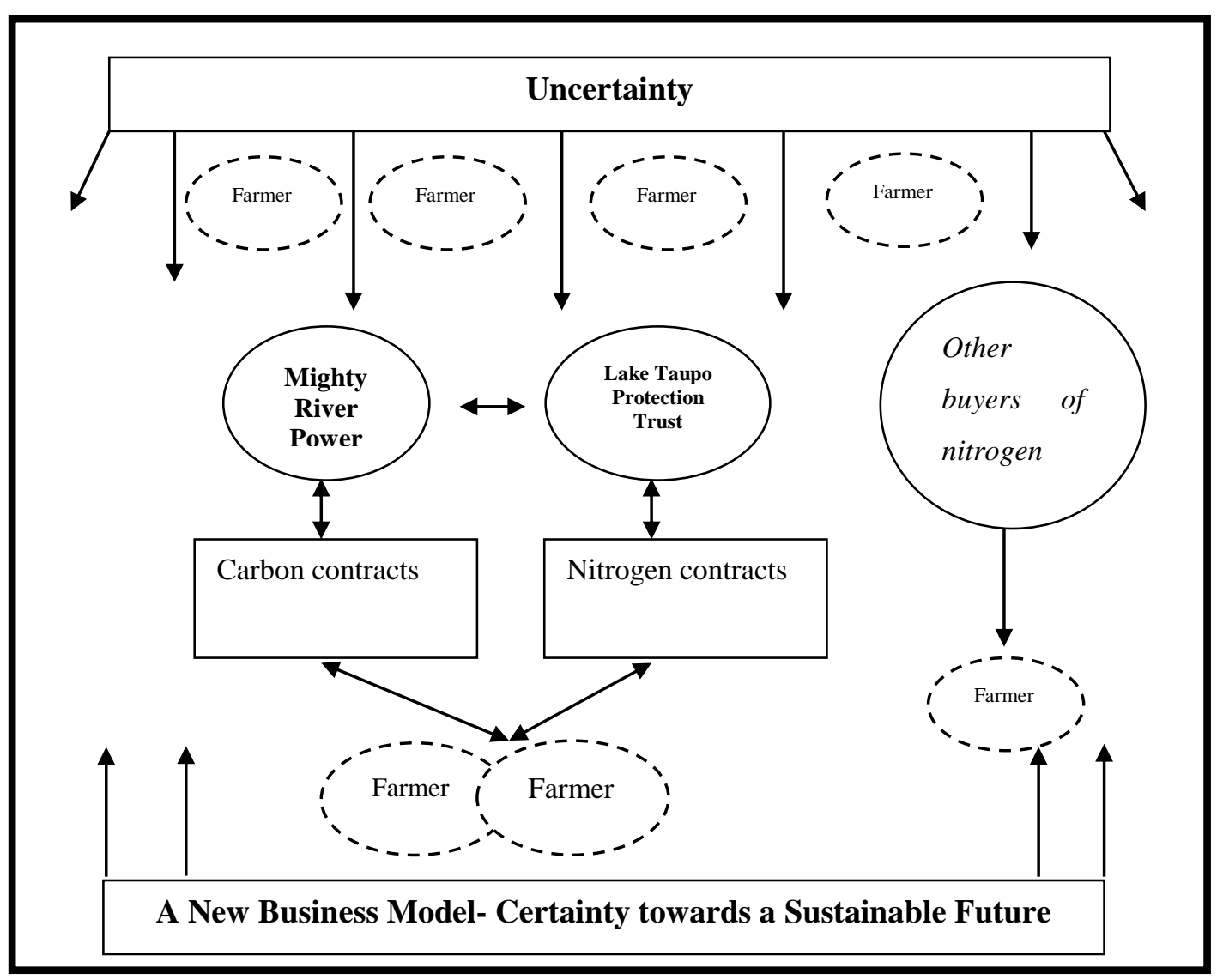

Figure 12 Sustainable Business Models for Landowners.

For an organisation such as MRP, the first mover advantage in trading carbon was a value added activity (Berns, et al., 2009). Taking such a long term approach reduced the uncertainty for them as an organisation in terms of purchasing carbon. The reason for such long term contracts was because the transaction costs are reduced due to the contracts being created to trade large volumes over a long term period. The ability to purchase carbon from a region in which MRP generated hydroelectricity was an initiative that would positively build on the stakeholder relations the company needed to maintain operations (Collins, et al., 2007). Natalie Haines from MRP noted this when she said stakeholder relations gave them the 'licence to operate.' The effect for MRP being involved in this project was: improved stakeholder relations: exposure on an international level; and protection of their ability to use the lake in perpetuity. The benefits for farmers and farming trusts included: alternative sustainable avenues such as trading carbon; a future that was not riddled with uncertainty and the ability to continue to farm in a profitable manner while the lake was being protected.

The business case for landowners was not initially viewed as compelling. Landowners, particularly farmers thought that regulators were wielding a stick at 
them as a punishment for polluting. It was through the actions of groups such as the LTPT, EW, LWAG and MRP who reduced such uncertainties and advanced sustainable business models for sustainable land use within the catchment. Individuals from EW, LTPT, LWAG and MRP have enabled landowners to see the business case and they became the first movers and entrepreneurs. The coupling of carbon and nitrogen led to the Taupo catchment becoming a low carbon and low nitrogen economy because of the involvement of these entities. Yet uncertainty and inequity was still apparent for some stakeholders.

\section{Uncertainty and inequalities}

The drawn out process in the final stages of RPV5 was not intended. The cause was due to groups such as Federated Farmers questioning wording of the policy. The continued questioning meant implementation of the legislation was not until 2011 when it was supposed to come into effect in 2008. EW sought to create a policy that was accepting of all stakeholders affected and represented what the community valued. The process of creating the policy was done in an integrative manner (Bührs and Bartlett, 1997; Hajer, 1997) and EW considered how the policy would impact on future generations (Connelly and Smith, 1999). By including farmers and foresters, the main groups impacted by land use changes, they developed legislation that compared and combined different approaches in a cooperative fashion (Hajer, 1997). There was however a downside as this was a lengthy process that created uncertainty for farmers and the LTPT.

Farmers had no certainty in the way they farmed from 2000-2010. The social impacts that uncertainty had on the farming community, for retirement and for future income, significantly impacted the rural community. The agricultural sector is one of New Zealand's largest exporters and to be a business in the catchment and then have a cap placed on productivity felt like a cap on farmers' incomes. It seemed the social implications were not fully considered. However the fact was the farming sector was one of the largest sectors discharging nitrogen in the catchment and that needed to be reduced. There was also inequality that existed between the landowners, as currently the larger landowners have the scale to be able to convert areas of their land into forestry to trade in carbon. Smaller land owners do not have the capacity to be able to initialise such large scale land 
conversions. This is particularly evident if larger landowners convert to forestry, as companies such as MRP had a minimum requirement of carbon that they would deal with, a requirement that small landowners could no contest. In saying this, all property-owners have the opportunity to sell their nitrogen to a buyer. This inequality between landowners was observed mainly between foresters and farmers.

The LTPT continued to operate and carry out their mission as if the legislation was in effect in the lead up to 2010, adding stability to the region with some farmers bravely stepping forward seeing the opportunity to be first movers. These 'entrepreneur' type farmers helped in pushing the community forward out of that uncertain paradigm. Once the policy was in place, that certainty in terms of farming and land prices and values will start to normalise within the catchment. The leadership that Graeme Fleming and the LTPT provided was enormously positive for the wider catchment. Promoting the business case for land owners to see enabled the start of wide spread land use change within the catchment.

The LTPT was an entity created towards the latter half of the engagement process and created in 2007.The. As the Protection Project was founded in the year 2000, the trust was formally established in 2007. On the Taupo protection timescale, as seen in appendix 1, it was a newly established entity. Formally detaching itself from EW was positive, even if groups such as Federated Farmers had tried to discredit the trust. Continuing on with the engagement process in finalising wording around RPV5 enabled Graeme and the LTPT to continue to fulfil the trust's mission even without concrete legislation. The role of the trust was to use public funds to reduce nitrogen levels by the 20 per cent agreed to by the funding partners. The process was innovative in itself as public money was being used to purchase private goods such as land and nitrogen. In that respect the Protection Trust was seen as using public funds in an efficient manner. This perspective was often contradictory as sellers of land and nitrogen wanted to be receiving the best deal for their commodity. However this resulted in some stakeholders viewing the trust as dubious because they were often the sole buyer of land and nitrogen.

The LTPT was recognized as an entity that was fulfilling its mission and creating innovative partnerships with the likes of MRP and Tuwharetoa farming trusts to 
secure carbon and nitrogen contracts. Some may have seen the Trust as the culprit in creating a social impact by removing farmers from the region and converting areas of pastoral farming into forestry or other low intensive land uses. It was the role of the trust to enact land change, and the social implications needed to be modelled and discussed earlier on in the process. Management and the facilitators of the engagement process should have taken the social and economic factors into consideration about how their decisions would impact stakeholders (Letcher and Giupponi, 2004). These impacts need to be modelled to satisfy stakeholder concerns and some stakeholders noted that this modelling was not conducted. Social impacts are something that future collaborative projects could take into consideration for similar engagement projects as it was high on the list of concerns from the farming sector.

Governance was important in generating the legislation that aimed to satisfy all stakeholders. Leadership from MRP and the LTPT should be commended in promoting a business case that reduced uncertainty. However the leadership from large businesses and industry bodies within the farming sector is contrasted to that of the above success stories. Lack of leadership from the farming sector is explored in the following section.

\section{Governance and Leadership}

The community strongly acknowledged that the lake was a resource that needed to be protected for future generations. The communities pressing concern enabled regulators to achieve a policy that would fit with that vision. A community based approach ensured that stakeholders understood the need to pursue sustainable development. With the financial involvement of all sectors of government; local, regional and central, collaboration at this level demonstrated the importance of the project and that the partners were willing to commit public funding to protect a resource that was being polluted by private entities. The process from 2000-2010 enabled all parties to come to terms with the challenges and opportunities from the policy intervention. Specific leaders and the impacts of their involvement or departure in the Protection Project are detailed with the lack of involvement from industry bodies within the farming sector finally examined. 
Continuity of leadership was an issue with many stakeholders. The changeover of councillors and employees in the three yearly election cycles were a challenge, more so for the education of the new councillors. The ten-year engagement process spanned over three election cycles and demonstrated the long term thinking of the three funding partners in continuing to push the project through. The changeover of councillors increased the level of uncertainty as to the motives of the new leaders within TDC, EW and CG. An example of this was the regional election of EW councillors in late 2010 where elected candidates were part of a rates control team. Stakeholders commented on the process slowing down as institutions had to educate incoming councillors about the Lake Taupo project and what had previously occurred in the project. The continuity of environmental policy did not really fit with political rationality (Bührs and Bartlett, 1997) as governments normally favour short-term thinking. In the case of the Lake Taupo Protection Project, it contradicted that theory as it showed the commitment of the funding partners and overall stability of the process. The continuing change of officials from the MfE was another factor that stunted progress. It meant that stakeholders had to update a new official in what stakeholders noted as periods every ' 3 months,' which lengthened the process. Credit particularly needs to be directed toward the leadership of EW in pushing the innovative project ahead in the late 1990's and early 2000's. Without EW's continued perseverance, the Taupo Protection Project might not have had so many stakeholders contributing valuable resources to protect the lake. The leadership of Graeme Fleming and MRP also can be noted as pushing innovative solutions for stakeholders to see the business case. Not only were farmers realising the positive alternatives for landuse, they were creating new economic models for the farming sector while protecting the natural environment in which farmers operate. This form of leadership was essential to support marginalised stakeholders in developing sustainable initiatives. This was further from the truth when it came to some industry players within the catchment.

\section{Leadership from Industry}

One of the biggest disappointments for many stakeholders was the lack of engagement from large organisations that could influence and represent industry interests. Federated Farmers and Fonterra engaged at a very late stage, so late it 
was in the Environment Court and many of its members noticed this lack of involvement early on. $\mathrm{CHH}$ was another large business who sold-out of the Catchment and decided to get involved in the Environment Court hearing due to the possibility of precedent setting. The question was why were these large entities not willing to get involved at a very early stage? MRP realised how important it was to maintain stakeholder relationships and take that first step to be considered first movers in trading carbon. Federated Farmers, Fonterra, and $\mathrm{CHH}$ had more to lose if they did not engage early on, and that was exactly how it eventuated. The three large organisations 'ring fenced' the catchment until they understood it could become precedent setting. When they did get involved it was too late to have any meaningful impact.

Large business can act as positive role models, and considering this was directly impacting their members, they should have played a part. The lack of leadership left many, particularly the farming community, feeling abandoned. The mindset of these larger businesses showed short-term thinking and that they did not consider long-term opportunities they have missed out on. The bailing of Land Corp was another industry leader who created a feeling of neglect for farmers. As a government controlled entity, they could have developed leading farming strategies for land use change under a cap. This was not on the minds of the board who agreed to sell their land and get out of the catchment.

The observed lack of the tourism sector in engaging in the protection of the lake was a group that was not involved. Considering this was the biggest contributor to GDP in the catchment, why were tourism operators not involved? The TDC and CG could possibly be seen as representing the needs of the tourism sector, but it would have been beneficial in having a tourism stakeholder who was tangibly involved. The lack of involvement from such large entities that could have represented their farming members ultimately let down the rural community. Here was an example when business could have acted as the 'engines of change' or at least represent their constituents and instead opted to ring fence the Taupo catchment as it did not impact the majority of their members, and this was further from the truth. Leaders should effectively listen to their constituent groups to understand their position. In the case of society's opinion within New Zealand and in the Taupo Catchment, local and regional governments listened to the 
community's opinions that had been changing as society became increasingly aware of environmental problems which are discussed below.

\section{Dynamic nature of societies changing opinions}

Another theme that emerged through the findings was the nature of communities' opinions and perceptions and how they have been changing within the New Zealand context. Farming traditionally has been viewed as invincible as the backbone of our economy. However the natural environment that supports the farming sector needs to be protected for the tourism value that it generates. The marketing campaign of being clean and green is not living up to the reputation that we have promoted to the rest of the world. With recent articles exposing New Zealand's disingenuous marketing campaign (Bennett, 2010; Cumming, 2010; Gibson, 2010; The Economist, 2010; Pearce, 2009) a global shift in the way resources are managed is occurring. This filtered through to the Taupo Catchment where the community realised businesses cannot continue to operate as 'businessas-usual'. A fundamental change in society's mind-set and in regional councils thinking is occurring. This change is what New Zealand as a country needs to be able to balance economic performance with environmental protection to silence the critics.

The description of a range of lake management cases was described within the literature review section. These cases enabled a comparison to be made and showcase the initiatives that are truly innovative within the Taupo context.

\section{Lake Taupo and its comparison to international water management cases}

Bernauer (2002) discusses how environmental resource management relies heavily on community and local stakeholder groups working in an intricate manner to advocate for protection of a resource. This is exactly what occurred within the Lake Taupo Catchment and EW took charge in taking the issue to central government, which meant the uptake of stakeholders collaborating was higher because of national leadership (Bernauer, 2002). 
The process that occurred in Latin America with Lake Chapala is relatively similar in that it was the community who wanted to protect the lake because of an algal growth that threatened recreational use. A range of public and private entities collaborated and regulated to protect the lake, but the Chapala case illustrates how the control and access of water resulted in the hands of a few, left the needs of the poor not being met. The Lake Ulubat case in Turkey showcased a non-regulatory approach which was successful in a multi-sector approach. All of these cases use stakeholder collaboration for protection initiatives, but the Taupo Catchment is different in that a trust was set up to administer public funding from three levels of government to initiate land use change. The LTPT was involved in trading nitrogen and working alongside other businesses to also trade carbon. In addition, the Taupo context showcases an innovative mechanism with a multisector engagement phase spanning over 10 years from 2000-2010 to develop a policy, RPV5, to regulate landowners in their leaching of nitrogen into Lake Taupo. The trading of diffuse sources is a practice that has not been trialled anywhere else in the world. This long-term approach seeks to create a catchment where industries can still operate in an environmentally benign way. As a result of this regulation, stakeholders have invested in creating a low carbon and nitrogen economy by seeing a business case for sustainable development. The next section is a summary of the discussion chapter before the theoretical contributions are explained.

\section{Summary}

The Taupo Protection Project presented itself as an undertaking which continually evolved and developed into an innovative context. The self-interested definitions of sustainability that stakeholders described enabled them to create a future that was specific to their own needs. The eventual outcome of RPV5 and the creation of the LTPT were positive for the future health of the lake.

The engagement process demonstrated the lack of comprehension when it came to seeing others perspectives. In some cases stakeholders were not able to understand other positions, yet it was mainly at the Environment Court when all stakeholders heard each other's true perspectives. Some stakeholders felt that their sectors future was significantly compromised. The involvement of business in 
encouraging landowners to develop sustainable business models aided in reducing such uncertainty, particularly working with farmers and Tuwharetoa farming trusts in trading nitrogen and carbon. The leadership that MRP, LTPT along with EW enabled stakeholders to see past the uncertainty. The leadership from the farming industry was another story. Lack of engagement at an early stage left their farming members unsupported and the rural community struggled to understand why such farming groups who were supposed to assist them left the catchment.

The fact that so many stakeholders engaged in a multi-sector setting has been replicated in other international lake management contexts. The unique aspect with the Lake Taupo Protection Project was that it demonstrated a world first approach, with legislation that prohibits landowners to exceed their nitrogen leaching limit in the form of a cap and trade policy. Thus lake water quality levels expect to stay at 2001 levels. The establishment of the LTPT was another innovative initiative that saw public money utilised to initiate land use change. The collaboration of public and private entities ensured sustainable development will continue within the Taupo Catchment area.

The subsequent section will conclude with theoretical contributions and go on to examine the implications for business managers and future policy makers. 


\section{Chapter VI: Conclusion}

\section{Theoretical Contribution}

The research question that this thesis set out to answer was how a multiple stakeholder perspective affected the business case for sustainable development. Interviewing a range of stakeholders from the Lake Taupo Catchment and gaining diverse perspectives from those stakeholders who were involved in the engagement process over the years of 2000-2010 has enabled the Lake Taupo Catchment case to be complied. The involvement of such a range of stakeholders has ensured the creation of a policy that incorporates, as best it can, the needs of all sectors within the community.

The development and creation of RPV5 attracted more stakeholders and businesses to take advantage of the opportunities that such an innovative policy provided. The aim for the catchment is to create a low carbon and low nitrogen economy. MRP and the LTPT were able to collaborate in delivering sustainable opportunities for the parties impacted by the policy to ensure that farming and forestry are viable industries that can operate within the catchment.

The research aims were to:

1. Determine the motivation behind stakeholders engaging and their view of sustainability within the catchment area.

2. Determine the effect that involvement has had through engagement and how this has affected stakeholders business or view on various businesses.

3. Explore the relationship between collaborative stakeholder engagement and sustainability.

These three aims will be summarised before the implications for managers and future policy makers are discussed in the subsequent section of this chapter. The interviews revealed the key motivation of most stakeholders to collaborate was an historical link to the region as they wanted others to share in their surroundings with future generations. Such a link was primarily the reason stakeholders wanted to protect the lake for future generations. A select few said that their motivation for protecting the lake was because it was the 'right thing to do'. 
Interviewing a wide range of stakeholders ensured multiple perspectives of the engagement process and the challenges and successes involved in the process towards a vision of sustainability was included in the case study. The research confirms previous studies demonstrating the complexity in the relationships between stakeholders engaging to manage and protect water resources (Rydin, 1999). Many stakeholders held a self-interested view of sustainability for their own policy demands. The self-interested position was consistent with the findings of many scholars in the inter-changeability of the term which hindered progress in policy development (Banerjee, 2000; Bendell, 2000; Hull, et al., 2003; Rydin, 1999; Vionoz, 2008). However I would disagree with Rydin (1999) who argues definitions of sustainability need to be ambiguous as it enables all stakeholders to reach a mutual position. In the Taupo Protection Project such ambiguity of the term led to stakeholders maintaining a firm position that did not change. Even at the Environment Court the arguments of the Tuwharetoa Forestry Trusts and the Farming groups were conflicting. Obviously stakeholders needed to convey their perspectives but they were choosing areas of sustainability which suited them such as promoting economic arguments over social aspects.

All stakeholders said they wanted to protect the lake, some were more genuine than others and this was consistent with Boutilier (2009) and his findings which encapsulates the relationships that stakeholders share between the natural environment and future generations. Having such varied stakeholder needs led to governing bodies making trade-off's which created a sense of inequity and uncertainty between stakeholders. Some of that inequity was unavoidable as not all stakeholders were going to be able to get what they wanted. EW, TDC and CG listened to all stakeholders and their perspectives to create a policy that looked at the contradictory approaches and ended up comparing and contrasting positions which was consistent with Hajer (1997) in trying to develop an all-encompassing policy.

The establishment of the Taupo-nui-a-tia initiative in 2000 by Tuwharetoa, TDC, EW, LWAG, and DOC in a joint committee was the first collective group who sought to survey the community on water values. This non-regulatory drive was the initial project that identified how strongly the community felt about protecting 
the lake and maintaining water quality levels at 2001 levels. The community's perception of sustainability and their advocating for the protection of Lake Taupo is consistent with many river and lake management cases (Bernauer, 2002) as they were the main drivers for the Protection Project to progress. This research has demonstrated the diverse understandings of sustainability that stakeholders share and the implications that this diversity has while engaging. It is important for stakeholders to share their perspectives, managers and policy makers need to be able to understand where the stakeholder is coming from to be able to move forward in a productive manner.

The second aim sought to determine the effect that involvement had through engagement and how this affected stakeholders business or view on various businesses. The main stakeholder businesses interviewed within this thesis were from the forestry, farming and electricity sectors. Foresters felt as though a hierarchy of stakeholders was created and they were not placed at the top of that hierarchy in the early 2000's. It seemed in those early years (2000-2001) the decision-makers did not fully comprehend the business impacts of not engaging with all stakeholders which Saint (2005) finds can be detrimental as stakeholders can feel marginalised.

The four main partners being the TMTB, EW, TDC and CG were working together and stakeholders, such as foresters and farmers, felt excluded. Such exclusion resulted in the LTFT and LRFT having differing mind-sets regarding sustainability to that of farmers, and the forestry groups began to feel marginalised. Foresters felt as though they were locked into forestry forever with the grand-parenting method. In contrast to this, farmers felt if averaging were to be chosen as a method, farming would become unviable in the catchment. These two stakeholder groups competed for the attention of EW, TDC, and CG with conflicting perspectives. Learning to appreciate the legitimacy of each other's perspectives is how Reed (2007) explains will enable adversaries to transform their relationship. In the case of the Taupo Protection Project, farmers did not understand the forestry perspective until the Environment Court. Farmers invited the forestry sector along to TLC meetings and still maintained their strong stance. Current literature does not aid in reducing such conflicts as many authors state trust, commitment, open communication and co-operation aid in developing 
relationships (Gao and Shang, 2006; Reed, 2008; Strand, 2006; Stringer, Prell, Reed, Hubacek, Fraser and Dougill, 2006). Yet in cases where the eventual outcome impacts on a stakeholder's livelihood there are bound to be selfinterested perspectives for survival that will hinder policy development. It seemed that the only way stakeholders understood all perspectives was when they were in front of a judge at the Environment Court where each stakeholder group was paying a lawyers to negotiate. The court setting needed to be replicated earlier to ensure a more efficient understanding of stakeholder perspectives while all being in the same room.

The farming sector in the catchment was the main source of nitrogen leaching into the underground waterways and lake. The pressure on them as business people to change their management practices caused serious unrest. It also created strong aspects of de-motivation in a farmer's ability to farm and created uncertainty for their future. There needed to be more support mechanisms available for groups who were impacted by policy implications and in the Taupo case, even though farmers were the main source of pollution, they needed to be supported. Whether the support was in the form of accurate social and economic modelling or ensuring there was a support network available for all landowners impacted.

The socio-economic factors are extremely important and need to be given more prominence within environmental engagement projects. The isolation that farmers experienced, particularly when they felt the urban community were pointing the finger at them as polluters, caused stress and discomfort. The practice of letting stakeholders come to deal with the policy in the engagement stage reduces such stakeholder fatigue (Burton, Goodlad, Croft, 2004; Duanne, 1999; Payne and Calton, 2002; Reed, 2008). However the social impact of policy implications impacted on select stakeholders, which meant they felt there was no support. This resulted in a lack of confidence for farmers and the promotion of a culture encompassing uncertainty. It is therefore imperative that facilitators ensure effective interventions to reduce such feelings of angst within future engagement schemes.

The third and final aim planned to explore the relationship between collaborative stakeholder engagement and sustainability. Collaboration among stakeholders for 
environmental management of water resources has been documented nationally and internationally (Bernauer, 2002; Kenney, 2000; Leach, Pelkey, and Savatier, 2002; Letcher and Giupponi, 2004). Natural systems are complex systems (Hahn, Schultz, Folke, and Olsson, 2008) and the Lake Taupo Case was the first time a multi-sector group had created an innovative cap and trade piece of legislation that dealt with diffuse sources of nitrogen pollution. The creation of the LTPT aided in land use change by promoting the business case was again another initiative that enabled a successful outcome.

The fact that fringe stakeholders, fringe being stakeholders who are outside the main Taupo Protection Project such as MRP, aligned with the LTPT to couple nitrogen and carbon trading so land owners could generate sustainable revenue streams had not been observed anywhere in the world. Collaboration between MRP and Tuwharetoa farmers enabled MRP to have a licence to operate (Hart and Sharma, 2004) within the community. Such collaboration supported the development of new business models that reduced landowners' uncertainty about future income and increased their businesses viability within the catchment. The business case was extremely important within the Taupo context as it enabled stakeholders, predominantly private entities, to see the economic drivers to continue to operate. Once entities such as the LTPT had worked with a few landowners who decided to change their management practices, these entrepreneurs were observed by the rest of the community and slowly other landowners began to change to more environmentally benign land uses. Many authors noted communicating the links between environmental stewardship and economic performance enabled landowners to see the business case (Berns, et al, 2009; Csutora and Szerenyi, 2008; Epstein and Roy, 2003; Hopkins, 2009). The development of sustainable business models would not have occurred without the engagement of diverse 'fringe' stakeholders and this therefore extends the literature. Ensuring community groups and other business who can act as 'engines of change' can communicate the economic, social and environmental benefits to landowners has a stronger uptake in sustainable initiatives than if it was communicated from regulatory authorities. 
The overall research question of this thesis along with the three research aims have provided the implications for future environmental engagement projects which are described in the following section.

\section{What are the Implications for Policy-Makers, Business Managers and Researchers}

The ten-year process that evolved in the Lake Taupo Catchment provides policymakers and managers some valuable guidelines for future environmental engagement projects. Obviously proactive environmental strategies are going to be context specific. There have been some unique characteristics that are particular to the Taupo region which are not similar for future projects. Some unique features include: the porous nature of the soil; the commitment from all levels of government in terms of funding; and the volcanic nature of Lake Taupo itself. The following are implications that can be applied to other environmental management situations. The first section will detail the implications for policy makers with the subsequent section detailing the implications for business managers, before a range of questions for further research are noted.

\section{Policy Makers}

The Taupo Protection project details world first initiatives and interviewees from TDC and EW stated there was interest from regional councils within New Zealand and overseas. The following detail guidelines for Policy Makers involved in environmental management projects. A Matrix of Multi-Sector Stakeholders 
Engaging towards Sustainable Development is detailed in Figure 13.

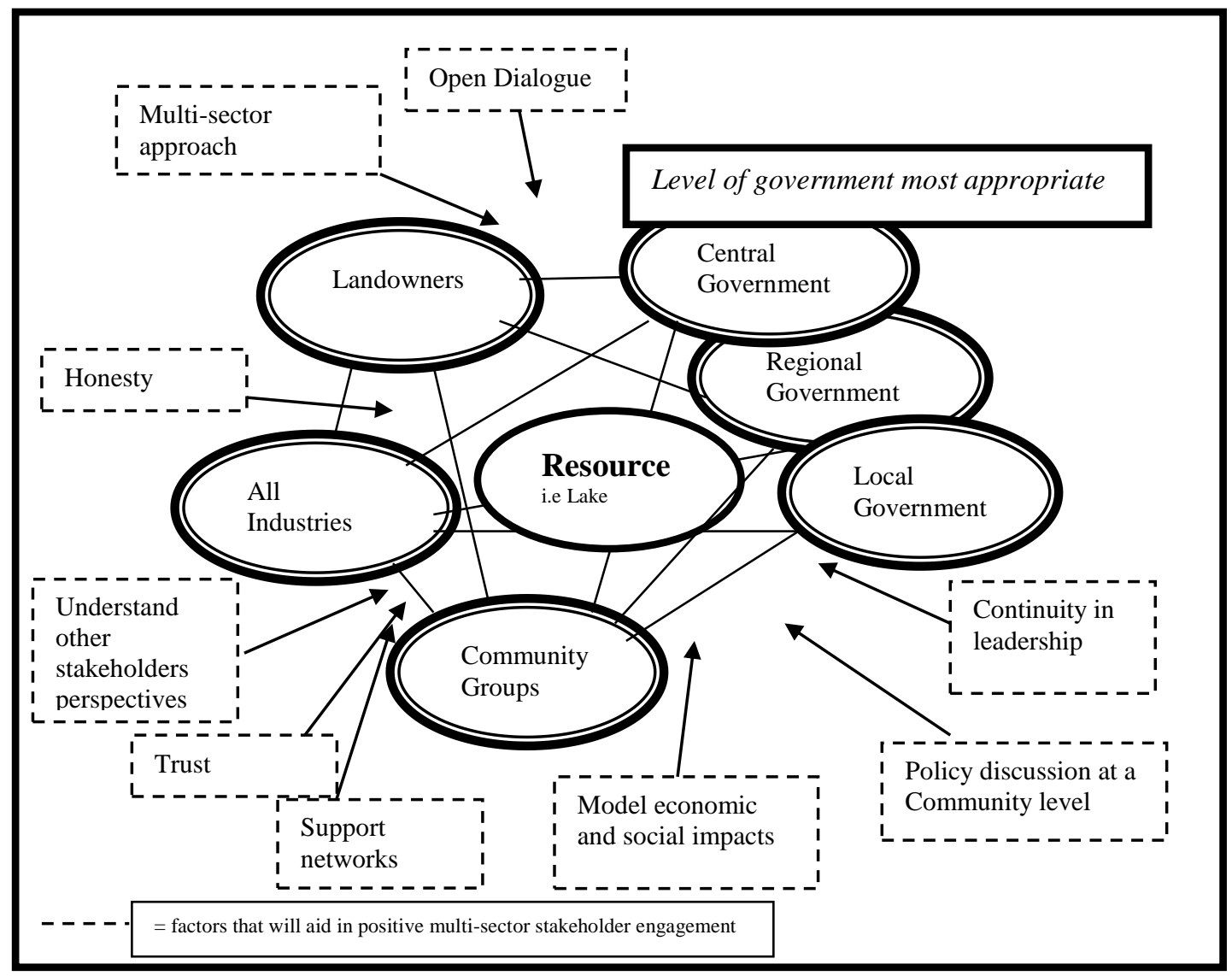

Figure 13: Matrix of Multi-Sector Stakeholders Engaging Towards Sustainable Development. The Learning's from the Lake Taupo Protection Project.

The fact that Lake Taupo is a public and private asset ensured there were public and private entities engaging throughout the ten year process. A multi-sector approach has guaranteed a diverse group of entities worked towards the protection of the lake (Everett and Jamal, 2004). This multi-sector approach is of particular importance as it ensures a systems view is adopted which is more network focused, rather than a mechanistic perspective which sees the problem in parts. With everyone in the room engaging it develops trust, and open dialogue meaning stakeholders can speak freely while engaging. Marginalised groups need to feel as if they are integrated within conversations and they cannot be pushed into a particular position. Time is important and as the Taupo Case illustrates, marginalised groups need to be given time from facilitators and the engagement process to come to terms with policy implications and its impacts. Adequate support needs to be offered to stakeholders that policy will impact. 
The next factor is community based discussion regarding policy creation as it is essential in creating workable legislation for sustainable development. The stakeholders involved will be subject to the legislation, and in gaining their perspective enables a policy that considers all angles. Engaging at a community level breaks down the hierarchical barriers, develops trust with all parties and builds social capital amongst stakeholders. Developing social capital will aid in continuing positive relationships between all parties involved, particularly when private and public entities are identifying strategies for sustainable initiatives. Building social capital amongst engaging parties aids in reducing the uncertainty and isolation for groups who feel vulnerable from the policy. It therefore seems strategically beneficial to have as many stakeholders from the community involved as possible to mitigate against a backlash to the policy post the implementation phase.

Continuity in leadership and governance is fundamental to the project staying on track. This factor ensures that all stakeholders understand who they need to talk to and what is occurring throughout the process. In the case of the Lake Taupo project, the changeover in leadership stalled and prolonged the process. In some respects that gave stakeholders extra time to comprehend the impacts of policy. But overall the implications of changing councillors and officials often delayed the progression of the project which irritated stakeholders. For future projects it is important for stakeholders to know who is in charge and view stability in the leadership team who is facilitating the process.

The involvement of industry in the engagement process is vital in gaining a workable solution for business. Industry was not present in the early stages of interaction amongst stakeholders in Taupo until it was too late. Fonterra, Federated Farmers, Landcorp Ltd and even Meat and Wool were groups who should have engaged at an early stage to represent their members. Businesses can be the 'engines of change' and this was evident with MRP and the LTPT encouraging farmers to adopt sustainable solutions within the catchment. I would disagree with the CEO from Landcorp who said early on in the process you only want a small number of stakeholders in a room so you can deal with them on a one-to-one basis (Yurex, 2010). Later down the track when the specifics need to be negotiated this approach could be useful. To have stakeholders detached and 
engage with them individually does not give a diverse perspective and in this case it did not work with the foresters and farmers. Larger businesses could have a different comprehension of what stakeholder engagement means if they only want to engage one-on-one, however business needs to recognise the benefits of this all-encompassing new model.

It seems important for stakeholders to see modelling of the social and economic impacts on the wider community. Economic modelling was conducted by EW at an early stage in the process and stakeholders, particularly the farming sector, felt that this was not accurate. To satisfy all parties involved, modelling of the social and economic impacts on all industries would show a true picture of policy implications within the community. Governing bodies should be concerned about the wider implications of policy and such modelling would at least satisfy the majority of stakeholder queries and assist as the base for further economic and social studies.

These factors will assist policy makers in their pursuit of engaging multiple stakeholders in an environmental Protection Project. The next section illustrates the implications for business managers for similar contexts.

\section{Business Managers}

The Taupo Project documented public and private entities who engaged toward a sustainable future. Managers from the forestry, farming and electricity generation industries observed the process from a business outlook. Not all managers can appreciate each other's views as many perspectives are self-interested in nature. The culmination of businesses and their individual perceptions of policy implications aid in regulatory authorities understanding the impacts directly. Therefore if a business is potentially impacted by a policy, managers need to engage to give their views for government to understand their position.

It is also important for managers to understand the economic implications of any policy and the impact it will have on their business. Economic modelling should be provided by regulatory authorities creating the policy, if not this needs to be 
advanced to reduce the uncertainty that businesses could face under policy conditions as they can see the economic impacts first-hand.

In a context where the outcome is in favour of sustainability, business should be provided the tools to develop a business case for sustainability. Diverse individuals and businesses that enable the productive sector to see sustainable business opportunities are exemplary leaders. The fact that many of these opportunities were promoted by entities within the community enabled a higher uptake of such initiatives. It seemed if initiatives came from entities other than regulatory authorities than business were more perceptive to adopt such ideas. This was evidenced through the involvement of the LTPT and MRP. The involvement of multi-sector groups promoted the business case and created new business models for landowners in the Lake Taupo Protection project. New business models that reduced nitrogen intensive land use to provide revenue streams from trading carbon and nitrogen trading are the biggest advantages from the creation of the RPV5 policy. The involvement of business in policy creation was important in developing a workable solution for all stakeholders.

The subsequent section lists questions for researchers to consider.

\section{Researchers}

In undertaking research for this thesis there are questions that have emerged for additional study. These include;

- Understanding why Landcorp Limited did not stay within the catchment to develop strategies for farmers operating under a cap. If they are leaders in developing innovative solutions for farm management then the situation in Taupo could have enabled them to develop such innovative strategies.

- Gain the perspective of Fonterra and Federation Farmers in why they did not engage and work to represent their farming members early on in the process.

- Determine the implications on the relationship between EW policing RPV5 and the individual landowners NMP. From 2000-2010 the process 
has been based on developing a workable policy and recently benchmarking landowners and their NDA. When the legislation is finalised it will be EW's job to ensure farmers are sticking to their NMP and any agreements formed with the LTPT. The inequality between landowners may cause neighbours to report farmers who are not complying with their NMP which would cause tensions between stakeholders.

- Ascertain the implications of increasing the total tonnage of nitrogen to be taken out of the lake increasing from $153 \mathrm{~T}$ to a new estimate of $180 \mathrm{~T}$ and how this affects the funding partners.

These questions raised are recommended for future researchers to continue to understand the evolving context of the Protection Project within Taupo catchment.

\section{Final remarks}

The protection of Lake Taupo illustrates the continuing evolution of a case where stakeholders interact in an unfamiliar situation. A low carbon and nitrogen economy was created and a diverse group of entities collectively engaged toward that vision which ensured the lake will continue to be enjoyed by future generations. However, in the process of achieving that goal; a number of stakeholders were shrouded in uncertainty from regulation; several saw a business case and worked together to try to reduce that uncertainty, whilst a number left the catchment in an attempt to relocate to other areas with lax environmental regulations. The entities that have left for greener pastures will soon find that they cannot continue to discharge pollutants as the changing opinion of society leads to stricter environmental laws nationwide. For New Zealand to continue to maintain its pristine environmental reputation it needs to take a collective approach in changing the way businesses operate. As a country, all industries need to affirm leadership in the area of environmental protectionism to uphold New Zealand's position as a highly sought after tourism destination. Similar proactive environmental strategies are going to be utilised by regional councils on a national and international scale. The learning's from this process are beneficial not only for similar catchments but for any environmental protection projects as it has been identified that businesses can act as the 'engines of change'. 


\section{References}

Agyeman, J., \& Evans, B. (1994). The New Environmental Agenda in Agyeman, J. And Evans, B. (Eds) Local Environmental Policies and Strategies. Longham: Harlow.

Alexander, G. (1998). Environmental Politics in New Zealand/ Aotearoa: Clashes and Commonality Between Maoridom and Environmentalists. New Zealand Geographer 54(1), 19-26.

Alexander, R. J. (2009). Framing Discourse on the Environment: A Critical Discourse Approach. New York: Routledge.

Andriof, J., \& Waddock, S. A. (2002). Unfolding Stakeholder Engagement. In J. Androif, S. A. Waddock, B. W. Husted, \& S. S. Rahman (Eds.), Unfolding Stakeholder Thinking. 1. Theory, Responsibility and Engagement. Sheffield UK: Greenleaf Publishing.

Andriof, J., Waddock. S., Husted, B., \& Rahman, S. S. (2002). Introduction. In Andriof, J., Waddock. S., Husted, B., \& Rahman, S. S. (Eds), Unfolding Stakeholder Thinking: Theory, Responsibility and Engagement, (pp. 1-315). United Kingdom: Greenleaf Publishing Limited.

Antaki, C., Billig, M., Edwards, D., \& Potter, J. (2002). Discourse analysis means doing analysis: a critique of six analytic shortcomings. Using thematic analysis in Psychology, Discourse Analysis Online [electronic version], 1(1).

Arnstein, A. (1969). A ladder of citizenship participation. Journal of the American Institute of Planners, 26, 216-233.

Aronson, J. (1994). A Pragmatic View of Thematic Analysis. The Qualitative Report,2(1), $1-3$.

Banerjee, S. B. (2000). Whose land is it anyway? National interest, indigenous

Bansal, P., \& Roth, K. (2000). Why Companies go Green: A model of ecological responsiveness. Academy of Management Journal, 43(4), 717-736.

Barrington, R. (2001). Biodiversity: New trends in environmental management. Corporate Environmental Strategy,8, 39-47.

Beacon (2009). The need to save water. Wellington, New Zealand: Beacon Pathway.

Becken, S., \& Simmons, D. G. (2002). Understanding energy consumption patterns of tourist attractions and activities in New Zealand. Tourism Management, 23, 343354. 
Benbasat, I., Goldstein, D. K., \& Mead, M. (1987). The Case Research Strategy in Studies of Information Systems. Management Information Systems Quarterly, 11(3), 369-386.

Bendell, J. (2000). Business, NGOs and Sustainable Development. United Kingdom: Greenleaf Publishing Limited.

Bennett, A. (2010, June $\left.6^{\text {th }}\right)$. Tourism and dairying set for 'terrible collision'- Greens. The New Zealand Herald. Retrieved from http://www.nzherald.co.nz/nz/news/article.cfm?c_id=1\&objectid=10650103

Berent, P. H. (1966). The Depth interview. Journal of Advertising Research, 6, 32-41.

Bernauer, T. (2002). Explaining success and failure in international river management. Aquatic Sciences, 64,1-19.

Berns, M., Townend, A., Khayat, Z., Balagopal, B., Reeves, M., Hopkins, M. S., \& Kruschwitz, N. (2009). Sustainability and Competitive Advantage: The Business of Sustainability: What it Means to Managers now. MIT Sloan Management Review, 51 (1), 19-30.

Bisley, A. (2010). Report of the Land and Water Forum: A Fresh Start for Fresh Water. New Zealand: Land and Water Forum.

Boyatzis, R. E. (1998). Transforming qualitative information: thematic analysis and code development. London: Sage.

Braun, V., \& Clarke, V. (2006). Using thematic analysis in psychology. Qualitative Research in Psychology, 3, 77-101.

Brereton, D. (2003). Implementing sustainable development principles in the mining industry- obstacles and opportunities. Centre for Social responsibility in Mining: Queensland Conference.

Brewer, T. L. (2003). Seeds of Change in the United States. New Economy, 10(3), 329341.

Briggs, S. A. (1997). Thirty-five years with Silent Spring. Organization \& Environment, 10(1), 73-84.

Brookfields Lawyers (2007). The Lake Taupo Protection Project: Project Agreement. Auckland: Brookfield Lawyers.

Bryman, A., \& Bell, E. (2003). Business research methods. Oxford: Oxford University Press.

Bührs, T., \& Bartlett, R. V. (1997). Strategic thinking and the environment: Planning the future in New Zealand? Environmental Politics 6(2), 72-100. 
Burton, P., Goodlad, R., \& Croft, J. (2004). How would we know what works? Context and Complexity in the Evaluation of Community Involvement. Evaluation, 12, 294-314.

Byrch, C., Kearins, K., Milne, M., \& Morgan, R. (2007). Sustainable "what"? A cognitive approach to understanding sustainable development. Qualitative Research in Accounting and Management, 4, 26-52.

Callicott, J. B., \& Mumford, K. (1996). Ecological Sustainability as a conservation concept. Conservation Biology, 11, 32-30.

Carroll, A. B., \& Buchholtz, A. K. (2008). Business and Society: Ethics and Stakeholder Management. USA: South Western Cengage learning.

Carson, R. (1962). Silent Spring. New York: Houghton Mifflin Company.

Carter, N. (2001). The politics of the environment: ideas, activism, policy. Cambridge, United Kingdom: Cambridge University Press.

Cavana, R. Y., Delahayne, B. L., \& Sekaran, U. (2001). Applied business Research: Qualitative and Quantitative Methods. Australia: Wiley.

Chang, H., \& Kristiansen, P. (2006). Selling Australia as 'clean and green'. The Australian Journal of Agricultural and Resource Economics, 50, 103-113.

Chevalier, M., \& Cartwright, T. (1966). Toward an action framework for the control of pollution. National Conference on Pollution and Our Environment: Paper D. Canadian Council of Resource Ministers. Ottawa: Queen's Printer.

Clandinin, D. J., \& Connelly, F. M. (2000). Narrative inquiry: Experience in story in qualitative research. San Francisco: Jossey-Bass.

Climate Change Information (2010). Questions and Answers about the emissions trading scheme. The New Zealand Government. Retrieved from http://www.climatechange.govt.nz/emissions-trading-scheme/questions-andanswers.html

Cloke, P., \& Perkins, H. C. (2002). Commodification and Adventure in New Zealand Tourism. Current Issues in Tourism,5(6), 521-550.

Clulow, V. (2005). Future dilemmas for marketers: can stakeholder analysis add value? European Journal of Marketing, 39, 978-999.

Collins, E., \& Kearins, K. (2007). Exposing Students to the Potential and Risks of Stakeholder Engagement When Teaching Sustainability: a Classroom Exercise. Journal of Management Education, 31, 522-542. 
Collins, E., Kearins, K. \& Roper, J. (2005). The Risks of Relying on Stakeholder Engagement for the Achievement of Sustainability. Electronic Journal of Radical Organisation Theory, 9 (1), 1-20.

Collins, E., Lawrence, S., Pavlovich, K., \& Ryan, C. (2007). Business networks and the

Connelly J., \& Smith, G. (1999). Politics and the Environment: From Theory to Practice. London: Routledge.

Corporate Sustainability (2008). Corporate Sustainability: How stakeholder management is engendering environmental consciousness, Strategic Direction, 24, 22-24.

Costanza, R., \& Patten, B. C. (1995). Defining and predicting sustainability. Ecological Economics, 15, 193-196.

Csutora, M., \& Szerenyi, Z. M. (2008). Sustainability and Corporate Responsibility Accounting - measuring and managing business benefits. Paper presented at the EMAN-EU 2008 Conference organised by Corvinus University of Budapest, Institute for Environmental Science.

Cumming, G. (2010, January 6). New Zealand: 100 per cent pure hype. The New Zealand Herald. $\quad$ Retrieved from http://www.nzherald.co.nz/nz/news/article.cfm?c_id=1\&objectid=10618678

Cumming, G. S., Barnes, G., \& Southworth, J. (2008). Environmental Asymmetries. In Norberg, J., \& Cumming, G. S. (Eds.), Complexity Theory for a Sustainable Future. New York: Columbia University press.

Daniels, C. (2010, Mar 18). Worsening pollution audit 'completely unacceptable' says Fonterra. The New Zealand Herald. Retrieved from http://www.nzherald.co.nz/business/news/article.cfm?c_id=3\&objectid=10632786

Darke, P., Shanks, G., \& Broadbent, M. (1998). Successfully completing case study research: combining rigour, relevance and pragmatism. Information Systems Journal, 8, 273-289.

Darke, P., Shanks, G., \& Broadbent, M. (1998). Successfully completing case study research: combining rigour, relevance, and pragmatism. Information Systems Journal, 8,273-289.

Davis, K. (1960). Can business afford to ignore social responsibilities? California Management Review, 2, 70-76.

De Bruijin, T., \& Tukker, A. (2002). Partnership and leadership: Building alliances for a sustainable future. Dordrecht: Kluwer.

Dean, K. L. (2007). Qualitative Interviewing: The art of hearing data. Organisational Research Methods, 10. 184-187. 
Dryzek, J. S. (1997). The Politics of the earth: Environmental Discourses. New York: Oxford University Press.

Duanne, T. P. (1999). Shaping the Sierra: Nature Culture and Conflict in the Changing West. Berkeley, CA: University of California Press.

Dyllick, T., \& Hockerst, K. (2002). Beyond the Business Case for Corporate Sustainability. Business Strategy and the Environment, 1-43.

Easton, G. (1992). Learning from case studies ( $2^{\text {nd }}$ eds.). United Kingdom: Prentice Hall.

Eisenhardt, K. M. (1989). Building theories from case study research. The Academy of Management Review, 14, 532-550.

Eisenhardt, K. M., \& Graebner, M. E. (2007). Theory building from cases: Opportunities and challenges. Academy of Management Journal, 50(1), 25-34.

Ekins, P. (1989). Beyond growth: the real priorities of sustainable development. Environmental Conservation, 16, (1), 1-12.

Environment Court (2008, May). Interim Decision from the Environment Court. Decision No. A 123/2008 in the matter of the Resource Management Act 1991 in the matter of appeals under clause 14 of the first Schedule of the Act. New Zealand: Environment Court.

Environment Waikato (2001, B). Environment Waikato Technical Report 2001Hydrology Of Lake Taupo Catchment- Phase 1. Environment Waikato: New Zealand.

Environment Waikato (2003, A) Protecting Lake Taupo: A Long Term Strategic Partnership. Hamilton, New Zealand: Environment Waikato.

Epstein, M. J., \& Roy, M. (2003). Making the Business Case for Sustainability: linking Social and Environmental Actions to Financial Performance. The Journal of Corporate Citizenship, 9,1-158.

Everett, J., \& Jamal, T. B. (2004). Multi-stakeholder Collaboration as Symbolic Marketplace and Pedagogic Practice. Journal of Management Inquiry, 13 (1), 5778.

Fallow, B. (2010, June $12^{\text {th }}$ ). Game on for Carbon Trading despite uncertainties. The New Zealand Herald. from http://www.nzherald.co.nz/business/news/article.cfm?c_id=3\&objectid=10651316

Feagin, J. R., Orum, A. M., \& Sjoberg, G. (1991). A Case for the Case Study. North Carolina Press: United States of America.

Fennell, D. D. (1999). EcoTourism: An introduction. London: Routledge. 
Fereday, J., \& Muir-Cochrane, E. (2006). Demonstrating Rigor using thematic analysis: A hybrid approach to inductive and deductive coding and theme development. International Journal of Qualitative Methods,5(1), 80-93.

Fischer, F. (2000). Citizens, experts and the environment. The Politics of Local Knowledge. Duke University Press: London

Flyvbjerg, B. (2006). Five misunderstandings about case-study research. Qualitative Inquiry, 12 (2), 219-245.

Freeman, R. E. (1984). Strategic Management: A Stakeholder Approach. Pitman, Boston, MA.

Friedman, M. (1970). The social responsibility of business is to increase profits. New York Times, Section 6, 126-127.

Gable, C., \& Shireman, B. (2004). The Stakeholder imperative. Environmental Quality Management, 14, 1-9.

Gago, R. F., \& Antolin, M. N. (2004). Stakeholder salience in corporate environmental strategy

Gao, S. S., \& Zhang, J. J. (2006). Stakeholder engagement, social auditing and corporate sustainability. Business Process Management Journal, 12, 722-740.

Gibson, E. (2010, March 24). Excavation jars with pure image: expert. The New Zealand Herald. Retrieved from http://www.nzherald.co.nz/nz/news/article.cfm?c_id=1\&objectid=10633965

Gleick, P. H. (1997). Water and Conflict: Fresh water resources and International Security. International Security, 18(1), 79-112.

Goulding, C. (2002). Grounded Theory: A Practical Guide for Management, Business and Market Researchers. London : Sage Publications.

Green, J. (1999). Epidemiology in Practice: Qualitative Methods. Community Eye Health, 12(31), 46-47.

Grosse, R. (2005). International Business and Government Relations in the $21^{\text {st }}$ Century. New York: Cambridge University Press.

Guillemin, M., \& Gillam, L. (2004). Ethics, Reflexivity, and "Ethically Important Moments" in Research. Qualitative Inquiry, 10, 261-281.

Hackwell, K. (2009, August 31 ${ }^{\text {st }}$. Undermining NZ's clan, green image [web log message]. Retrieved from http://blog.forestandbird.org.nz/underminingnz\%E2\%80\%99s-clean-green-image/

Hahn, T., Schultz, L., Folke, C., \& Olsson, P. (2008). Social Networks as sources of resilience in social-ecological systems. In Norberg, J., \& Cumming, G. S. (Eds.), 
Complexity Theory for a Sustainable Future. New York: Columbia University press.

Hajer, M. A. (1997). The Politics of Environmental Discourse: Ecological Modernization and the Policy Process. New York: Oxford University Press.

Hardin, G. (1968). The Tragedy of the Commons. Science, 162, 1243-1248.

Hardy, C., \& Phillips, N. (1998). Strategies of engagement: Lessons from the critical examination of collaboration and conflict in an inter-organizational domain. Organisational Science, 9 (2), 217-230.

Hart, S. L., \& Sharma, S. (2004). Engaging Fringe stakeholders for competitive imagination. The Academy of Management Executive, 18(2), 56-67.

Harvard Magazine (2002). Problems with the Protocol. Harvard Magazine. Retrieved from http://harvardmagazine.com/2002/11/problems-with-the-protoc.html

Hemmati, M. (2002). Multi-Stakeholder processes for governance and sustainability. Beyond deadlock and conflict. Earthscan: UK and USA.

Hill, M. R. (1993). Archival Strategies and Techniques. Qualitative Research Methods, $31,1-88$.

Hillman, A. J., \& Keim, G. D. (2001). Shareholder Value, Stakeholder Management and Social issues: What's the Bottom Line? Strategic Management Journal, 22, 125139.

Holliday, C. O., Schmidheiny, S., Watts, P. (2002). Walking the Talk: The business case for sustainable development. United Kingdom: Greenleaf Publishing Limited.

Hopkins, M. S. (2009). What Executives don't get about sustainability (and further notes on the Profit Motive). MIT Sloan Management Review, 51(1), 34-43.

Hull, B, R, Richert, D., Seekamp, E., Robertson, D., \& Buhyoff, G. (2003). Understandings of Environmental Quality: Ambiguities and Values held by Environmental Professionals. Environmental Management, 31(1), 1-13.

Hunter, C. (1997). Sustainable Tourism as an Adaptive Paradigm. Annals of Tourism Research, 24, 850-867.

Huxham, C., \& Vangen, S. (1996). Working together: Key themes in the Management of Relationships between Public and Non-profit Organisations. International Journal of Public Sector Management, 9 (7), 5-17.

Jick, T, D. (1979). Mixing Qualitative and Quantitative methods: Triangulation in Action. Qualitative Methodology, 24. 602-611. 
Jones, A., \& Bugge, C. (2006). Improving understanding and rigour through triangulation: an exemplar based on patient participation in interaction. Journal of Advanced Nursing, 55(5), 612-621.

Kenney, D. S. (2000). Arguing about consensus: Examining the case against western watershed initiatives and other collaborative groups active in natural resources management. University of Colorado School of Law: Boulder.

Klaassen, A. J., \& Opschoor, J. B. (1991). Economics of sustainability or the sustainability of economics: different paradigms. Ecological Economics, 4, 93115.

Kolk, A., \& Pinkse, J. (2004). Market Strategies for climate change. European Management Journal, 22,304-314.

Kolk, A., \& Pinkse, J. (2007). Toward strategic stakeholder management? Integrating perspectives on sustainability challenges such as corporate responses to climate change. Corporate Governance, 7, 370-378.

Krebs, J. R., Wilson, J. D., Bradbury, R. B., \& Siriwardena, G. M. (1999). The second Silent Spring? Nature, 400(12), 611-612.

Kvale, S. (2007). Doing Interviews. London: SAGE Publications Ltd.

Law, G. (2010). Taupo Lake Care Chairman's Report. New Zealand: Taupo Lake Care.

Lawrence, A., (2006). No personal motive? Volunteers, biodiversity, and the false dichotomies of participation. Ethics, Place and Environment, 9, 279-298.

Leach, W. D., Pelkey, N. W., \& Sabatier, P. A. (2002). Stakeholder Partnerships as Collaborative Policymaking: Evaluation Criteria Applied to Watershed Management in California and Washington. Journal of Policy Analysis and Management, 21(4), 645-670.

Letcher, R. A., \& Giupponi C. (2004). Policies and tools for sustainable water management in the European Union. Environmental Modelling \& Software, 20, 93-98.

Levy, D. L., \& Newell, P. J. (2005). The Business of Global Environmental Governance. Massachusetts: The MIT Press.

Lim, E. (1991). The Economic Impact of Tourism in New Zealand: Summary report. Wellington: New Zealand Tourism Department.

Lowe, D. J., \& de Lange, W. P. (2000). Volcano-meterological tsunamis, the c. AD 200 Taupo eruption (New Zealand) and the possibility of a global tsunami. The Holocene, 10,(3), 401-407.

March, J. (1979). Foreword in Hip capitalism. Susan Krieger. Beverly Hills, CA: Sage. 
Mathieson, S. (1988). Why Triangulate. Educational Researcher, 13-17.

Maxwell, J. A. (2005). Qualitative Research Design: An interactive approach (2 ${ }^{\text {nd }}$ Ed.). London: Sage.

Maykut, P., \& Morehouse, R. (1994). Beginning qualitative research: A philosophic and practical guide. London: Jossey Bass.

McChesney, I. G. (1991). The Brundtland Report and sustainable development in New Zealand. New Zealand: Lincoln University

McDermott Fairgray Group (2001). International tourism in New Zealand 2001-2007: a regional perspective. Auckland: McDermott Fairgray.

McLay, C. (2010, June 10). Report to Lake Taupo Protection Project Joint CommitteeFor Information Only. New Zealand: Environment Waikato.

MFE (2006). Freshwater for the Future (Information sheet). New Zealand: Ministry for the Environment.

Ministry for the Environment 'MFE' (2010). Environmental stewardship for a prosperous New Zealand: Tiakina te taiao kia tonui a Aotearoa. Wellington: Ministry for the Environment.

Mintzberg, H. (1983). Power in and around organisations. Englewood Cliffs, NJ: Prentice Hall.

Mitchell, R. K., Agle, B. R., \& Wood, D. J. (1997). Toward a theory of stakeholder identification and salience: defining the principle of who and what really counts. Academy of Management Review, 22, 853-886.

Mol, A. P. J., Spaargaren, G., Sonnenfeld, D. A. (2009). Ecological modernisation: three decades of policy, practice and theoretical reflection. In Mol, A. P. J., Sonnenfeld, D. A., \& Spaargaren, G. (Eds.), The Ecological Modernisation reader. Environmental reform in theory and practice. London/ New York: Routledge.

Nakayama, M. (1997). Success and Failures of International Organizations in Dealing with International Waters. Water Resources Development, 13(3), 367-382.

New Zealand Tourism Guide's Business Centre (NZTGBC) (2010). New Zealand Tourism Information. Retrieved from http://www.tourism.net.nz/business-centre/

Norberg, J., \& Cumming, G. S. (2008). Foreword. In Norberg, J., \& Cumming, G. S. (Eds.), Complexity Theory for a Sustainable Future. New York: Columbia University press.

O'Rielly, P. (2010, May 10). Decision on ETS is the right one. The New Zealand Herald. Retrieved from http://www.nzherald.co.nz/business/news/article.cfm?c_id=3\&objectid=10642749 
O’Riordan, T. (1989). The politics of sustainability. In R. K. Turner (Eds.) Sustainable environmental management. Belhaven.

Ollerenshaw, J. A., \& Creswell, J. W. (2002). Research: A comparison of Two Restorying Data Analysis Approaches. Qualitative Inquiry, 8, p 329-349.

Paehlke, R. C. (1989). Environmentalism and the future of progressive politics. Yale: New Haven University Press.

Patterson, M., \& McDonald, G. (2004). How Clean and Green is New Zealand Tourism? Lifecycle and Future Environmental Impacts. In Landcare Research Science Series No. 24. Lincoln University, New Zealand: Manaaki Whenua Press.

Payne, S. L. \& Calton, J. M. (2002). Towards a Managerial practise of stakeholder engagement: Developing multi-stakeholder learning dialogues. In J. Androif, S. A. Waddock, B. W. Husted, \& S. S. Rahman (Eds.), Unfolding Stakeholder Thinking. 1. Theory, Responsibility and Engagement. Sheffield UK: Greenleaf Publishing.

Pearce, D. D., \& Atkinson, G. D. (1993). Capital theory and the measurement of sustainable development: an indicator of "weak" sustainability. Ecological Economics, 8, 103-108.

Pearce, F. (2009, November $\left.12^{\text {th }}\right)$. New Zealand was a friend to Middle earth, but it's no friend of the earth: Lord of the Rings country trades on its natural beauty, but emissions have risen $22 \%$ since it signed up to Kyoto. The Guardian. Retrieved from http://www.guardian.co.uk/environment/cif-green/2009/nov/12/newzealand-greenwash

Pezzey, J. (1992). Sustainability: An Interdisciplinary Guide. Environmental Values, 1, 321-362.

Porter, M. E., \& van der Linde, C. (1995). Green and Competitive: Ending the Stalemate. Harvard Business Review, 120-136.

Post, J. E., Preston, L. E., \& Sachs, S. (2002). Redefining the Corporation: Stakeholder Management and Organisational Wealth. Stanford, CA: Stanford University press.

Preston, L. E., \& O'Bannon, D. P. (1997). The corporate social-financial performance relationship: A Typology and analysis. Business and Society, 36(4), 419-429.

Proposed Waikato Regional Plan Variation 5- Lake Taupo Catchment. (2007). Appeals Version. New Zealand: Environment Waikato.

Reed, M. S. (2008). Stakeholder participation for environmental management: A Literature Review. Biological Conservation, 141, 2417-2431. 
Reed, M. S., Dougill, A. J., \& Taylor M. J. (2007). Integrating local and scientific knowledge for adaption to land degradation: Kalahari rangeland management options. Land Degradation and Development, 18, 249-268.

Richardson, D. (1997). The politics of sustainable development. In The Politics of Sustainable Development: theory, policy and practice within the European Union. London: Routledge.

Richter, B. D., Mathews, R., Harrison, D. L., \& Wigington, R. (2003). Ecologically sustainable water management: Managing river flows for ecological integrity. Ecological Applications, 13(1), 206-224.

Rieckermann, J., Daebel, H., Ronteltap, M., \& Bernauer, T. (2006). Assessing the Performance of International Water Management at Lake Titicaca. In CIS Center for Comparative and International Studies. 12. Zurich: University of Zurich.

Robinson, T. G. (1993). The Limits to Caring: Sustainable Living and the Loss of Biodiversity. Conservation Biology, 7, 20-28.

Romme, N., \& Wijen, F. (2005). Stakeholder Power and Organizational Learning in Corporate Environmental Management. Organizational Studies, 27, 235-265.

Rondinelli, D. A., \& London, T. (2002). Stakeholder and Corporate Responsibilities in Cross-Sectoral Environmental Collaborations: Building value, legitimacy and trust. In J. Androif, S. A. Waddock, B. W. Husted, \& S. S. Rahman (Eds.), Unfolding Stakeholder Thinking. 1. Theory, Responsibility and Engagement. Sheffield UK: Greenleaf Publishing.

Roome, N. (1994). Developing environmental management strategies. Business Strategy and the Environment, 1, 11-23.

Rubin, I., \& Rubin, H. (2006). Qualitative Interviewing: The art of Hearing. Second edition

Rydin, Y. (1999). Can we talk ourselves into sustainability? The role of discourse in the Environmental Policy Process. Environmental Values, 8, 467-484.

Saint, D. K. (2005). The firm as a nexus of relationships: Toward a new story of corporate purpose. Doctor of Philosophy: Benedictine University.

Salihoglu, G., \& Kraer, F. (2004). Ecological Risk Assessment and Problem Formulation for Lake Ulubat, a Ramsar State in Turkey. Environmental Management, 33(6), 899-910.

Salzmann, O., Ionescu-Somers, A., \& Steger, U. (2005). The Business Case for Corporate uptake of sustainability practices: the case of New Zealand. Journal of Cleaner Production 15(8-9), 729-740. 
Scion (2010). Gorse a potential water pollutant. Rotorua, New Zealand: Scion Crown Research Institute.

Sekaran, U. (2003). Research Methods for Business: A skill building approach (5 ${ }^{\text {th }}$ ed.). New Jersey: Wiley.

Sewell, G. H. (1975). Environmental quality management. Englewood Cliffs, New Jersey: Prentice-Hall inc.

Sharma, S., \& Vredenburg, H. (1998). Proactive corporate environmental management strategy and the development of competitively valuable organizational capabilities. Strategic Management Journal, 19, (8), 729-753.

Shrestha, P. (2005). Conservation and management of Phewa Lake ecosystem, Nepal. (Master's thesis, Tribhuvan University). Retrieved from http://www.aehms.org/pdf/Shrestha\%20Proceedings\%20FE.pdf

Sneddon, C., Howarth, R. B., \& Norgaard, R. B. (2006). Sustainable development in a post-Brundtland world. Ecological Economics, 57, 253-268.

Snively, S., Kupenga, V., Nepe, T., O’Dea, D., Rashbrooker, G., Robins, A., Stephens, B., \& Stott, H. (1990). Who gets what?- the distribution of income and wealth in New Zealand. Wellington, New Zealand: New Zealand Planning Council.

South, G. (2009, October 31). Don't say that 'sustainability' word. The New Zealand Herald. $\quad$ Retrieved from http://www.nzherald.co.nz/economy/news/article.cfm?c id=34\&objectid=106062 $\underline{88 \& p n u m=0}$

Sprinz, D. F. \& Helm, C. (2000). Measuring the effectiveness of international environmental regimes. Journal of Conflict Resolution, 45, 650-652.

stakeholders and colonial discourses: The case of the Jabiluka uranium mine. Organization and Environment, 13 (1), 3-38.

Statistics New Zealand (2000). New Zealand official yearbook 2000. Wellington: Statistics New Zealand.

Steger, U. (2004). The Business of Sustainability: Building industry cases for corporate sustainability. New York: Palgrave Macmillan.

Steurer, R., Langer, M. E., Konrad, A., \& Martinuzzi, A. (2005). Corporations, stakeholders and sustainable development: A theoretical exploration of businesssociety relations. Journal of Business Ethics, 61, p 263-281.

Stewart, C., Johnston, D., Rosen, M., \& Boyce, W. (2000). Public involvement in environmental management of Lake Taupo: preliminary results of the 1999 survey. New Zealand: Institute of Geological \& Nuclear Sciences. 
Stokes, D., \& Bergin, R. (2006). Methodology or "methodolatry"? An evaluation of focus groups and depth interview. Qualitative Market Research, 9, 26-38.

Strand, R. (2006). The Stakeholder Dashboard. Greener Management International, 54, 23-37.

Strategic Plan (2008). Strategic Plan 2008-2011, Lake Taupo Protection Trust Te Wai, te Iwi. Taupo: Lake Taupo Protection Trust.

Stringer, L. C., Prell, C., Reed, M. S., Hubacek, K., Fraser, E. D. G., \& Dougill, A. J., (2006). Unpacking 'participation' in the adaptive management of socio-ecological systems: a critical review. Ecology and Society, 11, 39.

Sustainability: Literature Review and Research Options. European Management Journal, 23(1), 27-36.

Svendsen, A. C., \& Laberge, M. (1995). Convening Stakeholder Networks: A new way of thinking, being, and engaging. The Journal of Corporate Citizenship, 19, 91-105.

Taupo (2010). Population Map. Environment Waikato Regional Council. Retrieved from http://www.ew.govt.nz/environmental-information/About-the-Waikatoregion/Population-and-industries-map/Taupo/

Taupo District Council Annual Report 'LTDCAR' (2005). Sustainable Environment: Annual report 2005. New Zealand: Lake Taupo District Council.

Taupo District Council Annual Report 'LTDCAR' (2009). Taupo District Council: Annual report 2005. New Zealand: Lake Taupo District Council.

Taupo-Nui-A-Tia (2010). Taupo-Nui-A-Tia Management Board. Retrieved from http://www.tauponuiatia.org/tauponuiatia.htm

Taylor, S. J. \& Bogdon, R. (1984). Introduction to qualitative research methods: The search for meanings. New York: John Wiley \& Sons.

The Economist (2010, March 23). It's not easy seeming green: A Backlash to New Zealand's vow of purity. The Economist online. Retrieved from http://www.economist.com/world/international/displaystory.cfm?story_id=15763 381

Timberlake, L. (1989). The role of scientific knowledge in drawing up the Brundtland report. In S. Anderson \& W. Ostreng (Eds.), International resource management: the role of science and politics. London: Belhaven Press.

Tippett, J., Handley, J. F., \& Ravetz, J. (2007). Meeting the challenges of sustainable development- A conceptual appraisal of a new methodology for participatory ecological planning. Progress in Planning, 72, 247-268. 
Towards 2019 (2009). Our Neighbourhood, Our Future: Annual Report. New Zealand: Taupo District Council.

United Nations (2009). Water in a changing world. The United Nations World Water Development Report 3.

Valente, S. (2008). Intergenerational transfers, lifetime welfare, and resource preservation. Environment and Development Economics, 13, 53-78.

Van Marrewijk, M. (2003). Concepts and definitions of CSR and corporate sustainability: Between agency and Communion. Journal of Business Ethics, 44, 95-106.

VanNijnatten, D. (1998). The day the NGOs walked out: Accelerated reduction/Elimination of Toxic multi-stakeholder process' lack of support from non-governmental organizations. Alternative Journal, 24 (2).

Voinov, A. (2008). Understanding and communicating sustainability: global versus regional perspectives. Springer Science and Business, p1-16.

Von Bertrab, E. (2003). Guadalajara's water crisis and the fate of Lake Chapala: a reflection of poor water management in Mexico. Environment and Urbanization, $15,127-142$.

Walton, J. (1992). Making the theoretical case. In C.C. Ragin \& H. S. Becker (Eds.), What is a case? Exploring the foundations of social inquiry, 121-137. Cambridge, UK: Cambridge University press.

Watson (2008, August 28). Water, water everywhere, nor any fit to drink. The Dominion Post. Retrieved from http://www.stuff.co.nz/environment/596982

WCED (World Commission on Environment and Development), (1987). Our Common Future. Oxford University Press, Oxford.

Webb, C., \& Bodin, O. (2008). A Network Perspective on Modularity and control of flow in robust systems. In Norberg, J., \& Cumming, G. S. (Eds.), Complexity Theory for a Sustainable Future. New York: Columbia University press.

Webb, J. R. (1995). Understanding and design marketing Research. London: The Dryden Press.

Weinreb, A. A. (2006). The Limitations of Stranger- Interviews in Rural Kenya. American Sociological Review, 71, 1014-1040.

White, P. (2009). Building a sustainability strategy into the business. Corporate Governance, 9(4), 386-394.

Williams, H. (1975). A Dictionary of the Maori Language. $7^{\text {th }}$ edition. Wellington: Government Printer. 
Williams, J. (1997). Future Directions: Strategic focus of the Parliamentary Commissioner for the Environment 1997-2001. Wellington: Parliamentary Commissioner for the Environment.

Williams, J., \& Lawson, R. (2001). Community issues and resident opinions of tourism. Annals of Tourism Research, 28, 269-290.

Wood, D. J., \& Gray, B. (1991). Collaborative alliances: Moving from practice to theory. Journal of Applied Behavioural Sciences, 27 (1), 3-22.

World Business Council Sustainable Development (2002). The Business Case for Sustainable Development. Geneva: WBCSD.

Wright, J. C. (1988). Future Generations and the environment. Studies in resource Management No. 6. Lincoln College and University of Canterbury, New Zealand: Centre for Resource Management.

Yin, R. (1994). Case study research: Design and methods (2nd edn.). Thousand Oaks, CA: Sage.

Yin, R. K. (1994). Case Study Research: Design and methods. Thousand Oaks: Sage.

Young, A. (2010, May $31^{\text {st }}$ ). Smith enters the trenches in battle to defend the ETS. The New Zealand Herald. Retrieved from http://www.nzherald.co.nz/nz/news/article.cfm?c_id=1\&objectid=10648559

Young, J. (2010). Application of the Policy Choice Framework to Lake Taupo Catchment. Environment Waikato Technical Report 2010/20. New Zealand: Environment Waikato.

Young, O. R. (1999). The Effectiveness of international environmental regimes. Cambridge: MIT Press.

Younge, A., \& Fowkes, S. (2003). The cape action plan for the environment overview of an eco-regional planning process. Biological Conservation, 112, 12-28.

Yurex, S. (2010). Protecting Lake Taupo: The strategy and the lessons. New Zealand: Environment Waikato.

Zhang, Z. X. (2001). Greenhouse-gas Emissions Trading and the World Trading System.

In Chambers, W. B. (Eds), Inter-linkages: The Kyoto Protocol and the International Trade and Investment Regimes (pp. 1-279). New York: The United Nations University.

Zorn, T., \& Collins E. (2007). Is Sustainability Sustainable? Corporate Social Responsibility, Sustainable Business, and Management Fashion, In May, S., Cheney, G. and Roper, J. (Eds) The Debate over Corporate Social Responsibility, New York: Oxford University Press. 


\section{Appendix 1: Stakeholder Collaboration for the Protection of Lake}

\section{Taupo- Timeline}

1999-
EW identified that water quality issues were statistically significant
within the Taupo Catchment. Taupo community was surveyed and
said that lake water quality was central to the regions prosperity
(Stewart, Johnston, Rosen, and Boyce, 2000).
Tony Petch from EW 'If we can't do this in Taupo with the RMA
(Sec 30), then we couldn't do it anywhere else, and the agricultural
sector would be untouchable"
Tony gathered the support from EW politicians, TDC \& CG- MfE.
Marion Hobbs Minister of MfE knew that this was a flagship
environmental project- setting a precedent (Yurex, 2010).
EW signed an agreement with the NZ Dairy board not to issue
anymore dairy conversions in the Taupo catchment area. But Kiwi
Dairy company said the message was lost and issued dairy
numbers anyway (there are now 6 dairy farms within the
catchment as at 2008 (Environment Court, 2008)).
MOU between Tuwharetoa and EW- Nutrients issues surrounding
Lake Taupo started to emerge in discussion.
2020 Taupo-nui-a-tia, an Iwi based initiative partially funded by
MfE. Non-statutory collaboration that was commercially driven to
protect the lake. Its aim was to identify issues, develop key values
and create 'New Actions' to protect the lake. Said to be the
Foundation of the project to protect the lake. Representatives from
Tuwharetoa, DOC, Internal Affairs, EW, TDC and LWAG were
involved (Yurex, 2010).
EW notified landowners that land intensification cannot continue.
Letters sent to Fed Farmers, CG, TDC councillors, Dairy
companies and farmers.
EW \& Ag-research held community meetings to tell farmers they
were responsible for pollution. Shock to rural community, as this
was the first they had heard of their industry polluting.
Establishment of TDC to represent the collective farmers. By 2003
membership comprised of $90 \%$ of farmers in the catchment.
TLC and EW along with Ag-research engage. TLC consulting
team developed MOU with EW. Engaged for a further 3 years.
needed to be present. Cap and Trade policy decided.
Maye land owners
Eumade EW aware that foresters and undeveloped land

EW, Tuwharetoa, TDC, \& CG (MfE agreed on a whole government approach) set up a public fund with contributions from EW, TDC \& CG. Discussed policy around $20 \%$ solely to come off landowners or $20 \%$ off government owned land.

Findlayson and Thorrold (2001) report by Ag-research on Estimating the costs of restrictions on $N$ emissions in the Taupo Catchment released and peer reviewed in 2004. "it appears these controls will place substantial costs onto farmers, suggesting that 
voluntary adoption of restrictions is unlikely without substantial financial support" (Yurex, 2010).

2002- Discussions with MfE, EW, MAF, Treasury focussed on Landcorp and Corrections land in the catchment. Discussion flowed around changing Landcorps statement of intent for the Taupo properties. Landcorp is a developer of innovative practices for farmers in NZ. It was suggested that afforestation of landcorp land would help in the reduction of $20 \%$ nitrogen leaching into the lake. MfE Minister

Oct said 'its needs to be a whole community approach' not just one entity approach (Yurex, 2010).

Not satisfied with the economic modelling done in 2001 TLC employed Nimmo Bell \& Co Ltd an economics firm to model the economic impact of a nitrogen cap. They released a report stating a moderate loss with a $20 \%$ reduction cap would be $\$ 113$ million. Not including a significantly greater loss to landowners themselves.

\begin{tabular}{|l|l|l|}
\hline \multicolumn{3}{|c|}{ Land Use change without restrictions } \\
\hline Restriction & Moderate & Substantial \\
\hline Cap N output & $\$ 96 \mathrm{M}$ & \$159 M \\
\hline $10 \%$ Reduction & $\$ 104 \mathrm{M}$ & $\$ 167 \mathrm{M}$ \\
\hline $20 \%$ Reduction & $\$ 113 \mathrm{M}$ & $\$ 175 \mathrm{M}$ \\
\hline
\end{tabular}

This economic modelling was not taken into consideration by EW.

Meeting with MfE, MAF, EW, TMTB, TDC, LTFM surrounding equity issues as it was apparent that the policy in consideration locked forestry into forestry indefinitely (Yurex, 2010).

2003- $\quad$ MfE- along with Marion Hobbs MfE minter, TPK, MAF, TDC, \& EW councillors heard direct individual briefings from TMTB, TLC, and Foresters. They then all engaged to determine a workable solution. This was a key meeting for all stakeholders involved. Forestry had been in discussions surrounding equity issues with officials since 2001 . When they presented their case for averaging to Marion Hobbs- she had not been briefed of their prior stance. The issue is their forestry spokesperson was representing interests of industry and future precedents rather than focusing on foresters in the catchment, which ended up being a better stance.

Decision that a funding split of $1 / 3$ between CG, EW and TDC was not equitable, as Turangi is a poor community, tourism and holidaymakers from areas in NZ such as Auckland wanted high lake quality but were not prepared to pay. This enabled a decision to go to a funding split 45:22:33 CG, TDC, EW respectively, drip fed over 15 years. Calculation was based on 13,500 ha of land at $\$ 5000 /$ ha for land use change to forestry $=\$ 67.5 \mathrm{M}+\operatorname{admin}=$ $\$ 81.5 \mathrm{M}$

Direct discussions between EW, TMTB, CG, \& TDC. These were called partnership \& stakeholder meetings and they continued on a regular basis till RPV5 was notified in July 2005.

EW proposed targets with CG and TDC to deal with lake quality. It outlined a two pronged approach of cap on nitrogen discharge and a public fund to reduce $20 \%$ nitrogen from pastoral land. 
TMTB wanted a unified Iwi and called Hui's with all Maori Economic Authorities. A unified Tuwharetoa position eventuated which would come from LTFT (TMTB owns 50\% LTFT) (Yurex, 2010).

2004- Tuwharetoa questions science. MfE gets independent research conducted by UOW which verifies $20 \%$ reduction and pushes for a Sep 5 year review.

Release of draft RPV5.

2004-2005- Further engagement to determine impacts and implications of the new regulatory regime.

2005- $\quad$ The death of a key leader in Tuwharetoa Marlon Nepia was tragic and impacted on stakeholder relations. Maori Economic Authority meetings stopped and conflict between TLC, Forestry, and TMTB views emerged regarding representation and allocation (averaging or grand-parenting). It took a long time before they decided that each would represent their own interests in hearings (Yurex, 2010). RPV5 draft notified in July and continued meetings between EW, TMTB, TDC and CG.

Funding partnership group (CG, EW, TDC and TMTB) were under pressure to include TLC, forestry and other interest groups.

2006- May- 136 submissions with a further 36 submissions heard by Professor Nov Skelton (a previous Enviro-Court judge) and three EW councillors (Yurex, 2010).

Nov interests they wanted to advance.

$\mathrm{CHH}$ sold up and left the catchment post hearings and submissions- they had concerns for the implications that this would have elsewhere.

Stakeholders went to hearings and submissions for RPV5. Fonterra made a submission and the catchment issue became topical for Fed-Farmers even though they know about it for many years prior (and their farming members had been involved since 2000). EW released its decision on RPV5 in 2007.

2007- Feb Final LTPT documentation to be agreed and formally established. (Was delayed from Feb 2004 when it should have been established due to agreements over the entity (LTPT), rules and accountability.

Lake bed was returned to Tuwharetoa as part of a 2007 Deed of Settlement between the tribe and CG, the lake is held in trust for the "common use and benefit of all the people of New Zealand" (Environment Waikato, 2003, A).

2008- May Enviro-Court hearings. Parties involved included CHH, EDS, Fed Farmers, LTFT,LRFT,LTFM, TLC, TMTB, Fonterra, NTAG, LWAG, TPL, CGEFE, \& EW. All put forward their concerns Nov surrounding RPV5 (Environment Court, 2008).

Enviro-Court released its deliberations- major results include consent to farming being 25 years, changes from the historical average to a best year for a NDA and the science behind land to

Oct pine (Environment Court, 2008).

Sale of Lancorp Farming Ltd land- Landcorp sold out of the 


\begin{tabular}{|c|c|}
\hline & catchment, leaving many farmers feeling ditched. \\
\hline 2009 & $\begin{array}{l}\text { Continued mediations between EW, Fed Farmers, EDS, LTFM, } \\
\text { LRFT, LTFT, TMTB, TLC over wording in RPV5. Fed Farmers } \\
\text { strongly involved because they thought it was precedent setting. }\end{array}$ \\
\hline 2010 - June & $\begin{array}{l}90 \% \text { of farmed area has been benchmarked and given an NDA. } \\
\text { There are } 182 \text { farms in the catchment collectively involving } 52,000 \\
\text { ha of land. } 90 \% \text { equates to } 96 \text { farms covering } 47,000 \text { ha. NDA's for } \\
\text { the remaining } 86 \text { are still occurring and expected to be completed } \\
\text { by } 31 \mathrm{Dec} 2010 \text {. EW realise that original estimates of } 153 \mathrm{~T} \text { of } \\
\text { nitrogen are inaccurate and would only remove } 17-19 \% \text { rather than } \\
\text { the } 20 \% \text { reduction of manageable nitrogen in the catchment. New } \\
\text { estimates equate to } 814 \mathrm{~T} \text { where } 20 \% \text { of that figure is } 163 \mathrm{~T} \text { and } \\
\text { with } 10 \% \text { of NDA's to be completed it is expected to rise to } 180 \mathrm{~T} \text {. } \\
\text { This figure has changed due to a policy change at the Environment } \\
\text { Court from benchmarking farmers over a } 4 \text { year 'historical' period } \\
\text { to taking the 'best year' and more detailed data coming from the } \\
\text { benchmarking process. Average NDA's are now } 17 \mathrm{~kg} \mathrm{~N} / \text { ha under } \\
\text { best year compared to } 14 \mathrm{~kg} \mathrm{~N} / \text { ha (McLay, 2010). }\end{array}$ \\
\hline & $\begin{array}{l}\text { Mediation between EW, Fed Farmers, EDS, LTFM, LRFT, LTFT, } \\
\text { TMTB, TLC was held to finalise the last section of wording for } \\
\text { RPV5 before it becomes operative (Law, 2010). }\end{array}$ \\
\hline
\end{tabular}


Appendix 2: Ranking Quality of Life Threats

Ranking of Quality of Life threats ( $n=73$ )

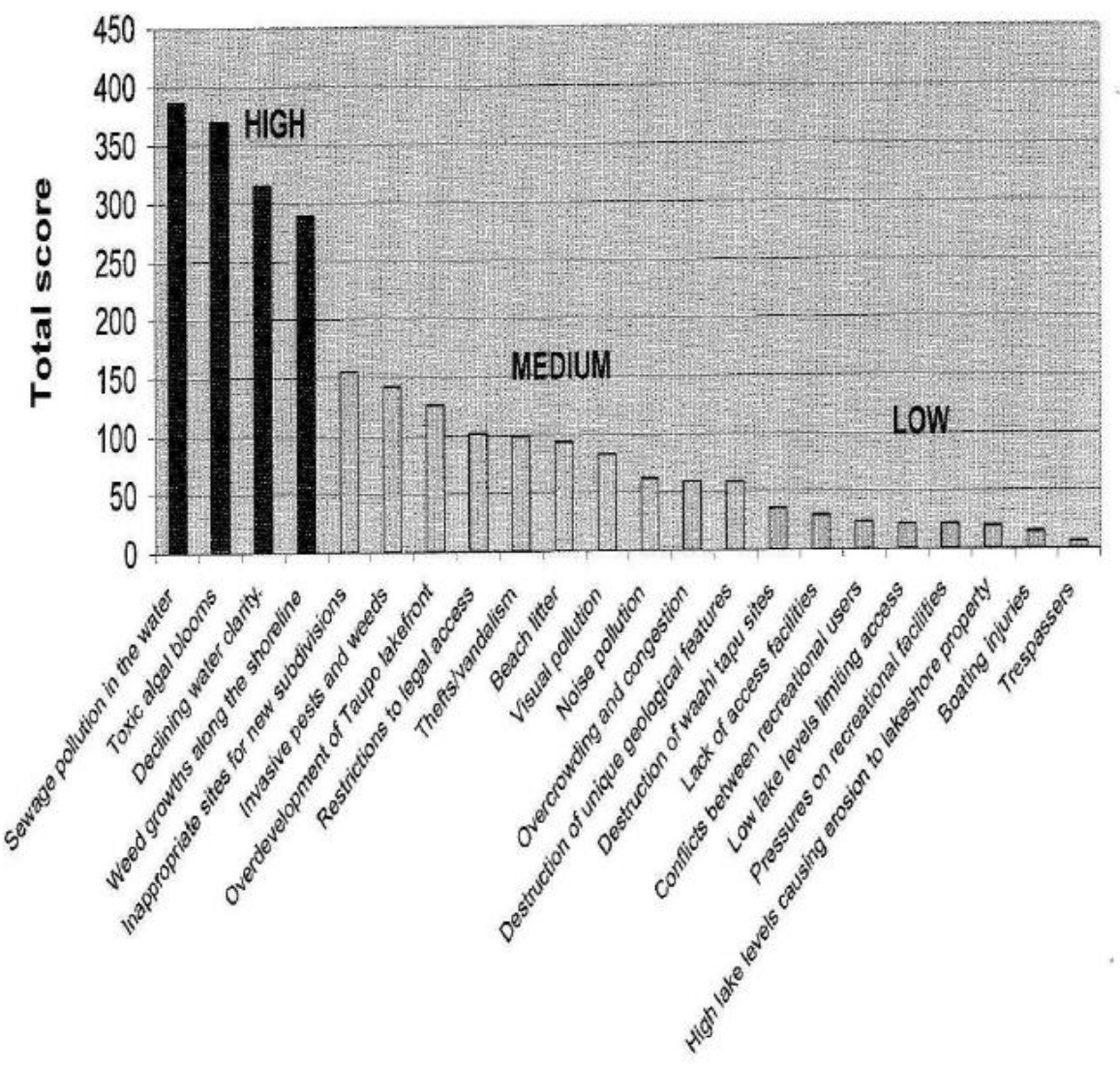


Appendix 3: Taupo-nui-a-tia Survey Respondents' level of concern about issues affecting Lake Taupo

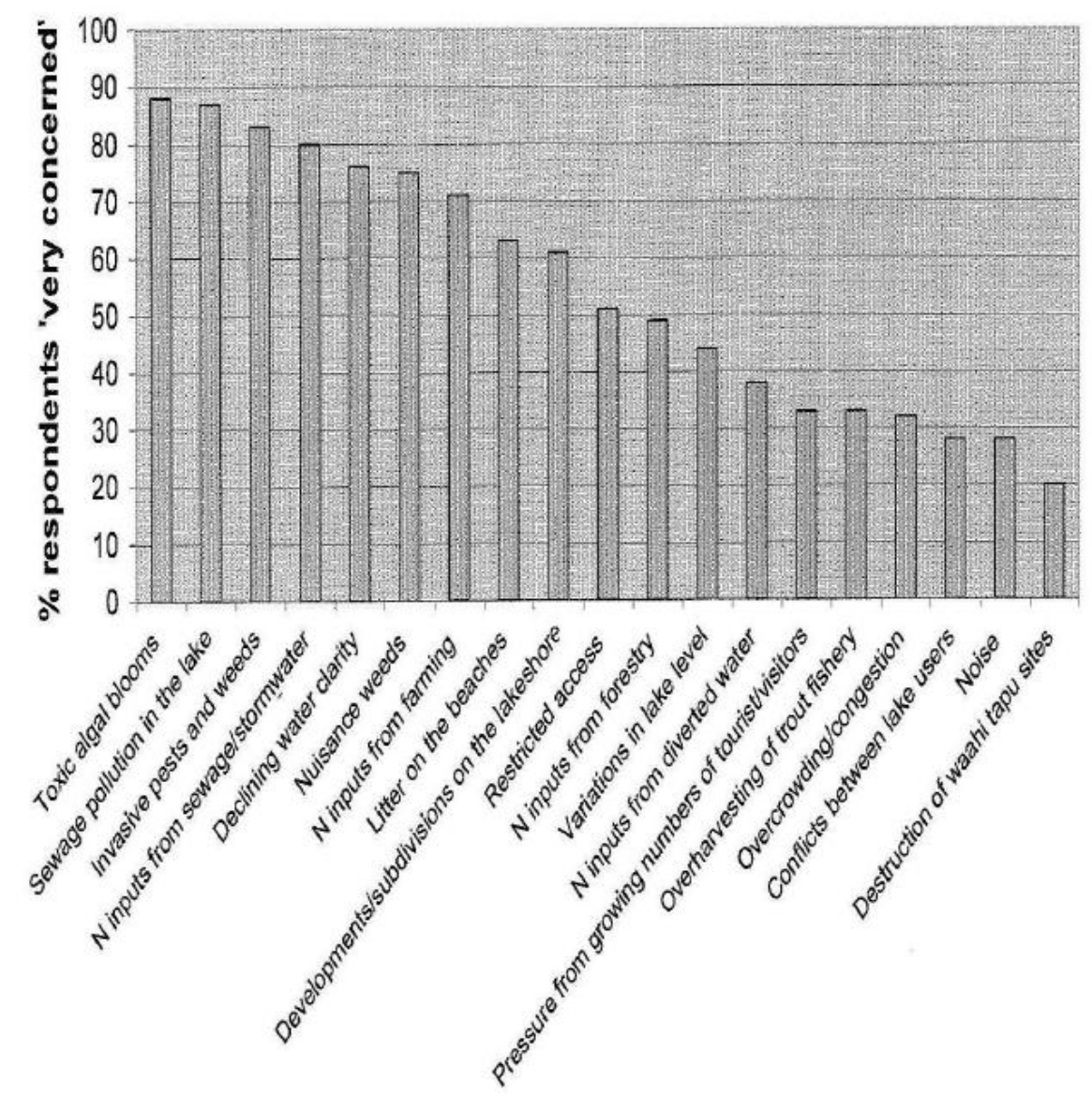

2020 Survey: Respondents' level of concern about issues affecting Lake Taupo (n=451) 


\section{Appendix 4:Interview Checklist}

\section{Checklist}

\section{Waikato Management School \\ Te Raupapa}

Research Question: How does a multiple stakeholder perspective affect the business case for sustainable development?

First of all thank you for taking the time out of your schedule to be involved in this research.

\section{The Business case for Sustainability}

1. What does sustainability mean to you or to your organisation?

2. What does Lake Taupo mean to you and how do you see the future of the lake?

A). A future with more central government regulation and intervention or more voluntary progress?

B) Why is it important/ significant to you or to your organisation to protect the lake?

3. How does the $100 \%$ pure image, New Zealand portrays, concern the region of Taupo and by association you or your organisation?

4. Can you describe how the ETS concerns you?

\section{Stakeholder Collaboration}

5. What was your motivation to collaborate in this project?

6. How do you feel :

The social, environmental, and economic concerns were considered and addressed in the process of setting up an entity to protect the lake?

That the management concerns were considered and addressed in the process of setting up an entity to protect the lake?

7. Did you feel that the right entities were being communicated with during the engagement process?

8. What other organisations have you worked/ engaged with in the Lake Taupo district?

How have those relationships developed over time?

9. What was the most rewarding/ hardest aspect in terms of engagement with other stakeholders?

10. What challenges did you face throughout this process?

Out of those challenges what was the hardest?

11. Did you ever have conflicting views to other stakeholders? How did you deal with that?

12. Was there any point in time when you felt your perspective was not taken into consideration?

13. What has been the best outcome in your opinion from the collaboration?

14. What were your expectations when engaging with other stakeholders for this project and how did this compare to what actually eventuated?

15. Do you think what has occurred in Taupo could be used is other contexts similar to the Taupo Catchment area?

Thank you for answering my questions today. Your contributions have been valuable and I appreciate the fact that you took time out of your schedule to let me come and interview you.

Do you have any question for me, or is there anything that I have missed and you would like to comment on? 


\section{Appendix 5: List of Interviewees}

I would like to gratefully acknowledge the contribution that each of the interviewees below gave to this study:

1. Mike and Sharon Barton, Farmer, member of TLC (Past chairman of TLC 20052009), members of LWAG. Even though Mike is a trustee for the LTPT he was not speaking as a trustee. (Interviewed $17^{\text {th }}$ September 2010)

2. Alex and Anne Richardson, Farmers, members of TLC, Sheep and Beef monitor farm (Alex is currently on TLC board) (Interviewed $21^{\text {st }}$ September 2010)

3. Derek Ryan, Agricultural Adviser Environment Waikato (Interviewed $26^{\text {th }}$ August, 2010)

4. Jocelyn Reeve, Farmer, secretary of TLC, member of LWAG (Interviewed $14^{\text {th }}$ September 2010)

5. Geoff Thorp, Forest operations Manager Lake Taupo Forest Trust (Interviewed $17^{\text {th }}$ September 2010)

6. Justine Young, Senior Policy analyst Environment Waikato, active role throughout the whole process (Interviewed $16^{\text {th }}$ November 2010)

7. George Asher, CEO Lake Taupo Forest Trust (Interviewed $17^{\text {th }}$ September 2010)

8. Nick Carroll, Manager strategic environmental policy Taupo District Council (Interviewed $14^{\text {th }}$ September 2010)

9. Anne Mcleod, Deputy CEO Taupo District Council (Interviewed $5^{\text {th }}$ October 2010)

10. Alistir Robertson, Owner operator Cascades motor lodge, Taupo (Interviewed $4^{\text {th }}$ November 2010)

11. Sue Yurex, Farmer, Founding member of TLC. Even though Sue is a trustee for the LTPT she was not speaking as a trustee. (Interviewed 21st September 2010)

12. Paul White, Senior Scientist GNS, Chairman of LWAG (Interviewed $16^{\text {th }}$ November 2010)

13. David Hamilton, Professor in the Biological Sciences department at the University of Waikato (Interviewed via email $17^{\text {th }}$ August 2010)

14. John Kneebone, Chairman of Lake Taupo Protection Trust ((Interviewed $27^{\text {th }}$ August, 2010)

15. Graeme Fleming, CEO Lake Taupo Protection Trust (Interviewed18th August, 2010)

16. Adam Smith, Mighty River Power, Carbon Trader (Interviewed $27^{\text {th }}$ August 2010)

17. Natalie Haines, Mighty River Power, Environmental Advisor, member of LWAG (Interviewed 26 ${ }^{\text {th }}$ August, 2010)

18. Dave Staite, Organic Fertilizer Sales Rep, member of LWAG (Interviewed $4^{\text {th }}$ November 2010) 


\section{Appendix 6: Waikato Management School Ethics Application}

Research Office

Waikato Management School

The University of Waikato

Private Bag 3105

Hamilton 3240

New Zealand

Amanda Sircombe

Research Manager

Phone +6478384376

Fax +6478384063

Email amandas@waikato.ac.nz

www.management.ac.nz

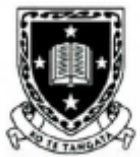

THE UNIVERSITY OF WAIKATO

Te Whare Wananga o Waikato

MANAGEMENT SCHOOL

Te Raupapa

$24^{\text {th }}$ June 2010

Josef de Jong

Dear Josef

Ethical Application WMS 10/112

Lake Taupo: a Collaborative Partnership of Innovation towards Sustainable Development

As per my earlier email the above research project, as outlined in your application, has been granted Ethical Approval for Research by the Waikato Management School Ethics Committee.

Please note: should you make changes to the project outlined in the approved ethics application, you may need to reapply for ethics approval.

Best wishes for your research

Regards,

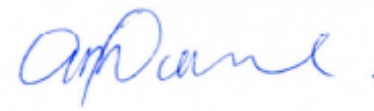

Amanda Sircombe

Research Manager 


\section{Letter of Invitation}

\section{Waikato Management School}

Te Raupapa

I am writing to invite you to participate in my research "Lake Taupo: A Collaborative Partnership of Innovation towards Sustainable Development" which is seeking to explore stakeholder engagement surrounding the sustainability of the Lake Taupo Catchment Area. I understand that you or your organization has been involved in the process of determining strategies to protect that lake with a number of other stakeholders. I am looking to document this unique case study and I would greatly appreciate your involvement and the significant contribution that you could make towards this research.

My research is part of my management and sustainability master's thesis under the sponsorship of a Marsden Funded Research grant 'Sustainability at a Cross Roads' and a University of Waikato Masters Scholarship. This research could be used in publications and scholarly journals. Your participation would build upon the foundation of multi stakeholder collaboration and create a unique case study showcasing the innovative forms of collaboration occurring in Taupo.

I would be very appreciative of your willingness to contribute and I would work around your schedule to have you involved in my research. I would travel to your location whether that is Taupo or Hamilton to meet with you and keep the requirements of your time to a minimum. Being involved would comprise of one interview with the possibility of a follow up interview. If any further information was required there is the possibility of following up via email or a phone call. Additional information about the research is attached on the 'participant information sheet'. If you would like more information regarding my research or you have any questions about your involvement please feel free to contact me at dejong.josef@gmail.com or call me on 027637 1952. I look forward to hearing from you.

Yours Sincerely,

Josef de Jong 


\title{
Appendix 8: Participant information Sheet
}

\section{Participant Information Sheet for Semi Structured Interview}

'Sustainability at a Cross Roads'

\section{Waikato Management School}

Te Raupapa

\author{
Lake Taupo: A Collaborative Partnership of Innovation towards Sustainable \\ Development
}

Researcher: Josef de Jong

Waikato Management School, Department of Strategy and Human Resource Management

The University of Waikato

I am a postgraduate student enrolled in a Masters of Management Studies under the sponsorship of a Marsden Funded Research grant 'Sustainability at a cross roads' and a University of Waikato Masters Scholarship. As part of this degree and in satisfaction with the research grants, I am investigating stakeholder engagement surrounding the business case for sustainability of the Lake Taupo Catchment Area. The Waikato Management School requires that ethics approval is gained before the commencement of involving human participants. The purpose of the research is to determine what successes and failures have occurred through stakeholder engagement and document this in the form of a report. I am currently working alongside a team of researchers who have gained a Marsden Research Grant. The researchers include Dr Eva Collins who is my direct Supervisor, Professor Juliet Roper, and myself.

For my Thesis I am aiming to interview a wide range of stakeholders who have been involved with the protection of Lake Taupo. To gain a greater understanding into the relationships surrounding the Lake and its sustainability I seek to interview individuals and organizations to answer questions and reflections based on their involvement. You will be involved in an interview that will last no longer than one hour. There is the possibility for a follow up interview if further clarification is needed, but this will not occur unless the participant has agreed. Information that is collected will remain strictly confidential and in the final report you and your organization will be indentified unless you state otherwise.

I will be using a Dictaphone (with your permission) to document the interview which will be transcribed and the information that I will use in my thesis can be sent to you for validation post the interview, if you wish. Only my supervisors and I will have access to interview recordings and notes. All material gathered will be confidential and kept in a secure location. You have the right to refuse to answer any question and there is no obligation to participate, any individual can ask to be withdrawn without any question prior to the interview occurring. If you are involved in an interview but feel that you would still like to withdraw from the research then please let me know before November 17 th 2010.

The interview responses will form the discussion and findings section of my Thesis and will be incorporated into my document to be submitted to the Waikato Management School- Te Raupapa at the University of Waikato. In addition some of the material used in this study could be used in articles for publication in scholarly journals or research presentations unless individuals have expressed otherwise.

If you have any questions or want further clarification regarding your involvement in this study, please feel free to contact me or my supervisor using the channels below.

Researcher: Josef de Jong: Email: dejong.josef@ gmail.com Phone: 027637 1952, Supervisors :

Dr Eva Collins: Email: evacolln@mngt.waikato.ac.nz Phone: 078384083

Professor Juliet Roper Email: JROPER@mngt.waikato.ac.nz Phone: 078384142

Best regards 


\section{Appendix 9: Consent forms}

\section{Consent Form for Participants}

Waikato Management School

Te Raupapa

Lake Taupo: A Collaborative Partnership of Innovation towards Sustainable Development

\section{Consent Form for Participants}

I have read the Information Sheet for Participants for this study and have had the details of the study explained to me. My questions about the study have been answered to my satisfaction, and I understand that I may ask further questions at any time. I understand that any information I give will be kept confidential by the researcher and supervisors and that this interview will be audio-recorded for transcribing later on. I understand that all information will be stored in an appropriate manner. I understand that my name and organisation will be used in the research unless I have stated otherwise.

I also understand that I am free to withdraw from the study at any time before the interview, or to decline to answer any particular questions in the study, or post the interview up until November the 17th. I agree to provide information to the researchers under the conditions set out on the Information Sheet.

Signed:

Name:

Date:

(please tick)

[ ] I would like a copy of the information that will be used in the Thesis post the interview

[ ] I would like to see a copy of the final report

Researcher's Name and contact information:

Josef de Jong: Email: dejong.josef@ gmail.com Phone: 027637 1952,

Supervisor's Name and contact information:

Dr Eva Collins: Email: evacolln@mngt.waikato.ac.nz Phone: 078384083

Professor Juliet Roper JROPER@ mngt.waikato.ac.nz Phone: 078384142 


\section{Appendix 10: Sample of themes emerging from transcript analysis}

Are the corporate farmers understanding the business case for sustainability and getting into things like forestry? How is that communicated to you?

Yeah I think they do, I think a lot of it has been through the lake Taupo protection trust. The CEO has been very proactive in sharing information and helping people to make decisions. And I think without his help a lot of people would not have known some of this stuff.

It's complicated and it's hard to assess what all the options are when some of unknown out of it and that's what has led these deals to progress. What has been the most rewarding and hardest aspect in terms of engagement with other stakeholders?

Probably the most rewarding was for - only some of the other stakeholdersprobably EW and TDC and some of the central government personal to see actually from a farmers perspective. Once you can put yourselves in other peoples shoes it helps to move forward and design workable policy. I found the formation of the trust very rewarding too. It was the combination of a few of the things that the consultation group recommended. Its' hugely positive to have ratepayer- local, regional and central government money to protect a resource in a totally unique way. The trust has worked well, and employed some fantastic staff and done some innovative things and done some innovative things for a win-win situation, like the MRP nitrogen carbon deal was terrifically rewarding. As land owners they were treated very inequitably especially the forest trusts. The inequity of the whole policy in the lake was Maori land was used in reserves and plantations since the 60 's and as guardians of the lake bed they were being asked to commit more. So when the trust could offer a win-win situation with MRP it is hugely rewarding. To a certain extent, people thought land use change, the conversion to forestry was the only way we would succeed. And yes that was but there was never enough private land to just do it on private land, but to deliver a workable policy to include trusts and incorporations is really great.

The biggest challenge was as a trust to hold the line and ride out the media storm that feds created. Two years ago. Right at the beginning when we had no resources, and really trying hard to convince EW staff we needed to talk and to have them come and say we've tried this before and it hasn't worked with farmers. But that process was hugely rewarding. One may have foreseen more dairy in the region. We didn't foresee- economic depending that one of the largest dairy farmers in the country would come and compete with the trust for purchasing nitrogen we didn't foresee that. That's one of the biggest disappointment where the landcorp land was sold and gone into a dairy farm which is in and out of the catchment which is hard to monitor. He has brought nitrogen- mainly small portions of nitrogen. Perhaps that may keep everyone honest but it's hard to compete with a large operator who has deep pockets.

\section{Themes:}

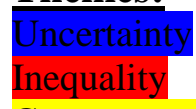

Governance and Leadership

Stakeholders perceptions

Communication between stakeholders

Business case for sustainability 